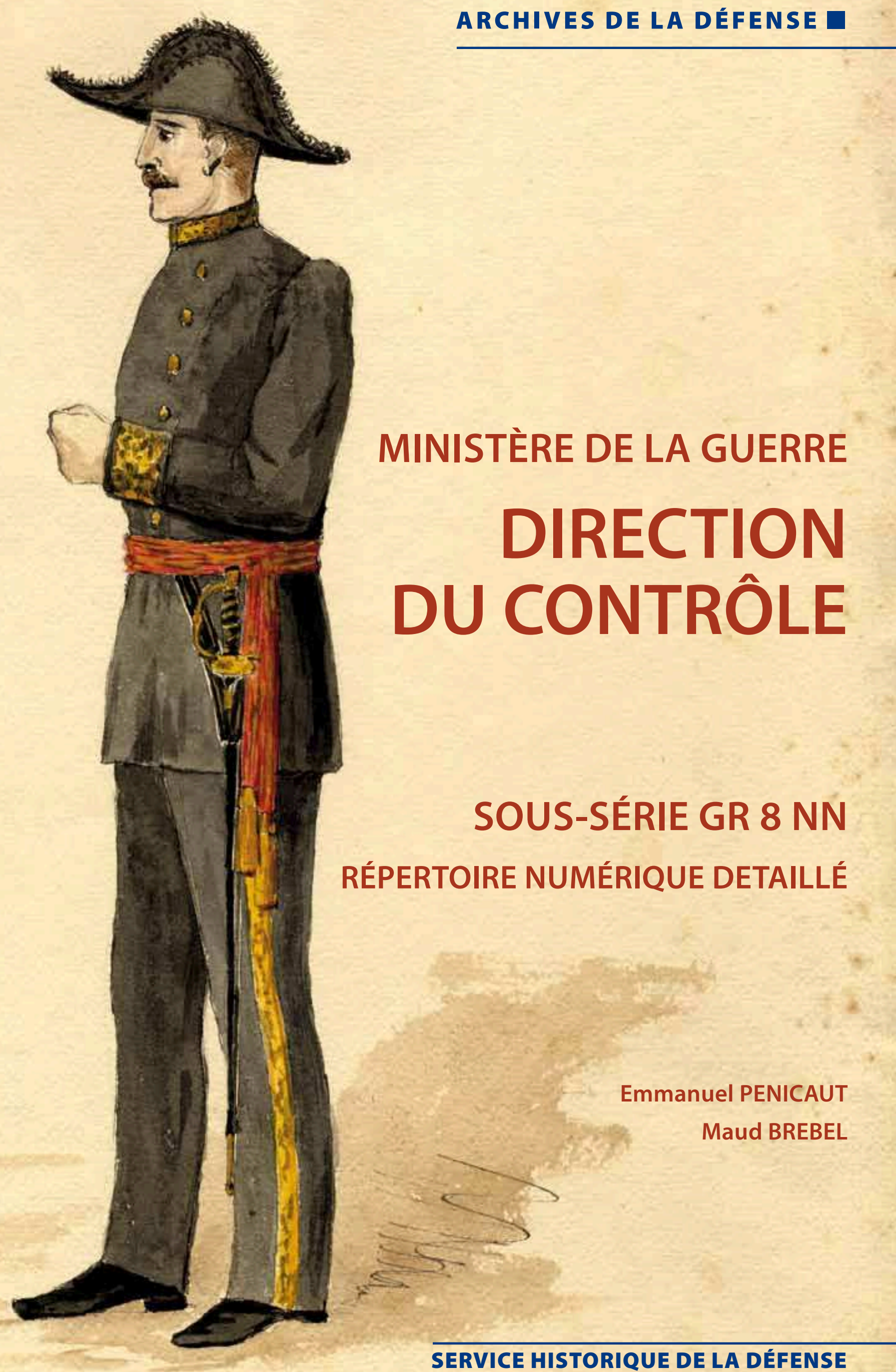


REPERTOIRE NUMERIQUE DETAILLE

DOCUMENTATION, CORRESPONDANCE, ORGANISATION ET FONCTIONNEMENT DU CORPSp. 25

Documentation p. 25

Correspondance p. 25

Cabinet du directeur

Service spécial

Bureaux financiers

Organisation et fonctionnement du corps

p. 26

1882-1919

$1939-1940$

ACTIVITÉ DU CORPS : ÉTUDES, INSPECTIONS, CONTRÔLES

1882-1914 p. 29

COMPTABILITÉ ET FINANCES DU MINISTÈRE

Budget et économie générale

Comptabilité et marchés

ADMINISTRATION CENTRALE

Organisation générale et réorganisations internes

Personnel

PERSONNEL - ÉCOLES.

Personnel

Personnel civil

Personnel militaire

Recrutement, avancement, statut, limites d'âge

Soldes, pensions, indemnités

Affaires individuelles

Écoles

HARNACHEMENT ET REMONTES

ARTILLERIE - MATÉRIEL - FORGES - POUDRES ET SALPÊTRES

Règlementation et études générales

Établissements

GÉNIE ET DOMAINE MILITAIRE

Règlementation et études générales

Afrique du Nord

INTENDANCE ET ADMINISTRATION DES CORPS DE TROUPE .p. 40

Règlementation et études générales 
Documentation. Presses régimentaires.

Administration des corps de troupe, ordinaires, subsistance

Fourrage

Habillement

Couchage

Coopératives, autres services et produits

Enquêtes ordinaires, irrégularités, affaires particulières

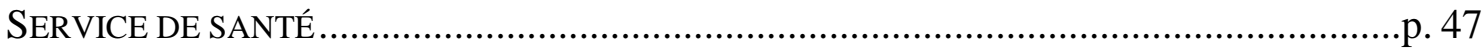

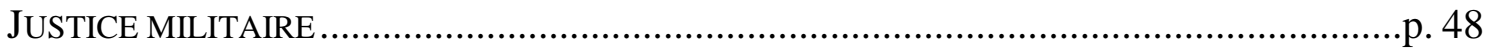

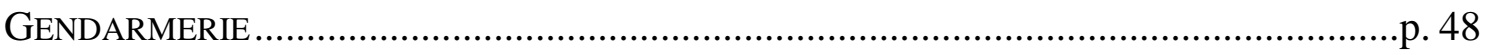

THÉÂTRES D’OPÉRATIONS EXTÉRIEURES, TERRITOIRES ENNEMIS ................................p. 49

RÉSERVE DE GUERRE ET SERVICE CENTRAL DES RÉQUISITIONS ................................ p. 49

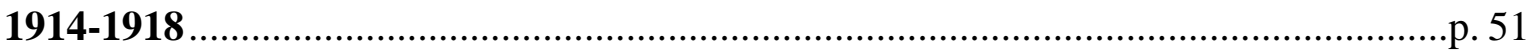

COMPTABILITÉ ET FINANCES DU MINISTÈRE...........................................................p. 51

THÉÂTRES D’OPÉRATIONS ET FAITS DE GUERRE ................................................. p. 51

ADMINISTRATION CENTRALE - PERSONNEL CIVIL ET MILITAIRE .................................p. 52

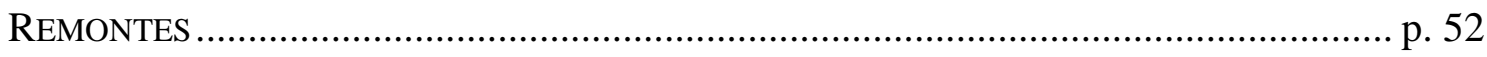

MATÉRIEL ET SERVICE AUTOMOBILE, AÉRONAUTIQUE, DOMAINE ET TRANSPORTS

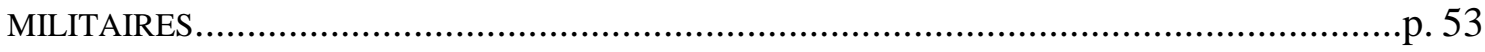

INTENDANCE ET ADMINISTRATION DES CORPS DE TROUPE ......................................p. 54

SERVICE DE SANTÉ ET JUSTICE MILITAIRE ...........................................................p. 55

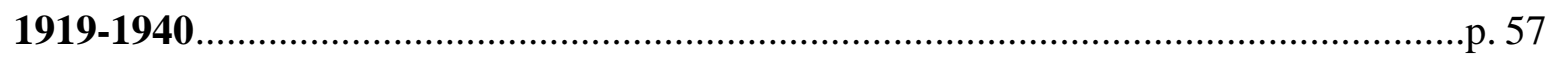

COMPTABILITÉ ET FINANCES DU MINISTÈRE........................................................p. 57

Budget et économie générale

Comptabilité et marchés

PRISONNIERS DE GUERRE - DÉMOBILISATION - LIQUIDATION DES STOCKS ET

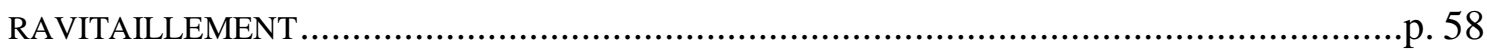

Démobilisation des hommes et des services

Gestion des stocks et questions de ravitaillement

ADMINISTRATION CENTRALE .................................................................... 60

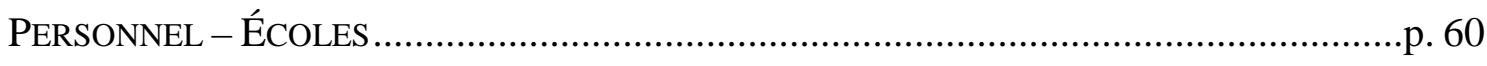


CheVAuX ET REMONTES, ARTILlERIE, MATÉRIEL, INDUSTRIE, SERVICE AUTOMOBILE, POUDRES

p. 61

Études générales

Affaires locales

AÉRONAUTIQUE p. 63

GÉNIE, DOMAINE MILITAIRE, SERVICES DE TRANSIT .p. 64

Règlementation générale

Affaires locales

Services de transit

INTENDANCE ET ADMINISTRATION DES CORPS DE TROUPE p. 65

Enquêtes de portée générale

Administration des corps de troupe, ordinaires, coopératives

Habillement et autres services

Enquêtes ordinaires dans les unités

Enquêtes extraordinaires

Unités et régions militaires

Services; mises en cause individuelles

SERVICE DE SANTÉ, JUSTICE MILITAIRE

p. 69

AlsaCE-LORRAINE - Troupes DE LA SARRE - ARMÉE DU RHIN .p. 70

Alsace-Lorraine, Sarre

Armée du Rhin

Organisation générale. Finances

Personnel civil et militaire

Artillerie, matériel, service automobile, aéronautique

Administration des corps de troupe, intendance, habillement

Prévôté, service de santé, transports

LEVANT

Groupe de missions de 1921-1922

Groupe de missions de 1922-1923

Groupe de missions de 1926

Mission conjointe des années 1927-1928, missions des années 1929 et suivantes

MISSIONS À L'ÉTRANGER - ORIENT . p. 78

Allemagne, Europe centrale, Russie Orient 


\title{
CONTrôler la GUERRE?
}

\section{UNE HISTOIRE DU CONTRÔLE DE L'ADMINISTRATION DE L'ARMÉE}

\author{
1882-1940
}

Les opérations de contrôle sont le propre de toute structure administrative responsable; l'histoire de France en a gardé des traces multiples, dont la plus manifeste est le nom du chef de l'administration des finances à partir du règne de Louis XIV. Mais, s'il paraît facile à mettre en œuvre, ou au moins à justifier, dans les opérations financières, le contrôle appliqué à la chose militaire pose des problèmes plus subtils. Non qu'il ne soit indispensable: les « contrôles de troupes », registres des présents dans l'unité dont la tenue fut imposée à partir de 1716, disent assez combien il est nécessaire à l'officier comme au ministre de connaitre les effectifs exacts de leurs troupes ${ }^{1}$. Mais les choses se compliquent lorsqu'il s'agit de placer ce contrôle au niveau adapté, et de définir la place du corps qui l'exerce au sein du ministère. Le propre du chef de guerre est le commandement, qui, dans le feu de l'action, ne doit pas souffrir de frein : est-il alors légitime de rajouter à la tutelle politique, déjà difficile à mettre en œuvre, une tutelle administrative ? Si celle-ci est militaire, peut-elle conserver son indépendance vis-à-vis du commandement ? Et si elle est civile, comment prendra-t-elle en compte la spécificité de la chose militaire ? Comment, enfin, ce contrôle peut-il coexister avec les structures comparables mises en place par le ministère des finances ? L'organisation, les prérogatives et l'activité du corps du contrôle de l'administration de l'armée, organisé par la loi du 16 mars 1882, apparaissent, sous cet angle, comme d'excellents révélateurs des rapports entre l'armée et les structures administratives qui la soutiennent et l'innervent. Le retour des archives rapatriées de Russie au Service historique de la Défense, et la quantité considérable d'archives du corps du contrôle qui s'y trouvent, nous ont paru justifier un nouveau regard sur l'histoire de ce corps, depuis sa formation jusqu'au déclenchement de la Seconde Guerre mondiale ${ }^{2}$.

\section{La création}

Soupçonnés de corruption et critiqués pour leur manque d'efficacité, les commissaires des guerres virent leur nombre et leurs attributions restreints par la création, le 9 pluviôse an VIII (29 janvier 1800), du corps des «inspecteurs aux revues » ${ }^{3}$. Sous l'autorité directe du ministre, ceux-ci avaient dans leurs prérogatives l'organisation, l'incorporation, la levée, le licenciement, la solde et la comptabilité des corps militaires, la tenue des contrôles et la

\footnotetext{
${ }^{1}$ Le terme même de «contrôle » l'indique, en faisant référence au «rôle », liste écrite des membres d'une unité, et au «contre-rôle », second exemplaire permettant la vérification par le «contrôleur ». Cette mission de contrôleur fut remplie, à l'époque moderne, par les commissaires des guerres, dont la fonction de contrôle, cependant, n'était pas distincte de celle de surveillance ou d'exécution des détails de la logistique militaire. Sur les contrôles de troupe, voir A. Corvisier, Les contrôles de troupe de l'Ancien Régime, Vincennes, 1968-1970, 4 vol. Sur les commissaires des guerres aux $\mathrm{XVII}^{\mathrm{e}}$ et $\mathrm{XVIII}^{\mathrm{e}}$ siècles, voir S. Gibiat, La militarisation des commissaires des guerres à la fin de l'Ancien Régime (1767-1791) : étude prosopographique, institutionnelle et sociale, thèse de l'École des chartes, Paris, 1996, et Hiérarchies sociales et ennoblissement au XVIII siècle : les commissaires des guerres de la Maison du roi, Paris, École des chartes, 2006.

${ }^{2}$ Les archives de la direction du contrôle anciennement détenues par le Service historique de la Défense sont cotées $8 \mathrm{~N} 1$ à 284.

${ }^{3}$ Sur les inspecteurs aux revues, voir M. Roucaud et T. Sarmant, « Une institution originale de l'administration consulaire et impériale : le corps des inspecteurs aux revues », La Revue administrative, $\mathrm{n}^{\circ} 347$, septembre 2005, p. 526-539.
} 
formation des revues. Par leur statut, qui les assimilait à des officiers généraux, comme par leur traitement ou leur origine, les membres de ce nouveau corps se trouvaient manifestement au-dessus des commissaires des guerres ; pour autant, ils ne donnèrent pas entière satisfaction, et des projets de réforme virent le jour dès 1801. L'un d'entre eux, dû à la plume de l'inspecteur Denniée, proposait déjà la création d'un corps spécifique de contrôle des dépenses de la guerre, qui n'aurait dans ses attributions que des missions d'inspection et de contrôle. Les inspecteurs aux revues furent pourtant maintenus dans leurs fonctions, et fournirent jusqu'en 1817 les plus hauts commis des ministères de la Guerre et de l'administration de la Guerre. Régulièrement augmenté, le corps comptait à cette date 231 membres, qui se répartissaient entre inspecteurs en chef, inspecteurs, sous-inspecteurs et adjoints. Mais la Restauration lui fut fatale : à la réduction des budgets s'ajoutèrent un bilan mitigé ainsi que la fronde des commissaires, qui n'acceptaient pas cette création bonapartiste. Louis XVIII résolut la question en supprimant l'un et l'autre corps, et en formant pour le remplacer, par l'ordonnance du 29 juillet 1817, un seul corps dit de l' «intendance militaire ». Il mettait ainsi fin à la première expérience d'un corps de contrôle séparé et autonome au sein de l'administration.

Le Second Empire reprit à son compte la question; toujours en vue de «séparer à leur source les deux attributions de l'administration et du contrôle », on choisit, plutôt que de recréer les inspecteurs aux revues, de mettre sur pied par le décret du 12 juin 1856 un collège d' «intendants généraux inspecteurs », rattaché directement au ministre et chargé de l'inspection administrative des établissements militaires. Mais ces intendants généraux occupèrent aussi des postes dans l'administration centrale, en particulier dans les directions administratives: en 1860, Daniel Darricau, intendant général inspecteur de la première promotion et conseiller d'État, dirigeait ainsi la $5^{\mathrm{e}}$ direction, qui coiffait à la fois l'administration et l'intendance du ministère, avant de passer en 1866 à la tête de la $7^{\mathrm{e}}$ direction («comptabilité générale »). La séparation entre l'administration et le contrôle était encore imparfaite, et la défaite contre la Prusse contraignit à revoir cette organisation.

L'intendance ayant été montrée du doigt pour son incapacité à assurer la logistique des troupes, des projets d'amélioration des structures de contrôle et d'administration de l'armée fleurirent alors de toutes parts, évoquant même un contrôle entièrement civil ${ }^{4}$. On se contenta dans un premier temps, dès la fin de l'année 1871, de quelques retouches à l'organigramme du ministère : la direction de la comptabilité, toujours dirigée par un intendant général, se transforma en une «direction générale du contrôle et de la comptabilité », dont le $1^{\text {er }}$ bureau avait dans ses attributions «contrôle des dépenses, contentieux, budgets généraux, agence comptable », ainsi que les relations avec l'assemblée, le Conseil d'État, la Cour des comptes et le ministère des Finances ${ }^{5}$. Puis vint la loi du 24 juillet 1873 , relative à l'organisation générale de l'armée, qui, au lieu de centraliser l'administration du ministère auprès du ministre, l'obligea à déléguer une partie de ses attributions dans ce domaine aux officiers généraux commandant les corps d'armée. Le législateur n'entrait pas dans les détails, mais l'article 17 annonçait un texte spécial sur l'administration de l'armée, en précisant que celuici « pourvoirait à l'établissement d'un contrôle indépendant». Il s'agissait alors d'un véritable bouleversement, comme le rappelait plus tard Charles de Freycinet :

\footnotetext{
${ }^{4}$ Le projet est cité par Eugène Trollard dans ses Mémoires d'un inspecteur des finances au XIX ${ }^{e}$ siècle, Paris, CHEFF, 1998, p. 90-91.

5 Journal militaire officiel, année 1871, «Arrêté portant réorganisation de l'administration centrale du ministère de la guerre », Versailles, 8 juin 1871, et «Arrêté relatif aux rapports de la direction générale du contrôle et de la comptabilité de la guerre avec les autres services de l'administration centrale de ce département », Versailles, 21 décembre 1871. La direction générale du contrôle et de la comptabilité coexistait avec les directions générales du personnel et du matériel.
} 
Ces questions qui, de 1876 à 1882, ont passionné le Parlement, paraissent aujourd'hui bien surannées. On est tellement habitué à voir le commandant du corps d'armée maitre de tous ses services, sous le contrôle du ministre, qu'il ne semble pas que les choses aient pu jamais être autrement. Mais, en 1876, l'ancienne école, qui plaçait le service de santé sous l'intendance, et celle-ci en dehors du chef militaire, avait de nombreux et brillants partisans ${ }^{6}$.

Il fallut en effet neuf ans pour que le texte annoncé en 1873 paraisse au grand jour. Récemment élu et nommé rapporteur de la commission chargée de sa rédaction, Freycinet proposa au Sénat, en juillet 1876, le projet élaboré par la Chambre ; le Sénat le modifia et adopta un nouveau texte en décembre, qui repassa à la Chambre, où il fut étudié à partir de février 1880, et fit l'objet des critiques du ministre de la Guerre, le général Farre, tenant de l' "ancienne école». Après de longues discussions, le texte fut enfin adopté par le Sénat en juillet 1881, et voté par la Chambre le 16 mars 1882, avec le soutien de Billot, ministre de la Guerre depuis le mois de janvier, et toujours de Freycinet, devenu entretemps chef du gouvernement. Les deux rapporteurs successifs du texte, Freycinet et Margaine, avaient insisté tous deux sur la création d'un contrôle indépendant comme corollaire au pouvoir donné aux commandants de corps d'armée et rappelé que, jusqu'alors, le contrôle s'était trouvé entravé par l'obligation qu'avaient ses agents d'exercer en même temps des responsabilités directes ou indirectes dans l'administration, constat qui visait en particulier le corps de l'intendance?

Aussi l'article 3 de la loi proclama-t-il la «séparation en direction, gestion ou exécution [et] contrôle » de l'organisation des services administratifs ; «la direction, lisait-on, ne participe pas aux actes de la gestion qui lui est soumise. Le contrôle ne prend part ni à la direction, ni à la gestion, et ne relève que du ministre ». Les articles 25 et 26 définissaient les missions et les responsabilités du contrôle :

«Le contrôle de l'administration de l'armée est exercé par un personnel spécial ne relevant que du ministre. Il a pour objet de sauvegarder les intérêts du trésor et les droits des personnes, et de constater dans tous les services l'observation des lois, ordonnances, décrets (...) qui en régissent le fonctionnement administratif (...). Les contrôleurs agissent comme délégués directs du ministre. Ils procèdent, soit par des vérifications sur pièces, soit par inspections inopinées. Ils se présentent, sans avis préalable, à l'autorité militaire du lieu où ils veulent accomplir leur mandat (...). Indépendamment de leurs inspections, les contrôleurs peuvent être chargés par le ministre, en temps de paix comme en temps de guerre, de toutes études ou missions intéressant le bon ordre des finances et la régularité de l'administration dans l'armée. »

Restait à mettre en place ce corps et la direction qui l'encadrait, ce qui fut fait par le décret du 28 octobre $1882^{8}$. La nouvelle «direction du contrôle » était rattachée directement au ministre ; cette place garantissait son indépendance par rapport à toute hiérarchie militaire, mais rappelait aussi l'autorité immédiate du ministre dans tout ce qui avait trait aux relations

\footnotetext{
${ }^{6}$ C. de Freycinet, Souvenirs (1848-1878), Paris, Delagrave, 1912, t. I, p. 333-334.

7 Notice historique sur l'organisation de l'armée depuis la Révolution jusqu'à nos jours, Paris, Impr. nationale, 1902, p. 463-466. Voir aussi contrôleur général Guérinet, «Le contrôle dans l'armée de terre », Revue historique des armées, $\mathrm{n}^{\mathrm{0}}$ hors-série, "Une institution séculaire : le contrôle dans les armées », 1982, p. 11-13, et P. Allain, Études sur les principes d'administration militaire et la loi du 16 mars 1882, Paris, 1982, thèse pour le doctorat de l'université de Paris II, p. 78-82. La loi traitait aussi, au titre de l'administration de l'armée, des services de l'artillerie, du génie, de l'intendance, des poudres et salpêtres, de santé, et de l'administration intérieure des corps de troupe.

8 Journal militaire officiel, $2^{\mathrm{e}}$ semestre 1882, «Rapport au président de la République française sur l'organisation du corps du contrôle de l'administration de l'armée » et « Décret portant organisation du corps du contrôle de l'administration de l'armée », 28 octobre 1882. Au printemps 1882, les tournées d'inspection habituelles furent encore confiées, par commodité, aux intendants inspecteurs généraux (SHD, GR 8 NN 17 , lettre du ministre de la guerre aux intendants généraux inspecteurs, 27 mai 1882).
} 
du nouvel organisme avec les autres directions du ministère (art. 3, 4 et 6 du décret du 28 octobre 1882). Les grands principes de l'action des contrôleurs étaient répétés : présentation sans avis préalable aux autorités militaires, accès libre à toute pièce réclamée "sur la seule exhibition de leur commission ${ }^{9} »$, possibilité de requérir la réunion de conseils d'administration... Ces pouvoirs étaient cependant contrebalancés, puisque « les contrôleurs [n'exerçaient] aucune action immédiate sur la direction ou l'exécution du service », et ne pouvaient «diriger, empêcher ou suspendre aucune opération »; ils n'étaient autorisés qu'à émettre des observations ou des rappels, ou encore à demander des explications (art. 10). Leurs opinions devaient être réunies dans un rapport, rendu au terme de chaque mission (art. 11). Le titre III du décret précisait quelques règles d'organisation et de recrutement du nouveau corps : on rappelait que les contrôleurs ne dépendaient, du point de vue administratif et disciplinaire, que du ministre, et on précisait le montant de la solde, les limites d'âge et les formalités d'entrée dans le corps. Deux décrets, le 7 novembre, permirent de nommer les premiers contrôleurs, et de choisir parmi eux le contrôleur général de $2^{\mathrm{e}}$ classe Vuillaume, ancien intendant militaire, pour prendre la tête de la nouvelle direction ${ }^{10}$.

\section{Naissance d'un corps}

L'organisation du corps fut à la fois le fruit du décret du 28 octobre et de la loi du 16 mars qui, dans ses articles 42 et 43 , fixait déjà la hiérarchie des contrôleurs : contrôleurs adjoint, de $2^{\mathrm{e}}$ et de $1^{\mathrm{re}}$ classe, contrôleurs généraux de $2^{\mathrm{e}}$ et de $1^{\mathrm{re}}$ classe. Elle précisait aussi leur mode de recrutement, strictement militaire : à la formation du corps, tous les titulaires devaient être issus, selon leur grade, du corps des officiers généraux ou des officiers. À terme, les contrôleurs-adjoints, futurs contrôleurs, devaient se recruter par voie de concours, parmi les chefs de bataillons ou officiers de grade équivalent ayant au moins deux ans de grade, ou parmi les capitaines ayant au moins quatre ans de grade; un cinquième des postes de contrôleurs généraux de $2^{\mathrm{e}}$ classe et de contrôleurs de $1^{\text {re }}$ et $2^{\mathrm{e}}$ classe pouvait être attribué, selon des conditions particulières, à des candidats directement issus de grades plus élevés. Les tarifs de la solde étaient plutôt valorisants : un contrôleur général de $1^{\mathrm{re}}$ classe et un général de division sur le pied de paix touchaient respectivement $19908 \mathrm{~F}$ et $19764 \mathrm{~F}$ par an, un contrôleur de $2^{\mathrm{e}}$ classe et un lieutenant-colonel, respectivement $8784 \mathrm{~F}$ et $8694 \mathrm{~F}^{11}$. L'avancement avait lieu exclusivement au choix, sur liste d'aptitude, et les effectifs complets du corps étaient fixés à 80 personnes.

Sur quels modèles le ministère s'était-il appuyé ? Les dossiers de la commission réunie au printemps 1882 pour dessiner les traits du corps, sous la présidence du général Vuillemot, chef d'état-major général, montrent que les «pères fondateurs » s'inspirèrent de l'expérience

\footnotetext{
${ }^{9}$ « Décret portant organisation du corps du contrôle... », art. 7. Un échantillon de « commissions », spécimen intéressant de diplomatique contemporaine, est conservé dans les archives du contrôle (SHD, GR 8 N 65).

${ }^{10}$ Annuaire du corps $d u$ contrôle de l'administration, du corps de l'intendance et du corps des officiers d'administration, année 1882 et suivantes. Pour des raisons obscures, le poste de directeur connut en trois ans trois titulaires successifs : après Vuillaume, Birouste ne resta en place que quelques mois (novembre 1884-juin 1885), et Boisbrunet à peine plus d'une année (juin 1885-décembre 1886). Prioul, directeur de 1887 à 1895 , resta dans les mémoires comme le premier à imprimer sa marque à la direction (SHD, GR 8 N 34, 75e anniversaire du contrôle de l'armée, sl, 1958). Appelé au secrétariat général du ministère en 1895, il fut remplacé par Lacapelle, son adjoint depuis 1887, qui resta en place jusqu'en 1905.

${ }^{11}$ SHD, GR 8 N 34, "Solde et frais de service des contrôleurs de l'administration de l'armée de 1882 à 1890 », 29 septembre 1933. L'évolution se fit en faveur du contrôle, si l'on en croit la comparaison dressée, par mois, en 1904 : général de division et contrôleur général de $1^{\text {re }}$ classe, 2389 et $2196 \mathrm{~F}$; général de brigade et contrôleur général de $2^{\mathrm{e}}$ classe, 1477 et $1626 \mathrm{~F}$; colonel et contrôleur de $1^{\text {re }}$ classe, 1047 et $1194 \mathrm{~F}$ (Anonyme, Le contrôle de l'administration de l'armée, Paris, E. Capiomont, 1904, p. 8).
} 
des intendants généraux inspecteurs ${ }^{12}$; ils étudièrent aussi le fonctionnement de l'inspection administrative du ministère de la Marine et des colonies, ainsi que celui de l'inspection générale des ponts et chaussées au ministère des Travaux publics ; ils examinèrent surtout de près les rouages de l'inspection des finances. Reprenant à son compte des critères d'organisation et de recrutement similaires, qui recoupaient des procédures déjà en place dans l'armée, le contrôle fit appel à l'expérience des inspecteurs des finances, qui, à l'aide d'exhortations ambitieuses, surent inspirer la naissance d'un «esprit de corps »: «Le contrôle de l'administration de la Guerre, rappelait ainsi l'inspecteur Renaudin, aura comme l'inspection des finances a dû le faire peu à peu, à établir ses traditions, à formuler ses méthodes ${ }^{13} »$.

La première promotion des contrôleurs fut nommée à la suite des travaux d'une commission regroupant tous les présidents de comités d'armes et présidée par le général Gresley, ancien ministre de la Guerre à la veille de la retraite ${ }^{14}$. Après examen des propositions faites par les corps d'armée, la commission aboutit à une liste de 21 membres $^{15} ; 13$ d'entre eux étaient issus du corps de l'intendance, chiffre qui marquait la continuité institutionnelle voulue par le ministère. Les huit autres étaient deux généraux polytechniciens, Dhombres, du génie, et Maucourant, de l'artillerie, deux colonels d'artillerie, deux colonels du génie, un lieutenantcolonel et un chef de bataillon d'infanterie. Fixé à 80, l'effectif complet fit rapidement l'objet d'âpres discussions. Le 7 décembre 1882, la direction de la comptabilité fit savoir qu'elle mettrait en place en 1883 les crédits nécessaires à la rémunération de 50 contrôleurs et, le 2 avril suivant, annonça que le budget de 1884 comprendrait les frais de service et la solde de 80 titulaires. Mais, dès le 15 mai, le directeur du contrôle lui-même remit au ministre une longue note dans laquelle il estimait que le chiffre pouvait être réduit à 60 : moyennant six mois effectifs de tournée pour chaque contrôleur, entrecoupés d'un repos d'un mois, «il semble possible avec cet effectif, écrivait-il, de faire contrôler en deux ans tous les services de la Guerre, soit à l'intérieur, soit en Algérie ${ }^{16} »$. Pour leurs opérations, les contrôleurs seraient répartis en «groupes » de trois ou quatre membres, chargés chacun de l'inspection d'un corps d'armée, selon un calendrier qu'il présentait dans un tableau détaillé. Pourtant, le chiffre fut encore jugé excessif par la Commission du budget et, le 5 septembre, le directeur du contrôle dut refaire ses calculs dans une nouvelle note. Défendant les six mois de tournée annuels, il jugeait impossible d'en exiger davantage, et rappelait incidemment que «les inspecteurs des finances, qui fonctionnent dans des conditions analogues, ne font que cinq mois». Additionnant les «groupes », il parvenait enfin au chiffre de 52 contrôleurs - 6 généraux de $1^{\text {re }}$ classe, 9 généraux de $2^{\mathrm{e}}$ classe, 16 contrôleurs de $1^{\text {re }}$ et 16 de $2^{\mathrm{e}}$ classe, 5 contrôleursadjoints - qui fut approuvé par le ministre le 11 septembre 1883. À cette date, les effectifs étaient presqu'au complet, et un concours fut annoncé en décembre 1883 pour le premier recrutement de contrôleurs-adjoints ${ }^{17}$.

Restaient à régler les questions d'avancement, de décorations, de discipline, d'uniforme, de préséances... Tous ces points donnèrent lieu à des discussions approfondies, qui montraient au moins la haute idée que les contrôleurs avaient déjà de leur mission. Les questions qui

\footnotetext{
${ }^{12}$ SHD, GR 8 NN 17, instructions aux intendants généraux inspecteurs, 1872-1881.

${ }^{13} \mathrm{Ibid}$, note de l'inspecteur des finances Renaudin, s.d. [1882].

${ }^{14}$ F. Vigo-Roussillon, Discours prononcé le 8 février 1884 aux funérailles de M. Paul Maldan, contrôleur général de l'administration de l'armée, décédé le 6 février 1884, Paris, 1884, p. 9.

${ }^{15}$ SHD, GR 8 NN 17, «Propositions relatives à l'achèvement de la formation du corps du contrôle », 5 novembre 1883 .

16 Ibid., «Recherche de l'effectif minimum qu'il serait possible de donner au corps du contrôle de l'administration de l'armée », 15 mai 1883.

${ }^{17}$ Une deuxième série de nominations avait eu lieu le 25 juin 1883 ; il ne manquait plus qu'un contrôleur de $1^{\text {re }}$ classe et deux de $2^{\mathrm{e}}$ classe (SHD, GR 8 NN 17, «Propositions relatives à l'achèvement de la formation du corps du contrôle, 5 novembre 1883).
} 
visaient à établir leur rang face aux commandants de place et à toutes les autorités militaires qu'ils seraient amenés à visiter furent étudiées minutieusement, d'autant plus que la loi ne prévoyait volontairement pas d'assimilation de grade ${ }^{18}$. Celles de la discipline interne et de l'avancement du corps furent aussi traitées avec soin: la note rédigée par Vuillaume en janvier 1884 sur ce sujet commençait naturellement par citer les pratiques de l'inspection des finances, en concluant qu'elles avaient donné à ce corps «trop d'unité et de force pour qu'on ne soit pas tenté de s'en inspirer ». Plutôt que d'imaginer des manquements à la politesse ou à l'obéissance, le directeur préférait considérer que "vis-à-vis d'un corps recruté comme celui du contrôle et dont les membres s'inspirent de sentiments aussi élevés, une pareille hypothèse serait tout simplement injurieuse » et attendre, pour définir des sanctions, "des éventualités qui ne se produiront vraisemblablement jamais ». Le problème de la notation des contrôleurs par les contrôleurs généraux et de l'avancement était résolu de la même façon : tous les contrôleurs devant, "en principe, être considérés comme fournissant un bon service », l'avancement devait être automatique et ne pouvait se faire qu'à l'ancienneté ${ }^{19}$.

Dès le mois de mai 1882, le cabinet du ministre avait demandé aux services de l'habillement d'imaginer un uniforme pour le nouveau corps, qui devait s'inspirer de celui de l'intendance. Bel exemple de mémoire administrative, la note ajoutait qu'il serait «utile de donner la description de l'uniforme des anciens inspecteurs aux revues et de faire ressortir [ses différences] avec celui des commissaires des guerres de la même époque ${ }^{20} »$. La nouvelle création ne devait prêter à aucune confusion entre les contrôleurs et les officiers de la hiérarchie militaire supérieure, tout en marquant suffisamment le caractère militaire et l'autorité des nouveaux fonctionnaires. Les traits en furent fixés par le décret du 28 janvier 1883 qui distinguait une petite tenue, articulée autour d'une tunique, et une grande tenue en habit brodé. Mais l'habit ne fut guère porté : le 23 février suivant, une simple décision ministérielle le remplaça par la tunique, et l'ensemble subit quelques modifications ultérieures : en 1891, en 1906, avec la substitution du noir à l'amarante sur la ceinture, et enfin en 1911, par l'adoption d'une troisième tenue, dite «tenue de travail », dépourvue d'épée et qui pouvait être portée dans les opérations quotidiennes de contrôle ${ }^{21}$.

\section{Premières missions}

La création de la direction du contrôle, en octobre 1882, avait entraîné le changement de nom de la direction du contrôle et de la comptabilité qui, tout en gardant ses attributions en matière financière, avait pris le nom de «direction de la comptabilité et du contentieux », et se chargeait toujours du contrôle intérieur, ou contrôle de l'administration centrale. Mais, démunie du contrôle extérieur, la direction de la comptabilité n'avait plus les moyens d'investigation et de surveillance nécessaire à son action ; et la nouvelle direction du contrôle s'aperçut vite que sa capacité d'action était entravée par son manque de visibilité sur les services de l'administration centrale. Plutôt que de conserver deux directions dont "l'une était aveugle et l'autre paralytique ${ }^{22} »$, le décret du 15 novembre 1884 supprima la direction de la comptabilité. Mais, pour éviter de redonner au contrôle des missions de direction et de gestion, on décida que les affaires comptables et financières seraient traitées par chacune des directions concernées; la direction du contrôle récupérait seulement les attributions liées au

\footnotetext{
${ }^{18}$ SHD, GR 8 NN 19.

${ }^{19} \mathrm{SHD}$, GR $8 \mathrm{NN} \mathrm{17,} \mathrm{«Analyse} \mathrm{au} \mathrm{sujet} \mathrm{de} \mathrm{certaines} \mathrm{mesures} \mathrm{d'ordre} \mathrm{relatives} \mathrm{au} \mathrm{fonctionnement} \mathrm{et} \mathrm{à} \mathrm{la}$ discipline du corps du contrôle », 30 janvier 1884 .

${ }^{20}$ SHD, GR 8 NN 18, note à la $5^{\mathrm{e}}$ direction, 16 mai 1882.

${ }^{21}$ SHD, GR 8 NN 18.

${ }^{22}$ SHD, 8 NN 19, note, juillet 1908.
} 
« contrôle central », exerçant ainsi comme «service centralisateur, organe d'information, d'ordre et de régularisation ». Les textes de 1882 avaient placé le contrôle au cœur de l'armée ; comme un second acte de naissance, ce décret du 15 novembre 1884 l'installa au cœur de l'administration du ministère, lui permettant de suivre tous les actes administratifs et financiers depuis leur origine jusqu'à leur exécution. L'organigramme de la direction fut modifié en conséquence : à côté du « service du contrôle extérieur » rattaché directement au directeur et articulé autour du «bureau du contrôle», cheville du corps tel qu'il avait été imaginé en 1882, apparut la sous-direction du contrôle central, munie de trois bureaux: budget et comptes, contentieux et liquidation des dépenses des armées, fonds et ordonnances ; à cette sous-direction étaient aussi rattachée une équipe de jurisconsultes qualifiés, avocats à la cour d'appel ou au conseil d'État ${ }^{23}$.

C'est avec l'ardeur des néophytes que les premiers contrôleurs se mirent en chemin pour inspecter un à un tous les corps de l'armée française, et les premiers rapports affluèrent peu à peu sur la table du directeur du contrôle. Dès 1888, un «Relevé des propositions formulées par les membres du corps du contrôle et des résultats acquis » fut rédigé, et séparé en deux parties : une première recensait les économies réalisées à la suite des rapports, une seconde établissait la liste des «simplifications et améliorations » proposées $^{24}$. On y relevait aussi bien des points de détails que des remarques de fonds: "appeler l'attention des conseils d'administration des régiments de cuirassiers et de dragons sur la nécessité de déterminer la nature et le nombre de pièces de casques à emporter en cas de mobilisation »; " déterminer de façon précise quelles sont les marques à apposer (...) sur les effets livrés aux corps par les fournisseurs »; « supprimer les logements d'officiers dans les places d'Algérie telles qu'Oran et Mascara, où il est facile de trouver des logements à louer»; «abandon du projet de construire une infirmerie de garnison à Constantine (économie : $72000 \mathrm{~F}$ ) »... En 1891, le contrôleur Demartial dressa au nom de ses confrères un «Aperçu des travaux du contrôle destiné à éclairer les contrôleurs dans leurs opérations ${ }^{25}$. À la lecture de ce rapport, on constate que l'enthousiasme des premières années avait cédé la place, devant les difficultés rencontrées, à un certain réalisme. L'intendance, dépouillée de ses prérogatives anciennes, avait montré l'opposition la plus vive aux opérations du contrôle, un intendant allant même jusqu'à affirmer que «le corps du contrôle et celui de l'intendance décapitée ne [feraient] pas, à eux deux, la même besogne que l'intendance toute seule ${ }^{26}$. D'autres autorités s'étaient faites prier, ou s'étaient plaintes du déroulement des visites des contrôleurs ; ceux-ci avaient répertoriés minutieusement, à partir de 1883, tous ces incidents, et préparé les réponses adaptées à la signature du ministre ${ }^{27}$. Mais il leur fallait accepter, soulignait Demartial, que, « dans beaucoup de cas, le résultat poursuivi par eux ne [fût] pas immédiatement obtenu »; sans se décourager, ils devaient au contraire « rechercher de nouveaux faits » et «produire de nouvelles raisons à l'appui de leurs propositions ». Outre ce problème des rapports laissés sans suite, les contrôleurs devaient faire face à des jalousies d'ordre statutaire : le montant jugé excessif des soldes et des frais de service était mis en exergue, de même que la rapidité de l'avancement pour les officiers subalternes qui remportaient le concours, qualifiés dans un pamphlet de «jeunes arrivistes disposés à troquer leur épée contre un porte-plume ${ }^{28}$ ». Beauregard, auteur du rapport annuel de 1897, jugea bon de rappeler que « les contrôleurs ne sont pas, comme quelques-uns le croient, et surtout le disent, des gens qui se promènent

\footnotetext{
${ }^{23}$ Annuaire du corps du contrôle de l'administration, du corps de l'intendance et du corps des officiers d'administration, année 1885 .

${ }^{24}$ SHD, GR 8 NN 20.

${ }^{25}$ SHD, GR 8 NN 21.

${ }^{26}$ Anonyme, Le contrôle de l'administration de l'armée (1882-1932). Lettres d'un ancien (janvier, février, mars 1932), Paris, Lavauzelle, 1933, p. 41.

${ }^{27}$ SHD, GR 8 N 67, dossiers d'incidents (1883-1911).

${ }^{28}$ Anonyme, Le contrôle de l'administration de l'armée, Paris, E. Capiomont, 1904, p. 13.
} 
pendant six mois de l'année et ne font rien pendant les six autres mois $»^{29}$. En guise de défense, les rapports annuels insistaient sur le travail accompli et la masse documentaire accumulée : ainsi, les missions de 1899 avaient donné lieu à l'envoi à la direction du contrôle d'un millier de rapports, lesquels évoquaient chacun deux ou trois questions : parmi ces deux ou trois mille questions, il avait fallu faire un tri, transmettre les sujets les plus importants aux directions concernées, attendre les réponses de celle-ci, se déclarer satisfait, ou bien au contraire insister, ou encore décider d'en référer au ministre... Du côté du contrôle intérieur, on dénombrait la même année environ 1500 affaires: examen de cahiers des charges, élaboration de conventions, rédaction de règlements ou d'instructions, examen des comptes généraux de l'administration...

L'organisation des missions elles-mêmes était un point largement discuté. Les premières notes d'organisation avaient prévu des missions géographiques; mais «alors que le contrôle prenait le premier contact et avait à cœur de préconiser sans retard des réformes depuis longtemps attendues », les contrôleurs s'étaient dans un premier temps orientés vers des missions thématiques, plus propre à faciliter la découverte du ministère. Puis les missions géographiques avaient repris le pas, dès la fin des années 1880 : au nombre de trois ou quatre, les contrôleurs visitaient, dans un corps d'armée donné, les établissements d'un certain nombre de services, et une fraction des corps de troupe variant entre le tiers et la moitié. On notait qu'un contrôleur ne pouvait guère voir plus d'une douzaine de places chaque année, la durée de son séjour variant de quelques jours à un mois, ou plus, dans les places les plus importantes. Usuelles, ces missions géographiques se doublaient déjà de quelques missions thématiques : Weil, rattaché au $4^{\mathrm{e}}$ groupe, chargé d'inspecter les $4^{\mathrm{e}}$ et $18^{\mathrm{e}}$ corps, avait reçu en 1898 une mission concernant l'artillerie ; Hagron, du $7^{\mathrm{e}}$ groupe, travaillait aussi sur le service de l'habillement; Jacobée n'avait été rattaché à aucun groupe, mais s'était vu confier une mission spéciale embrassant toutes les écoles militaires... Les missions se déroulaient principalement l'été. Entre novembre et mars, les contrôleurs, en résidence à Paris, formaient entre eux des « commissions d'études ${ }^{30}$. Réunies à partir du début des années 1890 , celles-ci servaient de cadre à la rédaction des rapports et de leurs résumés, à l'étude de différentes questions administratives, à l'examen des propositions des contrôleurs ou de tel ou tel budget. Beaucoup de contrôleurs travaillaient en outre au sein de commissions ministérielles ou parlementaires : en 1898, Romanet était membre de la Commission extra-parlementaire des marchés et adjudications passés au nom de l'État, Forot de celle des études budgétaires, Ventre de celle qui révisait le règlement sur le casernement, etc.

\section{Le temps des réformes}

Quelle était la physionomie du corps au tournant du siècle? Une nouvelle modification avait eu lieu en 1899, quand les difficultés éprouvées par la justice militaire justifièrent la création d'une direction propre : pour mettre en place la «direction du contentieux et de la justice militaire », on retira au contrôle quelques attributions en matière de contentieux ${ }^{31}$. Mais, pour ne pas raviver la rivalité entre comptabilité et contrôle, on précisa que «la préparation des lois de finances, la production des comptes généraux, ainsi que la correspondance y relative [resteraient] dans les attributions exclusives de la direction du contrôle », dont on précisait qu'elle devait être « obligatoirement consultée sur tous les projets

\footnotetext{
${ }^{29}$ SHD, GR 8 NN 23.

${ }^{30}$ SHD, GR 8 NN 24.

${ }^{31}$ Sur la direction du contentieux et de la justice militaire, voir l'introduction consacrée à ce fonds dans l'inventaire des archives rapatriées de Russie (SHD, sous-série GR 9 NN), ainsi que E. Pénicaut, « Une histoire des prisons militaires, $\mathrm{XIX}^{\mathrm{e}}-\mathrm{XX}^{\mathrm{e}}$ siècles », Histoire pénitentiaire, vol. 9, 2010, p. 6-36.
} 
de loi, décrets et arrêtés susceptibles d'affecter le budget de la Guerre ${ }^{32}$ ». Faveur supplémentaire, c'est au contrôleur Marie-Jean-Charles Crétin (1846-1933), chef du cabinet au secrétariat général du ministère, ancien intendant et spécialiste du contentieux administratif, que fut confiée la nouvelle structure ${ }^{33}$. Quatre ans plus tôt, en 1895, c'est le directeur du contrôle, Prioul, qui avait été placé à la tête de l'éphémère secrétariat général du ministère, poste auquel Demartial lui avait succédé en 1897 : la nomination de contrôleurs à des postes de direction n'était-elle pas en opposition avec les principes de création du corps ? On préféra considérer que l'emploi rentrait dans la catégorie des «études ou missions intéressant le bon ordre des finances et la régularité de l'administration de l'armée » définies par l'article 26 de la loi de mars 1882, et ni Demartial, ni Prioul, ni Crétin ne furent placés hors cadre: moins de quinze ans après sa création, le contrôle s'affirmait comme une pépinière d'administrateurs. Le recrutement, par ailleurs, s'était élargi : en 1899, si les seize contrôleurs généraux en activité étaient encore des anciens de l'intendance, la proportion descendait à 11 sur 16 pour les contrôleurs de $1^{\text {re }}$ classe, et à 4 sur 15 pour les contrôleurs de $2^{\mathrm{e}}$ classe. En 1910, la part des intendants avait encore baissé : 4 sur 9 contrôleurs généraux de $2^{\mathrm{e}}$ classe, 5 sur 16 contrôleurs de $1^{\mathrm{re}}$ classe, un seul sur 14 contrôleurs de $2^{\mathrm{e}}$ classe. Signe de cette évolution, le directeur Mauclère choisit en 1906, pour la première fois, un sous-directeur qui n'était pas issu de l'intendance, mais du génie. En revanche, alors que les pantouflages ou les nominations extérieures s'étaient multipliés à l'inspection des finances dès les années $1880^{34}$, le phénomène épargna le contrôle : l'Annuaire ne mentionne, avant 1914, qu'un seul contrôleur hors cadre, en poste à la Résidence générale de France au Maroc.

Si le corps avait trouvé son assise et sa place au sein du ministère, il frémissait aussi d'un vent de réforme, qui aboutit à deux nouveaux textes d'organisation, adoptés l'un en 1906 et l'autre en 1913. Les revendications des réformateurs portaient sur l'organisation jugée défectueuse du service des missions. En toile de fond, cependant, on distinguait un autre désir : il s'agissait de quitter les habits d'un corps technique aux missions spécifiques, dont la caricature aurait pu faire de simples experts-comptables dépouillant sans fin les registres d'intendance des corps de troupe, pour revêtir ceux d'un " grand corps », dont la vocation comme l'ambition paraissaient sans limite. En cela, les contrôleurs imitaient leurs voisins du Louvre, puisqu'un mouvement similaire touchait l'inspection des finances ${ }^{35}$; on discernait aussi les conséquences de l'élargissement du recrutement, et il est significatif que Fortuné Gallo comme Jules Boone, les plus actifs des réformateurs, ne fussent pas sortis du corps de l'intendance. Dès 1900, Gallo rédigea un plaidoyer pour la spécialisation des contrôleurs par domaine de compétences. Des missions thématiques spéciales furent confiées ad experimentum, en 1903-1904, aux contrôleurs Gallot, Bossut et Mercier. Ayant succédé comme directeur à Lacapelle à la fin de l'année 1905, Mauclère reconnut les défauts des habitudes en cours: les rapports particuliers ne traitaient que de questions de détail, les rapports généraux n'abordaient que les problèmes de réglementation, et, malgré les milliers de pages noircies, il était «difficile de trouver, chaque année, un nombre suffisant de rapports pouvant être utilement mis sous les yeux des rapporteurs du budget », dont les requêtes se faisaient toujours plus insistantes. Quant au Service spécial, qui aurait dû effectuer les synthèses nécessaires, le jugement était sans appel : "Son rôle, estimait Mauclère, s'est borné à peu près à couper en plus petites tranches, pour les transmettre aux services intéressés, les

\footnotetext{
${ }^{32}$ Bulletin officiel du ministère de la guerre, partie réglementaire, $1^{\mathrm{er}}$ semestre 1899 , « Rapport au Président de la République française sur l'organisation de l'administration centrale de la guerre », 13 janvier 1899.

${ }_{33}$ Bulletin officiel du ministère de la guerre, partie supplémentaire, $1^{\text {er }}$ semestre 1899 , décret du 13 janvier 1899.

${ }^{34}$ Emmanuel Chadeau, «Introduction », dans E. Trollard, Mémoires d'un inspecteur des finances au XIX ${ }^{e}$ siècle, Paris, CHEFF, 1998, p. XXV.

${ }^{35}$ C. Charle, «Naissance d'un grand corps : l'inspection des finances à la fin du XIX ${ }^{\mathrm{e}}$ siècle », Actes de la recherche en sciences sociales, 1982, $\mathrm{n}^{\circ} 42$, p. 3-17, en particulier p. 3.
} 
observations de détail consignées dans les rapports : il fait ainsi de la pulvérisation au second degré $^{36}$. » On convenait aussi que la coordination des contrôleurs entre eux était déficiente, que les commissions d'études s'étaient coupées des groupes de contrôle, et enfin que l'action extérieure n'était pas assez conjuguée avec le contrôle central. Aussi le nouveau directeur demanda-t-il au contrôleur Beauregard, dont l'expérience était reconnue, de rédiger un projet de nouvelle instruction, qui lui fut remis le 2 juillet 1906 ; après quelques remaniements, Mauclère le fit accepter par le ministre au début de l'automne, et une Instruction provisoire sur l'organisation et l'exécution des missions du contrôle fut publiée le 6 octobre. Le texte décidait d'étendre à trois ans, au lieu de deux, la durée des cycles; de combiner des groupes de contrôle régional et des groupes de contrôle spécial (ou thématique), lorsque celui-ci apparaîtrait comme plus efficace; de mettre en place des programmes pluriannuels d'enquêtes; de demander aux groupes des résumés annuels des travaux et des rapports d'ensemble en fin de cycle, dont les commissions devraient se servir pour élaborer à leur tour des rapports de synthèse.

Au même moment, plusieurs réformes touchaient la direction. L'année 1906 vit d'abord une menace planer sur les effectifs : rédigeant un projet de nouvelle loi sur les cadres, l'état-major de l'armée fit savoir qu'il trouvait excessifs les effectifs du corps. La direction du contrôle se défendit en arguant du fait qu'elle n'avait jamais dépassé le chiffre initial de 52, alors même que trois fonctionnaires avaient été affectés en 1899 à la direction du contentieux, et que le rattachement des troupes coloniales et les expéditions en Extrême-Orient avaient entraîné des missions supplémentaires, tout comme l'évolution de la législation, puisque le décret du 2 mars 1905 sur l'hygiène et la sécurité des travailleurs avait fait des contrôleurs les inspecteurs du travail du ministère. L'attaque de l'état-major resta sans effet, et on confia même des missions supplémentaires au contrôle. En 1909, c'est tout le service de la vérification des dépenses qui lui fut attribué par le décret de réorganisation de l'administration centrale du $1^{\text {er }}$ février $^{37}$ : c'était un aboutissement de la logique du décret de novembre 1884. La direction s'accrut en conséquence de deux bureaux, «liquidation et comptes en deniers », chargé de viser tous les trimestres l'ensemble des revues et rapports de liquidation, et «comptes en matières et réserve de guerre », chargé de l'examen des comptes de gestion et de leurs pièces justificatives après la clôture des gestions : 35 personnels administratifs rejoignirent ainsi les effectifs. Deux ans plus tard, surtout, la loi de finances de juillet 1911, sous l'impulsion du président du Conseil Joseph Caillaux, demanda l'organisation dans tous les ministères d'un service propre des dépenses engagées, ainsi que la rédaction d'un rapport annuel relatif à l'exécution du budget : le ministre de la Guerre confia, pour son département, cette mission au contrôle, transformant celui-ci en une véritable direction administrative et financière ${ }^{38}$.

Il n'était pas interdit de voir dans cette mesure un retour à la situation antérieure à 1882, ironie que le Parlement souligna en demandant, en 1913, des explications sur l'absence de séparation entre le contrôle et la gestion au sein du ministère de la Guerre. Le ministère se défendit en répliquant que la direction du contrôle préparait le budget mais n'intervenait pas dans son exécution, qui restait du ressort des directions ${ }^{39}$. Surtout, cette extension des

\footnotetext{
${ }^{36}$ SHD, GR 8 NN 25, lettre de Mauclère à Beauregard, 18 mai 1906.

${ }^{37}$ Décret du $1^{\text {er }}$ février 1909 portant réorganisation des services de l'administration centrale de la Guerre et répartition du personnel entre ces services, et arrêtés ministériels du 27 mars suivant.

38 «Dans chaque département ministériel où il existe un corps de contrôle financier, ce corps est chargé de suivre l'exécution du budget (...). Chaque année, le contrôleur des dépenses engagées, d'une part, le corps du contrôle, d'autre part, établissent un rapport d'ensemble relatif au budget du dernier exercice écoulé exposant les résultats de leurs opérations (...).» (loi de finances du 13 juillet 1911, art. 150 et 151). Sur cette réforme importante, voir S. Kott, Le contrôle des dépenses engagées : évolution d'une fonction, Paris, CHEFF, 2004.

${ }^{39}$ SHD, GR 8 NN 29. Des parlementaires réclamèrent aussi, à plusieurs reprises, la nomination d'inspecteurs des finances au ministère de la Guerre, épouvantail que les contrôleurs agitèrent régulièrement, en interne, pour défendre leurs effectifs et leurs attributions.
} 
attributions du contrôle aiguisa encore l'appétit des contrôleurs. Si la réforme de 1906 avait été appréciée, il fallait aller plus loin, et faire définitivement des membres du corps ceux qui «éclairent le ministre sur l'état général de son administration » afin de l' " orienter toujours vers le progrès ». Telle était l'opinion du contrôleur Boone, qui rédigea en février 1911 un long rapport dans lequel il plaidait pour une spécialisation plus poussée, et des missions calquées sur les chapitres budgétaires ${ }^{40}$ : «Nous sommes institués les gardiens du budget, écrivait-il un peu plus tard, et nous devons en surveiller l'exécution non seulement au point de vue de la régularité des opérations administratives, mais aussi en ce qui concerne l'utilité et l'opportunité des dépenses ${ }^{41} »$. Conscient de la nécessité de réformer, le ministre demanda au contrôleur Jacobée de réunir une commission de contrôleurs généraux, qui rendit son projet en octobre 1912. Celui-ci témoignait des débats qui agitaient le corps : refusant de trancher entre les dimensions thématique et géographique, il se contentait de confirmer l'instruction de 1906, d'étendre les domaines où pouvaient s'exercer des missions thématiques, et d'instaurer des groupes mixtes, où seraient effectués simultanément les deux types d'inspections. Une mission spéciale et permanente était en outre instituée pour l'inspection de la réserve de guerre $^{42}$, et un contrôleur était nommé inspecteur du travail. Ces propositions furent mises par écrit dans l'Instruction sur l'organisation et l'exécution des missions du contrôle, adoptée le $1^{\text {er }}$ février $1913^{43}$.

\section{Contrôler la guerre?}

Le déclenchement des hostilités, à la fin de l'été 1914, empêcha d'abord l'application sereine de l'instruction de 1913. Il mit aussi les contrôleurs, et le ministère de la Guerre avec eux, devant une situation nouvelle : aucun texte, aucune réglementation ne prévoyait l'emploi du corps en temps de guerre. Celui-ci ne pouvait poursuivre ses missions normales, mais n'avait pas non plus sa place aux armées... Aussi les quatre années suivantes furent-elles pleines d'hésitations. Le 31 juillet 1914, le ministre décida d'abord, avec un certain pragmatisme, d'envoyer les contrôleurs en «missions régionales », afin de contrôler le déroulement de la mobilisation dans chacune des régions militaires. Un mois durant, les contrôleurs remplirent donc cet office. Mais l'inefficacité des services de l'intérieur, incapables de répondre aux besoins démultipliés du front, conduisirent à des mesures plus radicales. Constatant qu'il détenait avec le contrôle un vivier de bons techniciens, le ministre Millerand choisit de les incorporer pleinement dans l'administration de la guerre : le décret du 31 août 1914 créa auprès de chaque général commandant de région un poste de «directeur des services du matériel », confié à un contrôleur. Secondant le commandant, celui-ci était comme un secrétaire général de la région; il relayait aussi à l'échelon local les structures créées au mois d'août en administration centrale, direction générale des services de l'administration et direction générale du ravitaillement ${ }^{44}$. L'action des nouveaux directeurs s'exerça principalement dans les domaines de la mise en œuvre des ressources, de l'utilisation du matériel disponible, de l'examen des marchés passés par les services locaux, de l'inspection des services ou des dépôts des corps de troupe, et fut généralement appréciée, les

\footnotetext{
${ }^{40}$ SHD, GR 8 NN 28, «Étude sur le fonctionnement et l'organisation du contrôle extérieur », février 1911, $54 \mathrm{p}$.

${ }^{41}$ Ibid., note du contrôleur Boone, août 1912.

${ }^{42}$ La loi de finances de 1888 avait institué le contrôle garant de la bonne tenue de la réserve de guerre, mission dont il s'accomplit avec régularité (voir plus bas, SHD, GR 8 NN 210-211).

${ }^{43}$ SHD, GR 8 NN 28.

44 Bulletin officiel du ministère de la Guerre, «Décret portant création dans chaque corps d'armée d'une direction des services du matériel », Paris, 31 août 1914, et «Instruction sur les attributions des directeurs des services du matériel des régions territoriales », Paris, $1^{\text {er }}$ septembre 1914.
} 
commandants de région reconnaissant volontiers que les qualités d'administrateurs des contrôleurs et leur connaissance des mécanismes du ministère avaient permis de pallier la désorganisation des services intérieurs. Pourtant, après une année d'exercice, les premières critiques apparurent : trop consciencieux peut-être, les contrôleurs avaient délaissé leur mission de contrôle pour créer un échelon administratif nouveau dont, une fois les premières surprises passées, l'utilité paraissait moins nette. Boysson, directeur du contrôle, qui avait succédé à Mauclère en 1914, prit lui-même la plume pour demander aux généraux, au printemps 1915 , leur avis sur ces services ${ }^{45}$. Trois mois plus tard, les postes de directeurs des services du matériel furent supprimés et transformés, par décret du 20 septembre 1915, en postes de contrôleurs en "mission spéciale ». Toujours placés auprès des commandants de région, les contrôleurs perdaient leurs attributions exécutives, et devenaient des «conseillers administratifs », avec une double mission de contrôle et de conseil. Cette solution un peu bâtarde, qui laissait les contrôleurs dans la main des commandants de région, fut supprimée par Gallieni quelques mois son arrivée au ministère. Le 2 janvier 1916, il rapatria tous les contrôleurs - vingt-cinq d'entre eux se trouvaient alors en «mission spéciale » - à l'administration centrale de la Guerre. Mais celle-ci n'avait plus le caractère uniforme d'avant 1914 ; elle avait éclaté en multiples sous-secrétariats d'État ${ }^{46}$, et les directions d'avant-guerre avaient pris aussi une importance singulière : on préféra donc affecter les contrôleurs de retour à plein temps dans ces nouveaux organismes, où ils exercèrent en tant que délégués du directeur du contrôle ${ }^{47}$. Si le résultat fut satisfaisant, il ne fit que contribuer à l'éclatement des structures, provoquant la réaction du Parlement, qui cherchait par ailleurs à accroître sa surveillance sur l'administration de la Guerre. Le 30 décembre 1916, Albert Lebrun, rapporteur du budget de la Guerre, considérait que l'accroissement énorme des dépenses du ministère rendait «plus indispensable que jamais un contrôle fortement organisé, assurant le meilleur emploi des crédits en même temps que la satisfaction complète et rapide des besoins de l'armée », et plaidait pour une intensification forte de l'action du contrôle ${ }^{48}$. Relayé par Louis-Lucien Klotz, président de la Commission du budget, le texte fit son effet : le $1^{\text {er }}$ février 1917, le ministre de la Guerre reprit sous sa tutelle directe l'ensemble des contrôleurs, qu'il réorganisa aussitôt en onze groupes de missions spécialisés ${ }^{49}$. Retrouvant leurs attributions et leur mode de fonctionnement d'avant-guerre, les contrôleurs reprirent leurs investigations dans des domaines coutumiers: subsistances, habillement, harnachement, couchage et ameublement, service de santé, aéronautique, hôpitaux vétérinaires, travailleurs coloniaux, prisonniers de guerre, Algérie-Tunisie, enquêtes particulières. Un secteur, cependant, leur resta fermé presque tout au long des hostilités; dès le début de la guerre, le grand quartier général avait fait savoir son hostilité à l'envoi de contrôleurs dans la zone des armées, estimant «qu'il ne pouvait y avoir de contrôle pendant l'action ${ }^{50}$ ». Le ministère dut batailler longuement pour obtenir, en janvier 1916, l'envoi de missions sur le front ; celles-ci furent finalement tolérées, à condition que le GQG restât juge de leur opportunité et que leurs

\footnotetext{
${ }^{45}$ SHD, GR 6 N 13, lettre du ministre de la Guerre aux généraux commandant les régions militaires, 25 mai 1915.

${ }^{46}$ Artillerie, Intendance, Service de santé... La liste est dressée par P. Renouvin, Les formes du gouvernement de guerre, Paris, 1925, p. 153.

47 Neuf contrôleurs, en outre, siégeaient à plein temps depuis l'été 1915 dans les commissions chargées d'inspecter les services de l'intérieur pour y dénoncer les emplois inutiles, en application de l'article 9 de la loi du 17 août 1915, dite « loi Dalbiez ».

48 SHD, GR 6 N 297, «Rapport sur la réorganisation et l'intensification du contrôle », s.d. [30 décembre 1916].

${ }^{49}$ SHD, GR 8 NN 218 ; Fonds privés, GR 1 K 513/2, Rapport d'ensemble exposant le résultat des opérations du corps du contrôle de l'administration de l'armée pendant la période de guerre, 1914-1919, p. 261.

${ }^{50}$ Citation du général Joffre lue par le ministre à la Chambre, 20 août 1915 (SHD, Fonds privés, GR 1 K 513/2, Rapport d'ensemble..., 1914-1919, p. 377).
} 
rapports fussent soumis à son visa ${ }^{51}$. Quelques contrôleurs purent ainsi inspecter les services de l'arrière en 1916, mais l'expérience fut sans lendemain : seuls des tâches sans importance furent confiées au contrôle aux armées entre 1917 et $1919^{52}$.

Si le contrôle local et aux armées donna lieu à ces tâtonnements, les années de guerre furent fertiles du point du vue du contrôle central. La direction du contrôle affermit son rôle tant dans le domaine des marchés et des achats que dans celui des réquisitions. Pour les marchés, ce fut à elle qu'il revint de mettre en œuvre la simplification et l'accélération des procédures, ainsi que le contrôle des prix et la chasse aux irrégularités et aux "profiteurs de guerre » indélicats ; en 1916, trois contrôleurs siégeaient à la Commission des marchés de la Chambre, et trois autres à celle du Sénat. Les réquisitions faisaient partie des attributions du contrôle depuis les origines, le décret du 2 août 1877 ayant créé une Commission centrale des réquisitions qui fut rapidement dirigée par un contrôleur général ${ }^{53}$. Cette commission fut doublée, le 7 juin 1916, d'un Service central des réquisitions, aussitôt rattaché à la direction du contrôle : de moins de 2000 affaires traitées en 1914, on passa à 15096 en 1917, 13508 en 1918 ou 14379 en 1919, qui furent autant d'occasions pour la direction du contrôle de mettre en place une véritable jurisprudence ${ }^{54}$. Il en fut de même dans le domaine des achats : la multiplication des achats à l'étranger entraîna la centralisation, dès l'été 1914, de ces opérations à la direction du contrôle. Celle-ci répondit à ce nouveau besoin, bien qu'il se situât à la marge de ses attributions normales, en organisant un «Service des achats à l'étranger », transformé par décret du 17 avril 1917 en « Service interministériel des dépenses à l'étranger », qui supervisait en particulier deux missions permanentes, à Londres et aux États-Unis, confiées aux contrôleurs Enselme et Johannet. L'expérience administrative des contrôleurs, enfin, assura leur succès dans toutes les branches de l'administration de la Guerre, et nombre d'entre eux y trouvèrent l'occasion de saisir des postes brillants. À l'intérieur du ministère, on pouvait citer Lavit comme directeur général des services au soussecrétariat d'État à la Présidence du Conseil, Bosch et Boone comme inspecteurs généraux adjoints des effectifs, Mauclère comme directeur général du ravitaillement puis directeur général des poudres et explosifs ; à l'extérieur, Vidal fut détaché en 1919 au commissariat général des effectifs coloniaux, Audibert chef de cabinet du ministre des Colonies (19181919), Gaillard directeur général au ministère du Commerce, Enselme détaché au commissariat des transports maritimes et de la marine marchande. Boysson lui-même, directeur depuis 1914, fut appelé en janvier 1916 à un poste de directeur du ministère des Travaux publics, laissant la place à Alombert, à qui ses années de direction valurent trois ans plus tard, en juillet 1920 , le poste de secrétaire général du ministère ${ }^{55}$. Quant à Guinand, à disposition de Klotz à la Chambre en septembre 1915, il fut appelé au cabinet lorsque celui-ci retrouva le portefeuille des finances (1917-1920) dans le gouvernement Clemenceau.

Les tâtonnements des années 1914-1915 ne furent pas propres au contrôle, et on pourrait citer plusieurs branches de l'administration militaire où les mesures prises dans l'urgence de l'été 1914 furent rapportées quelques mois plus $\operatorname{tard}^{56}$. Même si ces hésitations témoignaient

\footnotetext{
${ }^{51}$ SHD, GR 5 N 137, « Note au sujet des missions de contrôle dans la zone des armées, 18 février 1916.

${ }^{52}$ L'armée d'Orient représenta une exception, le général d'Amade ayant demandé la présence à ses côtés du contrôleur Gache, qui était un de ses amis, pendant son temps de commandement (mars-mai 1915). En 1919, les missions du contrôle aux armées s'exercèrent sur les éléments stationnés en Russie du Nord et sur les chemins de fer de l'armée d'Orient (sur ce dernier point, E. Pénicaut, «Les rails de la discorde. Politique française et rivalités internationales sur les chemins de fer de l'armée d'Orient (1915-1933) », Revue d'histoire des chemins de fer, n 40, 2009-1, p. 183-203).

${ }^{53}$ Voir plus bas, SHD, GR 8 NN 214.

${ }^{54}$ SHD, GR 10 N 163, Rapport d'ensemble..., 1925, p. 591-594.

${ }^{55}$ SHD, GR $6 \mathrm{Y}^{\mathrm{g}} 149$, dossier individuel de Paul Alombert-Goget.

${ }^{56} \mathrm{Il}$ en fut ainsi des procédures appliquées par la justice militaire (S. Ottavi et T. Sarmant, Guide des sources de l'histoire de la justice militaire pendant la Première Guerre mondiale, Vincennes, 2000, p. 5-7).
} 
d'une réelle difficulté de positionnement du contrôle, le bilan, au terme des quatre années de guerre, était positif : outre le travail effectué, les hostilités avaient confirmé les contrôleurs dans leur rôle de grands administrateurs. Les succès rencontrés dans les fonctions supérieures auxquelles ils avaient été appelés, concomitants de l'échec de leur tentative d'insertion dans l'administration locale des corps d'armée et de présence au front, avaient manifesté les qualités acquises par le corps, et justifié a posteriori les combats des réformateurs de la première décennie du siècle.

\section{L'Entre-deux-guerres}

Nommé directeur le 4 juillet 1920 en remplacement d'Alombert, Lavit avait trouvé sous ses ordres une direction élargie : outre le service spécial et quatre bureaux (budget et dépenses engagées, liquidation des comptes deniers et matières, marchés, fonds), trois services temporaires étaient rattachés au contrôle : le service interministériel des dépenses à l'étranger, qui avait perdu une partie de ses attributions en 1918, mais récupéré les cessions de matériel aux gouvernements étrangers, le service central des réquisitions, qui fut supprimé le $1^{\mathrm{er}}$ avril 1921, et le service de la liquidation du ministère de la Reconstitution industrielle. L'activité du corps dans les années d'après-guerre porta principalement sur l'organisation de la démobilisation, sous toutes ses formes, et en particulier sur la gestion des stocks de matériel et de ravitaillement. Deux missions spéciales furent créées en 1919, l'une pour examiner les baux et marchés en cours et les transformer ou les résilier en cas de besoin, l'autre pour déterminer les quantités de matériel existant et les mesures de garde et de conservation nécessaires ${ }^{57}$. À la nécessité de revenir à un fonctionnement normal des institutions s'ajoutait un impérieux besoin d'économie. En 1921, la circulaire annonçant aux contrôleurs leur programme annuel leur demandait encore de «s'attacher à la réduction de l'importance des établissements, services ou organes qui se sont développés depuis 1914 [et] à la suppression de ceux qui sont nés de la guerre", et de "poursuivre impitoyablement les abus (de personnel, de deniers et de matières) et les dépenses somptuaires de toute nature ${ }^{58}$. Pour atteindre cet objectif, l'organisation des missions en cycle triennal recommandée par l'instruction de 1913 fut temporairement abandonnée : en 1921 comme en 1922, on préféra constituer quatre ou cinq groupes solides, propres à éviter la dispersion des efforts et à garantir des résultats concrets ${ }^{59}$. Un relatif apaisement permit en 1923 de recréer une dizaine de groupes d'un à trois contrôleurs et à vocation essentiellement thématique, qui contrôlèrent les services passés entre les mailles du filet les années précédentes; le nombre de groupes oscilla, dans les années suivantes, entre dix et quinze ${ }^{60}$. Au contrôle des corps de troupe de métropole, s'ajouta celui des théâtres d'opérations extérieures: la présence française en Rhénanie, au Maroc ou au Levant entraîna l'envoi de missions multiples, dont les rapports, par la quantité d'irrégularités qu'ils soulevaient, n'avaient pas de peine à justifier le bienfondé ${ }^{61}$.

Exception propre au ministère de la Guerre, l' « unité du contrôle sous toutes ses formes », dans laquelle le ministre Maginot voyait «un puissant instrument de poursuite des économies », et qu'il vantait encore dans une lettre au ministre des finances en juin $1922^{62}$,

\footnotetext{
${ }^{57}$ SHD, Fonds privés, GR 1 K 513/2, Rapport d'ensemble..., 1914-1919, p. 315.

${ }^{58}$ SHD, GR 8 N 62, Rapport d'ensemble..., 1921, p. 2.

${ }^{59}$ SHD, GR 10 N 163, Rapports d'ensemble..., 1922 et 1923.

${ }^{60}$ Ibid., Rapport d'ensemble..., 1925.

${ }^{61}$ Sur l'armée du Rhin, voir SHD, GR 8 NN 350 à 378 ; sur le Levant, 8 NN 379 à 420.

${ }^{6}$ SHD, GR 8 N 62, lettre de Maginot au ministre des finances accompagnant le rapport annuel de 1921, 22 juin 1922.
} 
n'était pas du goût de tous ; dès 1920, certains avaient préconisé la séparation entre la direction du contrôle et le contrôle des dépenses engagées ${ }^{63}$. Répondant à ce vœu, la loi Marin du 10 août 1922 et le décret du 15 juin 1923 entraînèrent la création d'un service des dépenses engagées qui ne dépendait plus, à l'intérieur de chaque ministère, que du département des finances : pour la première fois depuis sa création, la direction du contrôle voyait ses attributions restreintes en matière financière. Elle conserva cependant un avis préalable sur toutes les affaires transmises au contrôleur des dépenses engagées, ainsi que ses missions de préparation et de surveillance de l'exécution du budget, d'examen des marchés et des liquidations des comptes. En 1925, 3679 marchés furent ainsi contrôlés, de même que 5000 dossiers de liquidation, 900 dossiers de pénalités... ${ }^{64}$. La réforme du secrétariat général du ministère, en 1926, toucha également le contrôle, en causant une entorse au principe du lien direct entre les contrôleurs et le ministre établi par la loi de $1882^{65}$. Pour renforcer ce secrétariat, le texte prévoyait que son chef exercerait la haute direction de l'administration de l'armée et, à ce titre, recevrait communication de tous les rapports du contrôle et proposerait ou prendrait les décisions suggérées ; il apposerait également son visa sur les propositions de toute nature concernant les fonctionnaires du corps. La décision n'était pas orientée contre le contrôle - Paul Alombert (1920-1924), Pierre Guinand (1926-1936) ou Robert Jacomet (1936-1940), qui occupèrent successivement le poste, étaient des contrôleurs -, et permettait d'améliorer les modalités d'application concrète des conclusions des rapports. Elle provoqua cependant une réaction du corps qui obtint, en décembre 1935, que le directeur rencontrerait le ministre une fois par trimestre pour lui rendre compte de son activité, et pourrait le saisir directement en cas de besoin ${ }^{66}$. De la même façon, la création des "Comités de contrôle financier» dans chaque ministère, prévue par le décret-loi du 30 octobre 1935 et qui participait d'un nouveau système de contrôle interministériel dont la Cour des comptes devait être la clé de voûte $^{67}$, s'accompagna, à la Guerre et à la Marine, d'un texte spécifique précisant que ces comités n'empièteraient en rien sur les attributions du corps du contrôle ${ }^{68}$. Comme en 1922-1923, cependant, le contrôle apparaissait sur la défensive, et les palliatifs trouvés pour répliquer aux mesures élaborées par le Parlement et le ministère des Finances cachaient mal sa difficulté à conserver l'ensemble de ses pouvoirs.

Le corps avait alors évolué. Après un étiage en 1931, dû à des difficultés de recrutement, ses effectifs avaient remonté lentement ${ }^{69}$; la part des intendants avait encore diminué : sur 50 contrôleurs en activité à l'été 1936, 20 provenaient de l'infanterie, 13 de l'artillerie, neuf du génie, deux de l'aéronautique et six seulement de l'intendance. 17 étaient titulaires du brevet

\footnotetext{
${ }^{63}$ SHD, GR 8 N 50, Rapport sur les opérations du contrôleur des dépenses engagées du département de la Guerre pour l'année 1920, 87 p., p. 10.

${ }^{64}$ SHD, GR 10 N 163, Rapport d'ensemble..., 1925, p. 565 et 582.

65 «Décret fixant les attributions du secrétariat général du ministère de la guerre », 10 novembre 1926. Quelques changements mineurs avaient affecté les bureaux de la direction en 1924 (J. Nicot, Inventaire des archives de la Guerre. Série N, 1920-1940, t. I, Vincennes, 1995, p. 33-34).

66 «Décret modifiant le décret du 28 octobre 1882 portant organisation du corps du contrôle de l'administration de l'armée », 6 décembre 1935. Faut-il voir dans ce texte la marque d'une rivalité entre Lachenaud, tout juste promu directeur du contrôle après avoir été, depuis le début de l'année, chef du cabinet civil du ministre, et Guinand, secrétaire général du ministère sur le départ ?

${ }^{67}$ F. Descamps, «La Cour des comptes et le contrôle financier des administrations publiques : histoire d'une tentation, histoire d'une tentative (1914-1940) », Revue française d'administration publique, $\mathrm{n}^{\circ}$ 124, 2007, p. 659-672, p. 669.

68 «Décret relatif au contrôle financier en ce qui concerne les ministères de la guerre et de la marine », 3 décembre 1935.

${ }^{69}$ On ne comptait plus cette année là que 37 contrôleurs et 8 contrôleurs-adjoints (SHD, Fonds privés, GR 1 K 513/3, Rapport d'ensemble..., 1931, p. XIII). En 1933 et en 1934, les effectifs légaux furent diminués de 10 postes, à la suite de la création du corps du contrôle de l'aéronautique et de mesures de réduction du nombre des agents de l'État (SHD, GR 6 N 316, d. 1, note de septembre 1939).
} 
d'état-major, 26 sortaient de Saint-Cyr et 20 de Polytechnique. Parallèlement, le poids du corps dans le ministère s'était encore accru: un tiers des contrôleurs était en service permanent dans les structures de l'administration centrale. C'est là qu'émergeaient quelques brillantes figures, parmi lesquelles, outre celle de Pierre Guinand, premier président de la Cour des comptes en 1936 et premier président de la SNCF le $1^{\text {er }}$ janvier $1938^{70}$, dominaient celles de Robert Jacomet et Jean-Baptiste Lachenaud. Docteur en droit, spécialiste des institutions financières, objet des louanges les plus vives pour sa puissance de travail et sa faculté de jugement, Robert Jacomet avait été remarqué dès son entrée dans le corps, en 1920. Chef de cabinet du secrétaire général en 1923, il était retourné au contrôle en 1925, où il avait accumulé les missions de confiance. Nommé en 1924 conseiller technique de la Délégation française à la Conférence de limitation des armements, il avait acquis une connaissance approfondie de ce domaine de l'industrie, qu'il put mettre en œuvre lorsqu'il fut appelé par Daladier au secrétariat général du ministère en 1936. Son activité effrénée en faveur des fabrications d'armement et de la préparation de la guerre ne lui porta pas chance: accusé d'être l'un des artisans de la défaite, il fut mis en disponibilité au début de l'année 1941, interné, jugé à Riom puis mis à la retraite d'office, avant de retrouver en 1944 la considération qu'il méritait $^{71}$. Né la même année que Jacomet, en 1881, moins brillant peut-être mais également travailleur, Jean-Baptiste Lachenaud s'était aussi fait remarquer dans les cercles politiques, et avait été choisi en juin 1935 pour le poste de chef du cabinet civil du ministre, qui l'avait porté six mois plus tard à la direction du contrôle et au Conseil d'État. Alors que le décret du 20 mai 1940 supprimait le secrétariat général, privant Jacomet de ses attributions, Lachenaud réussit à cumuler les deux fonctions dans un poste de «directeur de l'administration de la guerre et du contrôle », créé pour lui le 23 mai. Après avoir tenu ce poste délicat pendant plus de dix-huit mois, il eut la prudence de demander un congé pour motif exceptionnel en janvier 1942, et n'obtint, en 1944, qu'un blâme de la Commission d'épuration du Conseil d'État ${ }^{72}$.

\section{Vers la guerre}

Le travail quotidien des contrôleurs, rythmé par l'instruction annuelle organisant les missions, ne changea pas beaucoup dans la décennie précédant la guerre. À partir de 1927, on reprit le cycle trisannuel d'avant 1914, gage de continuité dans l'exercice, tout en évitant l'éparpillement ; la doctrine n'avait pas évolué, et le rapport annuel du corps rappelait encore que l'activité des fonctionnaires « doit se manifester non par le nombre des questions traitées, mais par l'étude complète de quelques questions particulièrement intéressantes au point de vue du meilleur fonctionnement et du meilleur rendement des services ${ }^{73}$ ». Le nombre de rapports produits, généraux ou particuliers, avait diminué en conséquence : 240 en 1932, 279 en 1934, 160 en 1936. Chaque groupe avait dans son escarcelle le contrôle d'un service administratif ou d'une branche d'un service sur tout le territoire, et celui des corps de troupe d'une ou plusieurs régions de corps d'armée. Mais, si l'on insistait encore sur la nécessité du contrôle fin des corps de troupe, on constatait aussi l'émergence des missions ponctuelles et définies, «missions spéciales » qui prenaient le pas, progressivement, sur les missions de

\footnotetext{
${ }^{70} \mathrm{SHD}, \mathrm{GR} 8 \mathrm{~N} 34,75^{e}$ anniversaire du contrôle de l'armée, sl, 1958.

${ }^{71}$ SHD, GR $15 \mathrm{Y}^{\mathrm{d}}$ 1344, dossier individuel ; voir aussi R. Jacomet, L'armement de la France, 1936-1939, Paris, Lajeunesse, 1945. Jacomet fut l'un des membres fondateurs de l'Institut international de finances publiques, en 1938 (SHD, GR 6 N 365, d. 2).

72 SHD, GR $15 \mathrm{Y}^{\mathrm{d}}$ 1345, dossier individuel de J.-B. Lachenaud et, plus loin, $8 \mathrm{NN}$ 3. Après la guerre, Lachenaud se consacra à la création de la Sécurité sociale militaire.

${ }^{73}$ SHD, Fonds privés, GR 1 K 513/3, Rapport d'ensemble..., 1927, p. IX.
} 
contrôle « habituelles », et donnaient lieu à des rapports de synthèse de portée plus générale. En 1935, ce fut la création du «Comité supérieur des économies », par le décret du 2 juillet, qui contraignit les contrôleurs à travailler de concert avec leurs homologues de l'air et de la marine, et à produire un nombre important d' «études particulières » qui sortaient des classifications habituelles $^{74}$. En novembre 1937, le rapport d'activité rédigé par Lachenaud notait que plus des deux tiers des rapports rédigés cette année-là avaient été le fruit de «missions spéciales » ${ }^{75}$.

Déjà considéré comme problématique, ce déséquilibre ne fit que s'accroître avec la menace de la guerre. Dès 1930, Maginot avait recommandé aux groupes de missions de s'intéresser de nouveau aux questions de réserve de guerre, délaissées depuis la victoire ${ }^{76}$. $S$ 'ajoutèrent peu à peu le contrôle des centres et des opérations de mobilisation et, surtout, celui des fabrications d'armement. Dans ce domaine, le champ d'action des contrôleurs dépassa largement les établissements du ministère, pour s'étendre aussi bien aux entreprises nationalisées qu'à l'industrie et au commerce privés, dans le cadre du suivi et de l'exécution des programmes d'achat et de commande. À partir de juin 1936, sous l'impulsion conjointe du ministre Daladier et de Jacomet, la création du ministère de la Défense nationale et de la guerre et l'importance accordée aux préparatifs du temps de guerre furent autant d'occasions supplémentaires d'employer les compétences des agents du contrôle ${ }^{77}$, et aussi de les contraindre à une coopération accrue avec le contrôle de la marine et de l'aéronautique ${ }^{78}$. Parallèlement, l'état-major et la direction du contrôle réfléchirent à ne pas répéter, en cas de guerre, les palinodies des années 1914-1915 et à fixer les modalités de l'emploi du corps durant les hostilités. De longues discussions aboutirent à la publication, le 23 mai 1936, de deux instructions qui prévoyaient la mise à disposition du général commandant en chef d'une mission de contrôle dans la zone des armées, et la constitution, pour la zone de l'intérieur, de missions spéciales ${ }^{79}$. On s'accordait aussi à reconnaître que la mission du contrôle en temps de guerre relevait plus de la coordination et de l'animation que du contrôle : si les fauteurs de trouble devaient être poursuivis, les irrégularités constatées devaient aussi être jugées à la lumière des nécessités du moment.

L'année 1939 commença de façon habituelle, les priorités établies en février assignant aux dix groupes de missions des domaines précis: exécution des programmes d'armement, préparation de la mobilisation, mise en place de la Défense passive, bien-être de la troupe et des cadres ${ }^{80}$. Le déclenchement de la guerre modifia ce programme et la direction s'organisa en application des textes de 1936. Après le rappel des contrôleurs du cadre de réserve ou en retraite, consécutif à la mobilisation, on constitua neuf missions spéciales: sept furent envoyées dans les diverses régions de la zone de l'intérieur, deux furent mises à la disposition

\footnotetext{
${ }^{74}$ SHD, GR 8 N 64, Rapport d'ensemble..., 1935, p. XIV. Sur le contrôle de l'aéronautique, créé en 1933, et sur le contrôle de la marine, organisé en 1902 mais dont les origines remontent aussi loin que celles du contrôle de l'armée, voir les articles du contrôleur Enfrun, «Le contrôle dans la marine », et des contrôleurs Britsch et Lefèvre, «Le contrôle de l'aéronautique », Revue historique des armées, $\mathrm{n}^{\circ}$ hors-série de 1982, p. 19-29 et 3137.

${ }^{75}$ SHD, GR 8 NN 32.

${ }^{76}$ SHD, GR 8 N 65, d. 1, instruction du 19 mars 1930.

${ }^{77}$ Ceux-ci furent systématiquement employés dans les organismes mis en place pour les besoins de la défense nationale : service de défense nationale au secrétariat général du ministère, direction générale du contrôle des matériels de guerre, direction de la défense passive.

${ }^{78}$ Témoignage supplémentaire des discussions qui émaillèrent l'année 1936 sur le commandement unique ou la coordination, le Comité permanent de la défense nationale étudia à l'automne les conditions dans lesquelles le corps du contrôle d'un département de la défense nationale pourrait exercer dans des établissements relevant d'autres départements (SHD, GR 2 N 21, d. 2).

${ }^{79}$ SHD, GR 8 N 34, Rapport d'ensemble sur l'activité du corps du contrôle de l'administration de l'armée du 3 septembre 1939 au 30 septembre 1940, p. III.

${ }^{80}$ SHD, GR 8 NN 32.
} 
du général commandant en chef les forces terrestres et du général commandant le théâtre d'opérations en Afrique du Nord. Neuf contrôleurs furent détachés au ministère de l'Armement récemment créé pour renforcer son administration et aider au contrôle de la production; un contrôleur fut nommé directeur des ordonnancements aux États-Unis, et un autre président de la Commission centrale des réquisitions. Pour faire face à ces pertes d'effectifs, la direction réclama dès le 30 septembre le retour aux effectifs théoriques de la loi de 1882 - soit 80 contrôleurs, chiffre qui n'avait jamais été atteint -, en mettant en avant les postes perdus en 1933 et en 1934, les efforts exigés depuis 1936 et, surtout, l'ampleur prévisible du conflit ${ }^{81}$. Elle ne reçut, dans un premier temps, qu'un renfort de cinq inspecteurs du ministère des colonies, mais Lachenaud obtint, en décembre, le maintien en situation d'activité des réservistes rappelés puis, en janvier 1940, la création d'un corps des "attachés du contrôle de l'administration ", appelé à fournir aux contrôleurs des adjoints officiers de réserve issus d'autres grands corps, Cour des comptes, Conseil d'État ou inspection des finances. Trente-six postes d'attachés furent ainsi pourvus à la suite d'un concours organisé au printemps ${ }^{82}$. Entretemps, la direction s'était réorganisée aussi sur le plan géographique : un échelon gouvernemental avait été maintenu à Paris et Saint-Germain-en-Laye et un échelon replié avait été envoyé dès septembre 1939 à Lacroix-en-Touraine, Saint-Martin-le-Beau et Dierre (Indre-et-Loire).

Pouvait-on, au terme des dix mois de «drôle de guerre », tirer un bilan de l'activité du contrôle ? Du point de vue du contrôle intérieur et de l'administration centrale, la situation était comparable à celle de 1914 : la Commission centrale de règlement des réquisitions et le Service central des réquisitions avaient repris leur activité, et de nouvelles structures étaient apparues (direction générale du contrôle des matériels de guerre en avril 1939, service de coordination administrative en septembre, service de cession des matériels à l'étranger), dans lesquelles les contrôleurs tenaient des places de choix. Les sept missions de contrôle à l'intérieur du pays furent actives dès le 6 septembre 1939. Dotées d'une compétence générale sur l'étendue du territoire qui leur était attribué, elles eurent pour mission la surveillance des opérations de mobilisation, le contrôle du recrutement et des affectations spéciales, ainsi que des études et travaux divers, liés à l'organisation des parcs de matériels, à la mise en œuvre de la reprise de la vie économique, etc. ${ }^{83}$. L'Exode bouleversa leurs projets : le 20 mai, le président du Conseil leur demanda, ainsi qu'à tous les membres du contrôle disponibles, de coordonner les efforts des administrations civiles chargées de répartir et d'héberger les centaines de milliers de réfugiés ${ }^{84}$. Aux armées, les résultats furent plus visibles qu'en 1914 : placée sous l'entière dépendance du commandement militaire, une mission de cinq contrôleurs, présidée par le contrôleur général de $1^{\text {re }}$ classe Bralley, arriva le 17 octobre au GQG. Malgré «des résistances assez nettes dans l'entourage immédiat du général commandant en $\operatorname{chef}^{85} \gg$, elle sut se faire apprécier en réglant des questions administratives diverses : organisation du rythme et de la logistique des permissions, fonctionnement des ateliers de réparation du Service automobile, qualité du vin fourni aux corps de troupe, etc. Son action s'estompa aussi dans la débâcle du printemps.

La défaite et la mise en place de l'armée d'armistice entraînèrent une série de réorganisations : la première d'entre elles fut la création de la direction de l'administration de la guerre et du contrôle, qui réunissait dans la main du contrôleur Lachenaud «toutes les affaires administratives et financières ressortissant aux directions et services de

\footnotetext{
${ }^{81}$ SHD, GR 6 N 316, d. 1, projet d'article à insérer dans la loi de finances pour 1940.

${ }^{82}$ SHD, GR 6 N 316, d. 1 et 8 N 34, Rapport d'ensemble..., 1939-1940, p. 3-4.

${ }^{83}$ SHD, GR 8 NN 33, comptes rendus hebdomadaires des missions de l'intérieur.

${ }^{84}$ SHD, GR 8 N 34, Rapport d'ensemble..., 1939-1940, p. 73.

${ }^{85}$ Ibid., p. 34.
} 
l'administration centrale ${ }^{86} \gg$. Avec la démobilisation des attachés du contrôle, le renvoi dans leurs foyers des contrôleurs rappelés en 1939 et la fixation de nouvelles limites d'âge dans l'armée d'armistice, les effectifs du corps connurent une déflation rapide. Les missions spéciales aux armées furent dissoutes, et les contrôleurs subsistants apportèrent leur concours aux problèmes de l'heure: mise en œuvre de la démobilisation, maintien de l'ordre et ravitaillement, rapatriement des réfugiés; un contrôleur fut affecté au Commissariat des chantiers de jeunesse pour établir les bases administratives de l'organisation ${ }^{87}$. Le 26 août 1940, en application de l'armistice, une loi transforma le corps en «corps civil du contrôle de l'administration de l'armée ${ }^{88}$. Les missions liées au temps de guerre étant considérées comme achevées, une nouvelle instruction, le 21 septembre, préconisa le retour à l'organisation de temps de paix ${ }^{89}$.

La création de la «direction de l'administration de la Guerre et du contrôle », en 1940, étaitelle l'aboutissement du vœu du législateur de 1882, ou bien au contraire le chant du cygne de la direction du contrôle telle qu'elle s'était elle-même conçue? Après soixante années d'existence, la fonction et le corps qui l'exerçait avaient montré à la fois leur utilité et les frontières auxquelles ils devaient se borner. À l'intérieur du ministère, la compétence et la légitimité des contrôleurs ne faisaient aucun doute, et la III $^{\mathrm{e}}$ République, en 1914 ou en 1918 comme en 1939, ne pouvait que se féliciter de l'expérience acquise et du travail accompli par cette communauté de grands administrateurs. La masse des rapports conservés, qui offrent à l'historien un tableau précis et mesuré du fonctionnement de toutes les branches du ministère, en témoigne encore aujourd'hui. Des limites étaient apparues aussi : la Première Guerre mondiale avait montré l'impossibilité, pour les contrôleurs, d'intervenir dans la chaîne du commandement, sauf à redevenir ces «surintendants » dont ils avaient tout fait pour rejeter l'héritage. À l'extérieur, sous réserve des résultats d'une prosopographie qui reste à faire, le corps du contrôle, toujours considéré comme un corps militaire, n'avait pas atteint la polyvalence et la notoriété de son voisin des finances. Les attributions budgétaires confiées aux contrôleurs l'avaient été dans le cadre d'un système de contrôle des dépenses de l'État en cours d'élaboration; en 1940, elles résistaient encore aux ingérences du ministère des Finances, mais au prix de victoires en trompe-l'œil, qui annonçaient les réformes de la fin des années cinquante retirant sa compétence financière au contrôle. Aussi l'attirance des contrôleurs pour l'administration du ministère de la Guerre et ses administrations sœurs, en particulier l'armement, était-elle aisément compréhensible : il y avait là un espace en voie de fort développement, dans lequel le corps pouvait s'engouffrer sans concurrence, ni externe, ni interne, la taille du ministère laissant une place à chacun. À la suite de Prioul, les contrôleurs « de l'administration de l'armée », selon les termes de leur loi fondatrice, étaient devenus, en 1940, contrôleurs «de l'administration du ministère de la Guerre ». Le pas n'était pas négligeable et la fusion des deux fonctions de contrôle et d'administration paraissait de ce point de vue l'objectif le plus élevé, à défaut d'être souhaitable, auquel pouvait prétendre le corps.

Emmanuel PÉNICAUT

\footnotetext{
${ }^{86}$ SHD, GR 8 N 34, « Décret portant création, au ministère de la guerre, d'une direction de l'administration de la guerre et du contrôle », 20 mai 1940.

${ }^{87}$ Ibid., Rapport d'ensemble..., 1939-1940, p. 77.

${ }^{88}$ Ibid., « Loi portant constitution d'un corps civil du contrôle de l'administration de l'armée », Vichy, 26 août 1940.

${ }^{89}$ Ibid., Rapport d'ensemble..., 1939-1940, p. 6.
} 


\section{SOURCES COMPLÉMENTAIRES}

Sous-série $X^{s}$

$\mathrm{X}^{\mathrm{S}}$ 43. Réorganisation des bureaux du ministère. 1882-1906.

$\mathrm{X}^{\mathrm{S}} 59$ et 61. Organisation de l'administration centrale du ministère. 1940-1944.

\section{Série $N$}

2 N 21. Comité permanent de la Défense nationale. Réflexions sur l'organisation d'un contrôle de la Défense nationale. 1936.

6 N 13. Fonds Buat. Circulaires issues de la direction du contrôle. 1914-1915.

6 N 297. Fonds Lebrun. Notes relatives au contrôle. 1916.

6 N 299. Fond Lebrun. Contrôle des crédits de la Défense nationale. 1921-1930.

6 N 316. Secrétariat général du ministère de la Défense nationale. Projet de renforcement du corps du contrôle. 1939.

6 N 422. Secrétariat général du ministère de la Défense nationale. Projet de modification du statut des contrôleurs de l'armée. 1935.

7 N 261-262, 295-296, 325. Correspondance du $1^{\mathrm{er}}$ bureau de l'état-major avec la direction du contrôle. 1914, 1916, 1918.

8 N 1-284. Direction du contrôle. 1882-1940.

9 N 90-91. Direction du contrôle. Correspondance des bureaux et du service spécial. 18801914.

10 N 162-201. Commission d'enquête des marchés de l’État. 1912-1928.

Sous-série $1 \mathrm{~K}$

1 K 513. Papiers Paul Alombert-Goget.

1 K 593. Papiers Pierre Guinand. 


\section{DOCUMENTATION, CORRESPONDANCE, ORGANISATION ET ACTIVITÉ DU CORPS}

\section{DOCUMENTATION}

1

Tableau synoptique des principales organisations du ministère de la Guerre (1776-1882) (s.d.), notes relatives à l'exécution des clauses de l'armistice conclu avec l'Allemagne (1918-1919), notes sur le budget du ministère de la Défense de l'Empire (Reichswehrministerium) (1920) et sur le budget du Reich (1932).

$1918-1932$

2 Documentation relative aux opérations de guerre et à leurs conséquences. Rapports de la place de Paris (septembre 1939-mars 1940), messages d'information de l'Agence télégraphique Radio (7-8 juin 1940), étude du médecin capitaine Pollet sur Les gaz de combat (février 1940), collection de circulaires reçues sur l'organisation des directions et services en temps de guerre.

$1939-1940$

\section{CORRESPONDANCE}

Cabinet du directeur. - Correspondance reçue et envoyée (mai-juin 1940) [à signaler, une série de lettres de félicitations adressées au contrôleur Lachenaud pour sa nomination à la tête de l'administration de la Guerre]. Correspondance relative à la fiche matriculaire du capitaine Jean-Baptiste Lachenaud (1921).

4-11 Affaires soumises au Contrôle pour examen et avis. - Collection de bordereaux de transmission issus du bureau des budgets, portant réponse du service spécial.

4 Infanterie (1923), gendarmerie (1923-1924), recrutement (1923), remontes (1923-1924), prisonniers de guerre (1923).

5 Contentieux (1923).

6 Artillerie (1923).

7 Génie (1923-1924), marchés (1923).

$8 \quad$ Soldes et intendance (janvier-juin 1923).

$9 \quad$ Soldes et intendance (juillet-décembre 1923). 
10 Soldes et intendance (janvier-juin 1924).

11 Subsistances, chauffage et éclairage (1923).

12-15 Bureau des marchés : chrono de la correspondance au départ.

1936-1937

$12 \quad 18$ avril-31 août 1936

1329 mai-31 août 1936

$14 \quad 1^{\mathrm{er}}$ avril-21 mai 1937

$15 \quad 22$ mai-8 juillet 1937

16 Bureau des fonds et ordonnances, service financier : collection de notes et de correspondance.

$1935-1940$

\section{ORGANISATION ET FONCTIONNEMENT DU CORPS}

$1882-1919$

17 Naissance, organisation et attributions du corps du contrôle : notes, correspondance, projets de textes réglementaires, collection de textes imprimés relatifs aux instances de contrôle existant dans les ministères de la Marine et des Finances.

$1882-1891$

18

Administration du corps du contrôle. - Distributions des cartes de circulation et d'identité (1888-1897), paiement de la solde (1882-1886, 1912-1914), dessin de l'uniforme (1883-1912) : notes, correspondance, planches.

$1882-1914$

19

Organisation et attributions de la direction du Contrôle. - Honneurs et préséances, conseils de guerre et d'enquête, contrôle des dépenses du ministère de la Guerre, frais de déplacement et de service des contrôleurs : notes, décrets.

Mai 1882-novembre 1911

Relevé des propositions formulées par le corps du contrôle en 1888 : rapports synthétiques, classées par service et par contrôleurs.

21 Commission chargée de présenter les résultats obtenus par le corps du contrôle depuis sa création jusqu'en 1892, présidée par le contrôleur général Demartial : rapports synthétiques, classés par services. 

« Note sur les opérations du corps du contrôle de la Guerre au cours de l'année $1899 »(1901)$.

Organisation pratique des missions et des commissions d'études. Établissement des groupes et des listes de corps ou services à contrôler, expression des vœux et désignation des contrôleurs, calcul de la durée et des frais des missions, convocation et répartition des tâches des commissions : registres, notes, tableaux synoptiques, instruction.

Réforme de l'organisation des missions du contrôle et du recrutement du corps. - Projets présentés par différents contrôleurs (Gallo, Bonhomme, Boone, Beauregard), examen des propositions : notes, correspondance, projets et texte de l'instruction du 6 octobre 1906.

1900-1906

Projets de loi sur les cadres de l'armée active. - Conséquences sur les effectifs et l'organisation du corps du contrôle: notes, correspondance, tableaux d'effectifs, projets de textes réglementaires.

1906-1910

Organisation interne de la direction du contrôle : attributions du service spécial, du bureau du budget, du contrôle de l'engagement des dépenses, création de nouveaux bureaux de vérification des comptabilités dans le cadre des réformes de l'administration centrale de 1909: correspondance, notes, rapport, organigrammes, plans d'occupation des locaux du ministère (bld SaintGermain), états nominatifs.

$1909-1913$

Organisation et administration du contrôle et des missions. - Expression des vœux des contrôleurs et déroulement des missions pour l'année 1912, demandes de communication des rapports par des tiers, projets et réflexions du contrôleur Boone sur la réforme du corps (1911-1912) : correspondance, notes, notes de synthèse.

$1911-1913$

Organisation et administration du contrôle et des missions. - Travaux de la commission des contrôleurs généraux réunie en 1912, élaboration de l'instruction approuvée le $1^{\text {er }}$ février 1913, correspondance avec les parlementaires : notes, rapports, correspondance, textes réglementaires (19121914). Archives du corps du contrôle : cadre de classement, inventaire (sd, 1916). 
Mission militaire ottomane chargée d'étudier le fonctionnement du Contrôle de l'administration de l'Armée (août 1913-janvier 1914). - Organisation de l'instruction et des déplacements des participants : notes, études, textes des conférences, correspondance, listes nominatives, photographies.

Dossier de travail du contrôleur général Cretin. - Copie d'avis, notes et rapports sur les affaires à lui confiées [à signaler, « Rapport de M. le contrôleur général de $1^{\text {re }}$ classe de l'administration de l'armée Cretin au sujet de $\mathrm{M}$. le sous-intendant Adrian », 11 mai 1917].

$1917-1919$

$1939-1940$

Organisation et fonctionnement du corps du contrôle, missions de 1939 et de 1940 : notes, notes de synthèse, rapports annuels.

Missions de 1940. - Organisation et suivi, activité des contrôleurs, projet de repliement de l'échelon gouvernemental: notes, correspondance, comptes rendus d'activité, listes des emplacements des corps et services et des caisses auxquelles ils se rattachent, classés par région militaire.

34 Dossier de travail du contrôleur Bigard. - Questions présentées au chef de service portant sur l'organisation du Contrôle en temps de guerre, suivi des enquêtes en instance, renseignements sur la situation militaire, politique et économique, information sur les réquisitions et les questions financières : correspondance, notes, circulaires, extraits de la presse étrangère et du Journal officiel. 


\section{ACTIVITÉ DU CORPS : \\ ÉTUDES, INSPECTIONS, CONTRÔLES}

$1882-1914$

\section{COMPTABILITÉ ET FINANCES DU MINISTÈRE}

\section{Budget et économie générale}

35 Commission réunie en 1888 sous la présidence du contrôleur Vuillaume, chargée de l'étude de différents aspects du budget du ministère : registre des procès-verbaux.

36-41 Commission d'études budgétaires, «chargée de rechercher les économies et simplifications qu'il serait possible de réaliser dans les divers services du département de la Guerre » et présidée par le général Haillot.

1896-1902

36

Registres d'entrée et de sortie de la correspondance (18961902), registre de la correspondance ministérielle (1896-1899), répertoire des aliénations d'emprises militaires (sd, classées par régions), table des matières des registres de procès-verbaux et de correspondance.

1896-1902.

37-39 Registres des procès-verbaux et de la correspondance.

1897-1902

$37 \quad$ Mai 1896-novembre 1897.

$38 \quad$ Novembre 1897-décembre 1898.

39 Décembre 1898-mars 1902.

$40 \quad$ Collection des rapports rendus au ministre de la guerre.

1896-1901.

41 Fonctionnement courant, archives: notes, correspondance, listes, notes de synthèse.

1896-1902.

42 «Mémoire en réponse au rapport fait au nom de la commission des finances chargée d'examiner le projet de loi adopté par la Chambre des députés, portant fixation du budget général des dépenses et des recettes de l'exercice 1903 », par le sénateur Antonin Dubost. 
Examen des comptes en deniers des exercices 1900, 1901 et 1902 : rapports des commissions d'études du contrôle, classés par chapitre budgétaire.

1901-1904

Redéfinition des masses dans le cadre de la préparation du budget de 1910 : notes, correspondances avec les directions (intendance, génie, cavalerie), tableaux.

Contrôle de l'exécution du budget des années 1911 et 1912. - Compte-rendu des opérations menées, observations et propositions : rapports d'ensemble établis en 1912 et 1913 par le corps du contrôle aux termes de l'article 151 de la loi de finances du 13 juillet 1911, documents préparatoires, rapports particuliers, correspondance.

$1912-1913$

\section{Comptabilité générale et marchés}

Comptabilité-matières. - Avis des directions sur les modifications à apporter à la réglementation de 1888 : correspondance.

$1890-1891$

Commission chargée d'élaborer le projet de règlement sur la comptabilitématières en temps de guerre (1902), présidée par le contrôleur Jacobée. Examen des modifications à apporter à la réglementation en vigueur, conséquences de l'expédition de Madagascar, projet et application d'un nouveau règlement, observations des bureaux du contrôle, de l'état-major et des directions: notes, études, extraits du Bulletin officiel, rapports, correspondance.

$1902-1908$

48-51 Commission de révision des cahiers des charges et des marchés: notes, correspondance, projets de textes réglementaires.

1895-1909

Organisation, désignation et remplacement des membres, fonctionnement courant.

1895-1904.

49 Élaboration de projets de cahiers des clauses et conditions générales des marchés de travaux et de fournitures, rédaction d'instructions sur les passations de ces marchés et sur les cautionnements.

1899-1903.

50 États de marchés passés pour l'année 1905, projets de modification à la réglementation.

1906-1909. 
52-54 Comparaison des cours commerciaux et des prix d'achat des denrées par les divers services de la Guerre : notes, rapports, listes de produits et de tarifs.

1897-1907

Années 1904-1905.

53

Années $1897-1907\left(1^{\mathrm{re}}, 2^{\mathrm{e}}\right.$ et $3^{\mathrm{e}}$ directions $)$.

54

Années 1897-1907 (4 à $8^{\mathrm{e}}$ directions).

55 Commission interministérielle de contrôle budgétaire instituée le 2 mars 1909, dite «Commission Caillaux». - Analyse des marchés de fournitures de matériaux pour le chauffage, l'éclairage, l'emballage, le travail de bureau, l'ameublement courant, passés dans chaque ministère depuis 1904: correspondance, états, tableaux, classés par ministère.

Commission de réorganisation de la comptabilité de différents services du département de la guerre, présidée par le sénateur Milliès-Lacroix. Constitution, travaux : notes, correspondance, rapports des sous-commissions, rapport d'ensemble.

1913-1914

\section{AdMinistration CENTRALE}

\section{Organisation générale, réorganisations internes}

Organisation générale de l'armée, de ses directions et services et de l'administration centrale, statut des officiers, affaires courantes : collection de notes et de correspondance réunies ou produites par la direction du contrôle. [ $\mathrm{A}$ signaler, un dossier sur la décentralisation des attributions de l'administration centrale (1887), un dossier sur la participation de l'armée à l'exposition universelle de 1900, un dossier sur un projet de remplacement des contrôleurs par des inspecteurs des finances (sd)].

$1887-1900$

«Commission de décentralisation et de simplification des écritures » instituée en 1908 au ministère de la Guerre. - Constitution, fonctionnement, travaux : notes, rapports, correspondance, projets de textes réglementaires.

$1908-1910$

Réorganisation de l'administration centrale. - Application des décrets du $1^{\text {er }}$ février 1909 relatifs aux personnels et à l'organisation, projets variés, concernant en particulier la direction du contrôle : notes, procès-verbaux, états chiffrés. 
60

Service intérieur. - Projet de règlement (1895-1898), installation de l'éclairage électrique (1897-1899) : correspondance avec le secrétariat général du ministère.

Activité de la "Commission des machines à écrire », présidée par le contrôleur Alombert et chargée de proposer un modèle au ministre de la Guerre : rapport, procès-verbaux des séances, annexes, correspondance.

Réorganisation des locaux et des services de l'hôtel des Invalides : notes, correspondance, en particulier avec le général Niox, rapports, plans d'occupation des lieux.

$1902-1913$

Commission chargée en 1904 d'étudier la mise à l'abonnement des imprimés fournis aux services locaux par l'administration centrale: notes, rapports, annexes, correspondance.

$1899-1911$

64

Section historique. - Projet d'organisation en service autonome (1912-1913), situation administrative et pécuniaire de Bonnal, archiviste (1906-1910): notes, correspondance, rapports.

1906-1913

\section{Personnel}

Agents secondaires de l'administration centrale. - Revendications statutaires, élaboration du décret de 1907 relatif à leur statut, réclamations de l'Association des agents secondaires, gestion du corps : notes, correspondance, projets de textes réglementaires, états.

1905-1908

66

Réorganisation du personnel, en particulier civil, des bureaux de l'administration centrale. - Propositions de la direction du contrôle, classées par services et directions: rapports généraux, projets d'ensemble, rapports particuliers sur le cabinet du ministre, le service intérieur, l'état-major et les services rattachés [à signaler, un rapport sur le bureau des archives administratives].

1907

67 Réorganisation du personnel, en particulier civil, des bureaux de l'administration centrale. - Propositions de la direction du contrôle, classées par services et directions: rapports particuliers sur les directions de l'étatmajor. 

personnel des bureaux de l'administration centrale. - Travaux préparatoires, discussions avec le ministère des finances, élaboration de projets successifs : notes, correspondances, coupures de presse [À signaler, un projet de règlement et d'organisation pour la section historique].

1906-1909

Personnel des bureaux de l'administration centrale. - Application des décrets du $1^{\text {er }}$ février 1909 et des textes consécutifs, en particulier pour l'avancement et le traitement des agents secondaires, modifications apportées ou proposées à ces décrets : correspondance, notes, états chiffrés.

1909-1912

Réorganisation de l'administration centrale. - Recrutement, affectation, rémunération, avancement, retraite du personnel des sous-directions, réclamations de services, de fonctionnaires et d'associations : notes, listes nominatives, extraits du Journal officiel.

$1909-1913$

Réorganisation de l'administration centrale. - Examen des dépenses occasionnées par le personnel civil et militaire, comparaison avec d'autres ministères, organisation d'examens et concours pour les emplois de commis de comptabilité, sous-chef de bureau et rédacteur stagiaire, travaux de la Commission extraparlementaire de la péréquation des traitements des personnels des administrations centrales : notes, correspondance, rapports parlementaires, instructions, états chiffrés et nominatifs, extraits du Journal officiel.

1909-1913

Effectifs des officiers employés à l'administration centrale : correspondance, notes, notes de synthèse, tableaux.

$1912-1913$

Personnel - Écoles

\section{Personnel}

\section{Personnel civil}

Comparaison des salaires des ouvriers civils de la guerre avec ceux des industries similaires [À signaler, notes relatives à l'organisation pratique de la mission des contrôleurs].

1900-1902

Travailleurs des établissements militaires. - Attribution au contrôle de l'inspection de l'hygiène, de la sécurité et des conditions de travail dans ces établissements, élaboration d'un projet d'instruction générale : études, notes, rapports. 
Statut des maîtres-ouvriers attachés aux corps de troupe : notes, correspondance, rapports, notices imprimées, projets de texte réglementaire.

Personnel civil des établissements militaires. - Projet de suppression des gratifications de fin d'année, propositions de réemploi des crédits correspondants : notes échangées avec les directions (1907-1910). Projet de création d'une inspection permanente du travail et de l'organisation ouvrière dans les établissements militaires (1908).

$1907-1910$

Avantages faits aux divers personnels du département de la Guerre en raison de leurs charges de famille: notes, correspondance, en particulier avec le ministère des finances, enquêtes, rapports.

\section{Personnel militaire}

Recrutement, avancement, statut, limites d'âge

78 Commission mixte des établissements militaires, présidée par Casimir-Périer. - Analyse du statut et des missions des personnels employés dans les établissements militaires des services (service de santé, poudres et salpêtres, artillerie etc.) : notes, correspondance.

Limites d'âge des officiers. - Analyse des conséquences financières des mesures en vigueur ou projetées, comparaisons avec l'armée allemande, étude sur la note du général Juillard (1897) relative à l'avancement des officiers et à l'abaissement des limites d'âge: notes, notes de synthèses, textes réglementaires.

$1891-1901$

Élaboration et projets de réimpression du volume du Bulletin officiel relatif à l'avancement des officiers.

1898-1902

Commission de la mutualité dans l'armée, présidée par le contrôleur général Mauclère. - Projets et refonte des statuts des sociétés de secours mutuels militaires, projet de transformation de la «Caisse du gendarme » en société de secours mutuel, participation aux congrès annuels de la Mutualité, travaux de synthèse : notes, rapports, bulletins, correspondance, textes réglementaires et législatifs.

$1904-1910$

Enquêtes liées au recrutement. - Affectation de jeunes soldats ayant des antécédents judiciaires, études sur le nombre de mariages contractés dans les grandes villes par les hommes du contingent sur le point d'être incorporés, 
affaires individuelles, liées en particulier à l'activité des commissions de réforme.

Proposition de loi complétant les dispositions de la loi sur l'avancement des officiers en vue d'assurer le recrutement du haut commandement : texte, note.

Incorporation de la classe 1910: rapports des commandants territoriaux, rapport d'ensemble du contrôle.

Examen annuel de l'instruction primaire des conscrits. - Modalités d'application de la loi du 29 juillet 1910 instaurant cet examen : notes, correspondance, projets de textes réglementaires.

Application de la loi du 11 avril 1911 créant pour les officiers une position dite «en réserve spéciale ». Conséquences financières de l'abaissement des limites d'âge : notes, correspondance.

$1910-1913$

Documentation parlementaire relative à l'élaboration de la «loi de 3 ans » en 1913 : propositions de loi, amendements, rapports, résumés des discussions.

Application de la « loi de 3 ans » de 1913. — Vérification des dispositions de logement, de couchage et d'habillement mises en œuvre pour l' accueil de la $3^{\mathrm{e}}$ classe : notes, correspondance, listes de contrôleurs envoyés dans chaque corps d'armée.

Soldes, pensions, indemnités

Révision du règlement sur le service des frais de route : notes, projets de texte réglementaire.

Départs à la retraite anticipés et pensions proportionnelles pour les officiers : notes, correspondance, rapports, projets de textes législatifs, tableaux.

$1889-1906$

91 Projet de concession de retraites anticipées avec la pension de grade supérieur : états numériques, en particulier pour l'Algérie et la Tunisie, notes, correspondance.

Commission chargée de l'unification de la solde de la troupe pour les hommes à pied et à cheval, et des modifications à apporter au fonctionnement administratif de l'alimentation des corps de troupe, présidée par le général 
Joffre : procès-verbaux des séances, correspondance, notes, rapports, états chiffrés.

93 Frais de déplacement des militaires isolés. - Projet de nouveau règlement, élaboration du volume $100^{5} \mathrm{du}$ BOEM : notes, correspondance, rapports, épreuves d'imprimerie.

1905-1908

94

Commission de révision des règlements sur la solde et les frais de déplacement.

$1909-1911$

95 Indemnités et pensions. - Travaux de la commission interministérielle des indemnités de résidence, indemnités pour frais de service, pensions militaires des indigènes, taxe militaire, main d'œuvre civile: études, notes, correspondance.

1909-1914, sd

\section{Affaires individuelles}

96 Indemnité spéciale accordée pour «frais de service » au général Haillot, chef d'état-major général : correspondance, coupures de presse.

Accusations portées contre le colonel Allaire, mis à la retraite d'office en 1894 : rapports d'enquête, mémoires et pièces justificatives de l'intéressé, correspondance.

Enquêtes à la suite d'accusations d'ordre personnel portées contre des militaires ou contre le ministère de la Guerre (dénonciations, corruption, réclamations formulées par des tiers, etc.).

$1898-1912$

\section{Écoles}

Gratuité dans les écoles militaires.

$1895-1910$

100 Commission de réorganisation administrative des écoles militaires. Application du régime de l'abonnement : notes, correspondance, rapports, états chiffrés.

1898-1902

101 Projets de suppression du Prytanée militaire et des écoles militaires préparatoires d'enfants de troupe : notes, rapports, correspondance avec les directions, projet de loi, notices imprimées, coupures de presse.

1904-1912 


\section{HARNACHEMENT ET REMONTES}

103

Service des remontes. - Organisation des missions de contrôle des services de remonte (1885-1895), projet de remonte à titre gratuit des officiers généraux et supérieurs (1886-1887), achat des chevaux de remonte (1884-1895), régime des achats de chevaux en fonction de l'époque des achats (1907), service de la remonte en Algérie-Tunisie (1909), habillement et couchage des hommes des classes 1912 et 1913 dans les compagnies de cavaliers de remonte (1913): rapports, correspondance, circulaires [Å signaler, circulaire sur l'organisation des missions en 1886].

$1885-1913$

104 Harnachement. - Élaboration et application du règlement du 11 octobre 1889 sur le service du harnachement dans la cavalerie (1887-1889), organisation du harnachement de la cavalerie et du service du harnachement en dehors des corps de troupe (1898-1903), application des tarifs provisoires de harnachement du 24 octobre 1911 (1911) : notes, correspondance, rapports.

\section{ARTILlerie - MATÉRIEL - Forges - Poudres et SALPÊTReS}

\section{Règlementation et études générales}

105 Commission chargée de l'application de la loi du 16 mars 1882 sur l'administration de l'armée au service des poudres et salpêtres : registre de procès-verbaux, rapport (1884). Projet de suppression de différentes poudreries nationales (1884-1886).

$1884-1886$

106 Achats et marchés de produits dans les services de l'artillerie, et en particulier dans les manufactures d'armes: notes, correspondance, rapports, classés par établissement.

$1888-1895$

107 Service des Forges. - Mode de transport du matériel mis en commande dans ce service : notes.

108 Commission chargée de la révision des nomenclatures des matériels du département de la Guerre : correspondance, nomenclatures imprimées. 
Action du contrôle sur le service des poudres et salpêtres de 1883 à 1896 : rapport d'ensemble [À signaler, renseignements relatifs à l'organisation pratique des missions].

110 Bicyclettes des corps de troupe. - Fabrication des bicyclettes militaires par l'artillerie ou l'industrie privée, examen du projet d'instruction sur l'organisation et l'emploi du service vélocipédique.

1900,1905

111 Passation des marchés et engagement des dépenses dans les services de l'artillerie : correspondance envoyée à la direction de l'artillerie (1901), notes de synthèse (1905). Modalités du passage d'un exercice financier à l'autre et projet de création d'un fonds de roulement dans les établissements constructeurs de l'armée (1901-1910).

$1901-1910$

112 Commission Weil, puis Picaud, chargée de l'étude des moyens propres à accroître la puissance de la production française de poudres de guerre: rapports, notes, notes de synthèses, correspondance.

1904-1909

113 Service militaire des chemins de fer. - Principes de gestion et de comptabilité du matériel, recensement du matériel en dépôt dans les gares du réseau français.

1905-1909

114 Achats de cuivre et de laiton effectués en 1910 et 1911 par le ministère de la Guerre (direction de l'artillerie) : rapports, notes, correspondance, coupures de presse.

115 Commission pour l'étude de l'organisation d'un service d'automobiles de garnison: notes, correspondance, notes de synthèse, propositions en provenance des commandements locaux.

116 Mesures à prendre en réponse à la création de trusts internationaux du plomb et des bois de fusil, contrôlés par l'Allemagne.

\section{Établissements}

117 Fonctionnement de la masse des machines dans les manufactures d'armes de Châtellerault, Saint-Étienne et Tulle : notes, correspondances, rapports, états, pièces justificatives (1885-1891). Application du système de régie ou d'entreprise dans les manufactures d'armes de Saint-Étienne et Châtellerault (1894-1895). 
118 Organisation de la poudrerie du Bouchet (1909). Fraudes dans le service des achats de coton de la poudrerie nationale d'Angoulême (1914).

1909-1914

\section{GÉNIE ET DOMAINE MILITAIRE}

\section{Règlementation et études générales}

119 Commission chargée de la révision des règlements du génie relatifs aux travaux de construction militaire, présidée par le contrôleur de Boisbrunet: notes, correspondance, rapports.

120 Commission chargée de la révision du règlement provisoire du 20 juin 1888 sur le casernement : notes, correspondance, rapports.

$1894-1896$

121 Commission chargée de l'étude des revendications financières exercées par la ville de Paris et le département de la Seine contre le ministère de la Guerre, et inversement. - Répartition des dépenses d'entretien de la Garde républicaine et de la caserne de la Cité, armement des gardiens de la paix : rapports, notes.

1901-1913

Conséquences sur les besoins en casernement de l'application de la loi de 1913 allongeant la durée du service militaire : correspondance, rapports classés par chefferies du génie ou places (Albi, Amiens, Ancenis, Arras, Auch, Avignon, Besançon, Briançon, Cambrai, Châlons, Chaumont, Cherbourg, Fontainebleau, Gap, La Roche-sur-Yon, Le Havre, Le Quesnoy, Lille, Lunéville, Lyon, Marseille, Mézières, Montpellier, Morlaix, Nancy, Nantes, Nice, Nîmes, Orléans, Perpignan, Poitiers, Reims, Roanne, Rochefort, Rouen, Toulon, Toulouse, Valenciennes, Verdun).

Conséquences sur les besoins en casernement de l'application de la loi de 1913 allongeant la durée du service militaire: rapports classés par chefferies du génie ou places (Angers, Autun, Belfort, Boulogne, Bourg, Bourges, Brest, Cahors, Calais, Clermont-Ferrand, Commercy, Dunkerque, Épinal, Langres, Laon, Limoges, Lorient, Maubeuge, Montauban, Mont-de-Marsan, Paris-nord, Remiremont, Rennes, Toul, Tours, Troyes).

\section{Afrique du Nord}

Domaine militaire en Algérie et Tunisie. - Gestion du domaine militaire et organisation du service du génie en Algérie (1886-1892), réorganisation des établissements de l'artillerie en Algérie (1894), emplacement des immeubles militaires à Sfax (1907), Alger (1909), Oran (1913), aliénations et 
expropriations d'immeubles en Tunisie (1902-1905): rapports, correspondance, plan. qui en dépendent.

INTENDANCE ET ADMINISTRATION DES CORPS DE TROUPE (MASSES ET COMPTABILITÉ DES UNITÉS, HABILLEMENT, SUBSISTANCES, FOURRAGES, ÉQUIPEMENT, COUCHAGE)

\section{Règlementation et études générales}

Documentation. Presses régimentaires.

126 Commission mixte chargée de rechercher les moyens d'assurer la subsistance de la population civile dans les places fortes : rapport.

Habillement, équipement et alimentation, administration et comptabilité au combat des corps de troupe: travaux d'étude envoyés par le capitaine en retraite Ferret.

$1897-1901$

128 Presses régimentaires. - Organisation, réglementation, résolution des cas de concurrence avec le privé : notes, correspondance, rapports.

$1897-1907$

Administration des corps de troupe, ordinaires, subsistance

Marchés d'approvisionnement de concentration.

Achats d'effets « de la $2^{\mathrm{e}}$ portion », ou petit équipement que les corps de troupe peuvent acquérir moyennant des procédures simplifiées : rapports particuliers, notes, textes réglementaires.

$1887-1894$

131 Organisation et attributions des fonctions de trésorier et de comptable dans les corps de troupe : correspondance, rapports, projets de textes réglementaires.

Révision du règlement sur l'administration et la comptabilité des corps de troupe: notes, notes de synthèse, correspondance, en particulier avec la direction de l'intendance, projets de textes réglementaires, états chiffrés, modèles d'imprimés. 
Administration des régiments de spahis algériens et des smalas (solde, masse etc.). - Préparation et conséquences du décret d'organisation du 13 novembre 1899, discussions avec la $5^{\mathrm{e}}$ direction et le XIX ${ }^{\mathrm{e}}$ corps d'armée : rapports, procès-verbaux de commission, textes réglementaires, correspondance.

1886-1902

134 Commission de révision du règlement du 14 janvier 1889 sur l'administration des corps de troupe. - Propositions de modifications de la réglementation administrative et comptable, mise à l'essai d'un nouveau mode de centralisation des recettes et dépenses des corps de troupe, application et interprétation du décret du 20 mars 1906, étude du cas des corps fractionnés et des détachements : notes, avis, registre.

1895-1907

135 Détermination du taux et des modalités de versement de la « prime de viande », accordée aux unités pour compenser les variations des cours de cette denrée : correspondance, notes, rapports.

$1899-1908$

Fourniture des effets de la $2^{\mathrm{e}}$ portion. - Questions règlementaires et financières : notes, correspondance, rapports.

$1899-1903$

Achats directs effectués par le service des subsistances: rapports, notes, correspondance. - Préparation et application du décret du 22 avril 1905 : correspondance, rapports.

1903-1905

139 Fonctionnement des ordinaires des troupes. - Rédaction d'une «notice générale » par la direction du contrôle, suivi de l'enquête menée par le professeur Maillard, membre de la Commission de révision de l'alimentation du soldat, dans les corps de troupes : correspondance, projet de notice.

1907-1909

Détournements de fonds commis dans les unités entre 1887 et 1902 : dossier de synthèse, constitués de notes, listes, correspondances, notes dactyl.

1895-1902

141 Refonte des règles de la comptabilité des troupes en campagne sous l'égide de la Commission de décentralisation: correspondance, projets de textes réglementaires, modèles de documents-types. 
142 Fourrage. - Analyse de la réglementation, études de simplification et d'amélioration des cahiers des charges pour le service des fourrages: notes, rapports, correspondance, en particulier avec la direction de l'intendance (1885-1895). Projet de décret et d'instruction relatifs à la création et au fonctionnement d'une masse partielle de fourrages (1906).

$1885-1906$

\section{Habillement}

143 Commission chargée de la refonte des règlements et instructions sur le service de l'habillement de 1885 et 1887: correspondance, en particulier avec la direction de l'intendance, notes, rapports, textes et projets de textes règlementaires, procès-verbaux de séances, rapports sur différents services de l'habillement.

Projet de règlement sur le fonctionnement du service de l'habillement dans les corps de troupe en campagne : correspondance, notes, études.

$1887-1889$

145 Masse d'habillement et d'entretien. - Modalités et conséquences de la fixation de nouvelles primes : notes, correspondance, coupures de presse, états chiffrés.

Règlement sur le service de l'habillement et du campement en dehors des corps de troupe : correspondance, projet de texte réglementaire.

$1890-1892$

147 Conditions de vérification et de réception du matériel de l'habillement. Dossiers réglementaires et rapports de différentes commissions envoyées par la direction de l'intendance à la direction du contrôle, à la suite d'une question posée par le rapporteur du budget de la Guerre (1896): notes, rapports, correspondance.

$1891-1896$

Habillement dans les corps de troupe. - Réglementation du service de l'habillement, projet d'instruction sur les services de l'habillement et du harnachement en temps de guerre, examen des fournitures de chaussures et d'équipement faites par les ateliers régimentaires, fourniture et paiement des effets de la $2^{\mathrm{e}}$ portion : correspondance, notes, rapports.

1896-1906

149 Commission chargée du remaniement du tarif des primes de la masse d'habillement, présidée par le général de Douvres. - Nomination, réunions, travaux : notes, correspondance, états comparatifs, rapports, règlement imprimé. 


\section{Couchage}

150 Exécution du service des lits militaires. - Exposé général de la question du point de vue du contrôle (1887-1899), dimensions des draps (1895), difficultés signalées en Algérie et en Tunisie (1897-1899), lavage et foulonnage des couvre-pieds (1898), suppléments demandés pour le nettoyage des taches dues à un usage extra-réglementaire (1897-1898, 1901-1902), emploi de militaires pour la manutention du matériel en Algérie (1899), imputations aux corps de troupe pour pertes et dégradations (1900-1901), système de régie directe en vigueur dans les troupes coloniales (1902-1903), reconfection du matériel (1902-1903), imputation du prix des châlits usés (1903), procédés de lavage (1903-1904), préparation des cahiers des charges de renouvellement des marchés (1903-1904), élaboration d'une réglementation nouvelle (1906-1907), lavage et entretien des fournitures (1907), reprise par l'État du matériel de la Compagnie des lits militaires (1907), difficultés ou cas d'espèce signalés dans différentes places de métropole ou d'Algérie (1895-1905): correspondance, notes, rapports ou extraits de rapports, projets de textes réglementaires.

Situation financière de la Compagnie des lits militaires: correspondance, rapport général et rapports particuliers, classés par corps d'armée (1904). Commission d'enquête administrative sur les marchés des lits militaires: procès-verbaux des séances (23 juillet 1907-11 mai 1909), rapports de la commission $(1907,1908,1909)$, pièces annexes.

1904-1909

152 Liquidation des sommes dues aux entrepreneurs des lits militaires, à la suite d'une procédure en contentieux devant le Conseil d'État entre le ministère et ces entrepreneurs : notes, correspondance, pièces de procédure.

1909-1912

Coopératives, autres services et produits

153 Associations coopératives militaires. - Analyse des statuts et du fonctionnement, comparaison avec des exemples étrangers : notes, rapports, correspondance, coupures de presses, textes réglementaires imprimés.

1886-1892

154 Fourniture de naphtaline aux corps de troupe et magasins administratifs : rapports, correspondance, en particulier avec la direction de l'intendance.

$1899-1911$

$155 \quad$ Boulangeries et buanderies militaires.

$1892-1910$

\section{Enquêtes ordinaires, irrégularités, affaires particulières}

Masses occultes et caisses noires signalées dans certaines unités. - Enquêtes, projets de réglementation : notes, correspondance, rapports. 

équipement des $4^{\mathrm{e}}$ et $13^{\mathrm{e}} \mathrm{CA}, 1^{\mathrm{re}}$ sous-intendance du $6^{\mathrm{e}} \mathrm{CA}$.

Administration des troupes en Algérie et Tunisie. - Réduction des parcs d'arabas en Tunisie, achat de vin pour les places d'Alger, Oran et Constantine, modalités de fourniture de vivres pour Philippeville, réduction du nombre des compagnies du train, organisation des compagnies montées du Sud-Oranais : rapports particuliers, correspondance.

$1885-1892$

159 Suppression des convois permanents de chameaux dans le Sud-Oranais, suppression de deux compagnies du train en Algérie : rapports particuliers, correspondance.

$1886-1894$

160

Transport des troupes et logements en Algérie et Tunisie. - Exécution du marché des transports en Tunisie (1887-1893), substitution de marchés de transports locaux aux marchés généraux (1886-1889), logement des officiers et fonctionnaires dans les postes dépourvus d'hôtels (1896) : rapports, notes, correspondance.

$1886-1896$

161 Confection ou achats d'effets non-réglementaires effectués sur l'ordre ou avec la tolérance du commandement (1890-1894). Irrégularités dans les adjudications de café vert au Havre : rapport, correspondance (1894).

1890-1894

162-163 Fraudes et irrégularités signalées par le député Cavaignac dans son rapport parlementaire sur le budget de la guerre de 1896.

$1890-1896$

Mise en cause de l'intendant général Baratier: rapport parlementaire, notes, correspondances, pièces justificatives des faits, coupures de presse.

1890-1896.

Affaire des faux poinçons portés sur des effets du magasin général de Paris : notes, correspondances, pièces justificatives des faits, coupures de presse.

1892-1896.

164 Service des fourrages des places de Lyon et Fontainebleau [À signaler, reliure d'origine russe].

$1892,1900-1901$

Affaires ayant entraîné la mise à la retraite du sous-intendant de $1^{\text {re }}$ classe Delachaise. - Transports de vivres pour le ravitaillement de deux colonnes 
entre Alger et Laghouat (1893), adjudication de blé à Delfa (1894-1895), fournitures de vivres par un entrepreneur privé de Blida (1894): rapports, correspondance, coupures de presse.

Installation des troupes dans les postes avancés du Sud de l'Algérie, création d'une masse de ravitaillement et de baraquement dans les territoires du Sud de l'Algérie.

1893,1906

Magasins du service de l'habillement (Besançon, Bordeaux, Limoges, Clermont-Ferrand, Marseille, Toulouse, Bourges), en particulier pour ce qui concerne la vérification des chaussures (1894-1896).

$1894-1898$

Extrême-sud de l'Algérie. - Économies à réaliser sur les transports, le personnel et les vivres : rapports, correspondance.

1895-1902

Irrégularités signalées dans des ateliers de confection, des magasins d'habillement, de harnachement et de campement en métropole et en Afrique du Nord (Avignon, Algérie, Amiens, Bourges, Châteauroux, ClermontFerrand, La Fère, Lille, Marseille, Nantes, Paris, Saint-Brieuc, Vincennes) [À signaler, des irrégularités constatées dans la passation d'un marché de réparation d'instruments de musique].

$1895-1913$

Gestion du service des fourrages des places de Belfort, Héricourt et Montbéliard, mettant en cause l'officier d'administration Doret.

$1899-1900$

Organisation et coût des réquisitions de chameaux pour les colonnes opérant dans le sud des divisions d'Alger et d'Oran : rapport, correspondance.

Enquêtes à la suite de mises en cause individuelles pour fraudes ou irrégularités dans l'administration des corps.

$1900-1913$

Enquêtes sur la gestion des ordinaires de différentes unités de l'intérieur (Vincennes, Vendôme, Lyon, Saint-Germain-en-Laye, Belley, Jausiers).

1901-1910

174 Irrégularités dans l'administration du $5^{\mathrm{e}}$ régiment de cuirassiers.

$1901-1907$

175 Défauts constatés sur des chaussures envoyées au magasin central d'habillement de Nantes et mise en cause de l'intendant militaire Bocquet. 
Accusations portées par le capitaine Stocker contre le sous-intendant militaire Blanchenay, pour des faits commis dans les années 1880 à Tunis.

Masse de couchage et d'ameublement dans les troupes coloniales : rapports, correspondance.

Fourniture de chaussures. - Défectuosités constatées dans les livraisons de brodequins «nouveau modèle »(1904-1905). Rémunération des ouvriers des ateliers de confection de chaussures dans le département de la Seine (19061908).

1904-1908

Sud-Oranais. - Abus dans l'entretien d'équipages permanents de chameaux et irrégularités administratives dans les procédures du service des constructions militaires.

Enquêtes sur le fonctionnement des ordinaires et sur des irrégularités signalées dans la fourniture de viande, de pain ou de confiture dans certaines unités.

1905-1909

181 Irrégularités dans la gestion du moulin militaire de Lille : rapport, notes, correspondance, coupures de presse faisant état du jugement de l'affaire devant le Conseil de guerre de la $1^{\text {re }}$ région (1907).

1906-1908

Accusations portées contre la maison Villard, Castelbon et Vial sur la qualité des effets d'habillements fournis au ministère de la Guerre: rapports particuliers, correspondance, en particulier avec la direction du contentieux.

183 Service des vivres (Argentan, Calais, Elbeuf, Verdun) et des fourrages (Abbeville, Angers, Aubervilliers, Bordeaux, camp de Châlons, Grenoble, Orléans, Saint-Denis, Versailles) dans différentes places de l'intérieur.

1907-1914

Entreprise des fourrages de la division d'occupation de Tunisie (1908). Irrégularités commises dans l'exécution du service des vivres à Saïda (19091910).

$1908-1910$

Accusations portées contre la maison Desbois, fournisseur de casques coloniaux, et contre la maison Duhamel, fournisseur de viande fraîche au $5^{\mathrm{e}}$ régiment d'infanterie coloniale.

1908,1912 
Fonctionnement du «service des distributions des denrées » (vivres et fourrages) dans les corps de troupe de métropole: collection de rapports particuliers, en réponse à une demande ministérielle.

187 Musiques militaires. - Mode d'achat par les corps de troupe des partitions et accessoires de musique, projet de réduction des dépenses des musiques.

Administration et comptabilité des corps de troupe ayant eu des détachements au Maroc et sur la frontière algéro-marocaine.

189 Collection de rapports particuliers sur le logement, l'habillement et le couchage des troupes, classés par corps d'armée (Gouvernement militaire de Paris, $1^{\mathrm{er}}$ au $\left.18^{\mathrm{e}} \mathrm{CA}\right)$.

\section{SERVICE DE SANTÉ}

Hôpitaux militaires d'Afrique du Nord. - Réduction dans les dépenses de construction de l'hôpital du Belvédère à Tunis, organisation générale des établissements, projet de construction à Tébessa, suppression du magasin de réserve du service de santé d'Alger par rattachement à l'hôpital du Dey, utilisation des lits à tréteaux en fer : notes, correspondance, rapports.

191bis Réorganisation du service hospitalier en Algérie: dossier général, cas particuliers des hôpitaux de Souk-Ahras, Philippeville, Bougie, Touggourt, Bône, Dra-El-Mizan, Aïn-Draham, Coléah, Sidi-Bel-Abbès.

191ter Réorganisation du service hospitalier en Tunisie: dossier général, cas particuliers des hôpitaux de Sfax et du Belvédère (Tunis) [à signaler, photographies de l'hôpital du Belvédère].

$1897-1901$

Organisation et gestion des ressources matérielles du service de santé : notes, correspondance, compte-rendu des travaux de la commission présidée par le général Renouard (1894).

Projet d'instruction réglementant le fonctionnement des commissions de réception des magasins du Service de santé (1895), essai de modifications du mode de comptabilité (1900-1903). 
194 Faits reprochés au médecin-inspecteur Delorme dans les hôpitaux de Paris (Bégin et Val-de-Grâce) et Châlons : rapports, coupures de presse, photographies.

195 Service de santé et hôpitaux militaires en Algérie. - Pièces annexes à un rapport général : notes, fiches de renseignements sur les établissements visités, plans des bâtiments, correspondance.

$1910-1911$

196 Enquête sur la fourniture d'instruments de chirurgie au service de santé.

\section{JUSTICE MILITAIRE}

Justice militaire. - Projets de réorganisation du service et de son personnel (1888-1890, 1895-1897), réorganisation du service en Algérie (1894), suppression du conseil de guerre et de la prison militaire de Blidah (1890), organisation du travail dans les établissements pénitentiaires d'Algérie (1889$1895)$ : rapports, correspondance, projets de textes réglementaires.

$1888-1897$

198

Action du contrôle sur le service de la justice militaire de 1883 à 1897 : synthèse de tous les rapports produits, en métropole et en Algérie.

199 Établissements pénitentiaires d'Afrique du Nord (Aïn-Beida, camp de BeniOunif, Bossuet, Douéra, Orléansville, Établissement pénitentiaire mixte de Tunisie, ateliers de travaux publics, sections métropolitaines d'exclus). Allégations d'irrégularités administratives ou de mauvais traitements : notes, correspondance, rapports.

$1902-1907$

200 Consommation, par le ministère de la Guerre, des produits de la main d'œuvre pénale. - Aspects financiers, règlementaires et matériels : notes, rapports, correspondance.

$1905-1912$

\section{GENDARMERIE}

Projet de remonte gratuite pour la gendarmerie. 
203 Refonte des règlements des 30 décembre 1892 et 12 avril 1893 relatifs aux soldes, à la comptabilité et à l'administration de la gendarmerie (1894-1901). Action du contrôle sur la gendarmerie de 1883 à 1897 : note de synthèse (1897).

$1894-1901$

\section{THÉÂTRES D'OPÉRATIONS EXTÉRIEURES, TERRITOIRES ENNEMIS}

204 Comptabilité et liquidation des comptes de l'expédition de Madagascar. Régularisation des comptes de gestion des services : notes, correspondance.

1892-1907

205 Chine. - Mode d'exécution du casernement des troupes de la brigade de réserve de Chine au Tonkin (1902). Irrégularités constatées dans le service des subsistances du corps expéditionnaire (1911).

1902,1911

206-208 Marchés passés à l'occasion du transfert et de la présence du Corps expéditionnaire au Maroc (casernement, transports, subsistances, remonte etc.).

1908-1909

$206 \quad$ Rapports.

207 Correspondance.

208 Pièces annexes.

209 Mobilisation. - Fonctionnement du service de la trésorerie aux armées, règles à appliquer dans l'organisation financière d'un territoire ennemi, renseignements sur l'Allemagne et l'Alsace-Lorraine : notes, études, cartes, notice bibliographique.

$1912-1913$

\section{RÉSERVE DE GUERRE ET SERVICE CENTRAL DES RÉQUISITIONS}

Matériel de réserve de guerre. - Organisation et suivi des visites de vérification effectuées par les membres de la Commission du budget: correspondance, comptes rendus, rapport général.

$1910-1914$

211 Inspection de la réserve de guerre : rapports particuliers, note de synthèse des commentaires des commandants de corps d'armée, textes réglementaires.

212-213 Commission d'étude des questions relatives aux réquisitions militaires, présidée par les conseillers d'État Marquès di Braga (1891-1897) et Cotelle. 
213 Organisation générale, fonctionnement, relations avec les compagnies de chemins de fer au sujet des transports de matériels de guerre (1891-1901).

$1891-1901$

214 Commission centrale d'évaluation des réquisitions sur le territoire national en cas de mobilisation générale. - Constitution, attributions, fonctionnement des commissions départementales, projet de révision des missions des commissions.

1894-1913 
1914-1918

\section{COMPTABILITÉ ET FINANCES DU MINISTÈRE}

215-216 Examen des marchés en cours et des avances consenties par le ministère à des fournisseurs, irrégularités de toutes sortes signalées par le contrôle pour l'année 1915, et particulièrement par les contrôleurs détachés dans les régions : collection de fiches récapitulatives classées par directions et régions militaires, réunies sur demande parlementaire et ministérielle.

$1915-1916$

215 Directions (artillerie et génie, intendance, santé, service des achats à l'étranger, autres services).

Régions militaires

$1915-1916$

217 Moyens de réduire la circulation fiduciaire aux armées.

218 Dossier «Klotz », du nom du président de la Commission du budget à la Chambre (1917). - Utilisation du corps et répartition des fonctionnaires du Contrôle, fixation des tarifs et mode de paiement de la solde, abus de consommation d'essence dans différents services, notamment l'aéronautique et l'automobile : notes, correspondance, rapports.

1916-1917

\section{THÉÂTRES D'OPÉRATIONS ET FAITS DE GUERRE}

Enquête sur les dépôts de prisonniers de guerre: notes, correspondance, tableaux, rapports, classés par place (1916-1917). Prisonniers de guerre alsaciens-lorrains employés comme ouvriers civils à Moulins (Allier) (1918).

1916-1918

Alimentation et rémunération des travailleurs du camp de Chambaran (Isère) (1917). Douilles de 75 enterrés à tort sur le champ de bataille (1917). Conditions de rattachement à des formations des armées ou de l'intérieur des unités rassemblées au camp d'instruction d'artillerie de Claye-Souilly (Seineet-Marne) (1918). Évaluation des dégâts occasionnés par un raid allemand aux docks de l'Intendance d'Aubervilliers (1918).

$1917-1918$

221 Italie. - Personnel des missions en Italie, cessions entre l'Italie et la France, fonctionnement de la mission militaire de ravitaillement, ligne d'étapes de l'Armée d'Orient et services accessoires. 
Forces militaires étrangères. - Questions d'ordre administratif soulevées par la présence des troupes américaines dans les bases de l'Atlantique (1918). Fonctionnement administratif et répartition des effectifs des armées polonaise, tchécoslovaque et yougoslave, organisation de la mission militaire francopolonaise (1918-1919).

$1918-1919$

223 Comptabilité de l'Association nationale des orphelins de guerre: rapport, correspondance, brochure imprimée («Au secours des enfants serbes », 1916).

1916-1917

\section{Administration Centrale, Personnel Civil ET Militaire}

Administration centrale. - Effectifs et conditions d'utilisation des secrétaires de l'administration centrale (1916-1917). Tableau distinguant, parmi les services relevant du ministre de la Guerre, ceux qui font partie intégrante de l'administration centrale et ceux qui doivent être considérés comme des organes extérieurs (1917).

$1916-1917$

225 Personnel civil. - Emploi dans les corps de troupe de la division d'occupation de la Tunisie, allocations d'indemnités de cherté de vie accordées au personnel du réseau ferré d'Alsace-Lorraine.

Enquêtes variées mettant en cause du personnel militaire. - Allégations contenues dans une dénonciation contre le général commandant la région du Nord (1915), conditions sanitaires de l'installation des tirailleurs sénégalais au camp du Courneau (Gironde) (1916-1917), irrégularités de gestion au bureau de recrutement de La Rochelle (1917), abus imputés par des exploitants agricoles à des officiers de cavalerie dans la zone des armées, en particulier dans l'Aisne (1917), examen des sursis accordés dans la 15 ${ }^{\mathrm{e}} \mathrm{RM}$ (1917), conditions d'emploi du personnel du cadre de l'École supérieure de guerre maintenu en fonctions depuis la mobilisation (1918), comptabilité des pécules constitués aux militaires mobilisés (1918).

$1915-1918$

Associations. - Subventions demandées par l'Association pour l'enrôlement volontaire des françaises au service de la patrie et l'Office central de l'activité féminine (1917), emploi des fonds mis à la disposition de l'armée d'Orient pour le secours des soldats nécessiteux par le comité de «La journée du poilu » (1918).

$1917-1918$

\section{REMONTES}

Service des remontes. - Conditions d'importation en France des mulets espagnols depuis le début de la guerre. 

- Conditions dans lesquelles les réquisitions de chevaux sont opérées par les Commissions de réquisition.

\section{MATÉRIEL ET SERVICE AUTOMOBILE, AÉRONAUTIQUe, DOMAINE ET TRANSPORTS MILITAIRES}

Consommation d'essence et mesures à adopter pour la réduire dans les $2^{\mathrm{e}}, 7^{\mathrm{e}}$ et 8 armées.

231 Réquisition de l'usine à gaz de Toulon. - Examen des dispositions à prendre pour l'exploitation, préparation de la liquidation des comptes pour l'exercice 1917.

$1917-1918$

Affaires particulières liées au Service de l'aéronautique. - Embauche de personnel féminin dans les écoles d'aviation (1917), salaires de l'école d'aviation d'Avord (1917), plaintes contre le capitaine Bourdet, du service des fabrications de l'aviation (1917), comportement d'officiers et de gradés du service aéronautique au Parc d'aviation 112 (1917), comptabilité-matières du service des fabrications de l'aviation et des annexes du service des entrepôts généraux de l'aviation (1918), recensement des moteurs «Rhône » 80 et 120 HP (1918), détermination des ressources dont dispose l'aviation tant à l'intérieur qu' aux armées (1918).

$1917-1918$

233 Questions diverses liées au domaine militaire. - Abandon d'un jardin potager mis en culture par la garnison de Belley (Ain, $7^{\mathrm{e}}$ région) (1917). Réquisitions abusives de chambres d'hôtels à Dijon en 1914 et 1915 (1917). Possibilités de logement et de cantonnement à Caylus (Tarn-et-Garonne) et Cahors (1918). Conditions d'instructions les demandes de locaux formulées par les Américains au Mans ( $4^{\mathrm{e}}$ région) (1918). Dégâts causés par les troupes françaises dans la zone des armées, et dommages aux cultures commis sur le territoire de la commune de Sézanne (Marne) (1918). Réquisition d'un immeuble pour le service de la circulation aux armées à Paris (1918). Conditions de passation d'un marché de pierres de route par le service du génie à Dijon (1918).

234 Transports militaires. - Travaux de la commission, constituée par arrêté du 27 décembre 1915, chargée d'examiner les questions litigieuses entre l'armée et les compagnies et administrations de chemins de fer.

$1915-1917$ 


\section{INTENDANCE ET ADMINISTRATION DES CORPS DE TROUPE}

235 Conditions des achats d'habillement effectués en Espagne pour le compte du service de l'intendance par la mission «Bertrand» (septembre-décembre 1914).

$1915-1916$

236 Irrégularités signalées dans différents corps et services et dans des marchés de fourniture. - Prison-annexe du Cherche-Midi à Bicêtre, Service de l'habillement des $13^{\mathrm{e}}$ et $15^{\mathrm{e}}$ régions, Groupement de travailleurs coloniaux de Castelsarrasin, Dépôt de remonte de Mostaganem, Inspection générale du ravitaillement, Direction des étapes de la $7^{\mathrm{e}}$ armée, Service du génie de la $7^{\mathrm{e}}$ région, Service de l'intendance de la $15^{\mathrm{e}}$ région.

$1915-1917$

Irrégularités commises dans les marchés d'habillement passés par le service de l'intendance du Mans («affaire Voisin-Cognacq »).

$1915-1918$

Collection de rapports relatifs à différents abus relevés dans le fonctionnement administratif de l'armée, et signalés en particulier par la commission sénatoriale de l'armée.

Accusations de vol et de faux portées contre l'officier d'administration Bolé et le sous-intendant militaire Thouvenin, de la $1^{\text {re }}$ division de cavalerie $\left(6^{\mathrm{e}} \mathrm{CA}\right)$ (1916). Euvre des «Parrains de Reuilly», soupçonnée d'être une masse occulte au bénéfice des permissionnaires, mise en place à la $22^{\mathrm{e}}$ section de COA, à Reuilly (Paris) (1916-1918).

$1916-1918$

Aspects de la gestion quotidienne des corps de troupe et irrégularités signalées. - Alimentation, ordinaire, fournitures en pain et en pommes de terre, gestion des caisses, tenue du registre des «fonds divers », opérations de liquidation, recensement des matériels, restriction des dépenses de logement et cantonnement, fourniture en combustible, produits des ventes de viande de cheval : rapports généraux et particuliers, correspondance [À signaler, une enquête sur le service de réception de la viande frâiche du gouvernement militaire de Paris, à Versailles et Vincennes].

Alimentation, couchage et hygiène des soldats de la classe $1918\left(3^{\mathrm{e}}, 4^{\mathrm{e}}, 9^{\mathrm{e}}, 12^{\mathrm{e}}\right.$ et $\left.18^{\mathrm{e}} \mathrm{CA}\right)$.

Irrégularités signalées dans différents corps et services et dans des marchés de fourniture. $-17^{\mathrm{e}}$ section d'infirmiers à Toulouse, commandement régional des dépôts de prisonniers de guerre à Marseille, établissements pénitentiaires d'Algérie, dépôt des chasseurs d'Afrique à Tarascon, groupement automobile 
du Gouvernement militaire de Paris, magasins de pommes de terre à Javel (place de Paris), contrats de tannage, de fourniture de graisse végétale et d'abattage.

Fonctionnement de l'administration des dépôts et corps de troupes : rapports généraux.

Irrégularités signalées dans différents corps et services et dans des marchés de fourniture, incidents. - Incendies de bâtiments militaires du service des fourrages de la place de Gray ( $21^{\mathrm{e}}$ région), réception de baraques Adrian construites par un entrepreneur à Paris, agissements d'un caporal acheteur de pommes de terre à Étampes, mise en cause d'un officier de l'inspection générale du ravitaillement, soupçons de concussion dans les achats du service des vins à Montpellier, malversations commises au $3^{\mathrm{e}}$ régiment de tirailleurs de Bône, gaspillages imputés aux troupes de l'armée d'Orient à Lyon, conditions de passation de marchés par un soldat du $6^{\mathrm{e}}$ régiment du génie, allocation de primes indues à la $11^{\mathrm{e}}$ section de COA à Nantes.

$1917-1918$

245 Irrégularités signalées dans différents corps et services et dans des marchés de fourniture. - Gestion du bureau des Euvres militaires diverses $\left(4^{\mathrm{e}}\right.$ bureau du cabinet du ministre), irrégularités au service de l'alimentation du détachement de sapeurs radiotélégraphistes du Champ de Mars, détournements commis à la section de COA de l'Intendance des troupes coloniales à Bordeaux, retenue sur solde pour l'occupation d'un logement à l'École militaire, faits signalés à la $41^{\mathrm{e}}$ compagnie de prisonniers de guerre du camp d'Amance (Haute-Saône), fourniture de la viande par le Service de l'intendance aux corps de troupe de la $4^{\mathrm{e}}$ région.

\section{SERVICE DE SANTÉ ET JUSTICE MILITAIRE} service de santé (1918).

Organisation et rendement des hôpitaux vétérinaires aux armées.

Affaires particulières liées au service de santé. - Excédents et déficits de matériel constatés à l'hôpital complémentaire 25 de Châteauroux, cumul d'indemnités signalé à l'hôpital militaire de Tréguier, prix de revient des tissus à pansement dans les $13^{\mathrm{e}}$ et $14^{\mathrm{e}}$ régions, sections sanitaires automobiles américaines offertes au service de santé à Paris. 
Régime des ateliers de travaux publics de May-sur-Orne, Roquettes et Perrières (place de Caen). 


\section{COMPTABILITÉ ET FINANCES DU MINISTÈRE}

\section{Budgets - Économie générale du ministère}

Situations budgétaires et dépassements de crédits dans différents services ou régions.

$1919-1922$

251 Préparation du budget de 1921. - Examen des demandes de crédits supplémentaires exprimées par différentes directions, à la suite de la décision du ministre de confier au contrôle ce travail : correspondance, notes, rapports particuliers.

$1920-1921$

Extraits des lois de finances, relatifs en particulier au département de la guerre (exercices 1883-1930) : trois vol. dactyl.

253 Bureau des fonds et ordonnances : échantillon de bordereaux d'annulation de crédits sur le budget de 1934, et du compte général et définitif de l'emploi des crédits ministériels ouverts aux ordonnateurs secondaires.

254 Préparation à la guerre. - Directives concernant la tenue du budget, l'organisation comptable et administrative du ministère, la protection de la main d'œuvre nationale et le secret militaire : circulaires et notes adressées aux directions et services de l'administration centrale.

1934-1939

255 Affaires budgétaires. - Emploi des crédits du compte des investissements en capital de la direction du génie de Paris : note de synthèse (1937). «Les crédits de la défense nationale depuis 1919 en ce qui concerne la guerre, la marine, l'air et la défense passive », par les contrôleurs de l'armée Chandelier, de la marine Moign, et de l'aéronautique Michaut, 144 p. dactyl. (1938). «Rapport présenté par la direction générale du contrôle des matériels de guerre sur les fabrications de guerre exécutées par l'industrie privée et les établissements d'État », note dactyl. accompagnée de tableaux, 20 et 49 p. (1939).

1937-1939

256-258 Préparation du budget de 1940.

$1939-1940$

256

Affaires générales et question des effectifs, ventilation du budget par chapitres, crédits additionnels: notes, correspondance, états imprimés. 


\section{Comptabilité et marchés}

Méthode à suivre en vue d'établir le décompte des créances de l'État relatives aux cessions de matériel faites à des gouvernements alliés ou à des particuliers. - Cessions faites par le service de l'aéronautique, les service des bois, de l'artillerie et du génie, les inspections des forges de Paris, Toulouse, Lyon, Nantes : notes, correspondance, rapports généraux et particuliers.

$1919-1924$

Service interministériel des dépenses à l'étranger. - Indemnités payées par le gouvernement britannique pour la résiliation de deux marchés de fournitures de moteurs (1919), échantillon de rapports de liquidation relatifs à des marchés passés à l'étranger par le Service du génie en 1917 (1920), avances faites aux industriels pour la création ou le développement d'installations ou d'outillages (1922-1923).

$1919-1923$

261 Situations financières respectives des ministères de la Guerre et du Ravitaillement, tant au point de vue central que local.

1920-1921

262 Modifications comptables. - Simplifications à apporter à la liquidation des dépenses et à l'établissement des pièces justificatives en administration centrale, étude de certaines modifications de détail et simplifications à apporter au règlement de décembre 1902 sur la comptabilité-matières.

263 Affaires particulières. - Examen des règles de comptabilité-matières suivies par la Compagnie de chemins de fer de Paris, à Lyon et à la Méditerranée (P.L.M.) et la société Éclairage, Chauffage, Force motrice (E.C.F.M.) (1925). Opérations de courtage dans des marchés de la défense nationale reprochées à un sieur Borel (1939).

1925,1939

\section{Prisonniers DE GUERRE - DÉMObilisation - LiQuidation DES STOCKS ET RAVITAILLEMENT}

Prisonniers de guerre. - Situation financière du «Comité du linge du prisonnier », œuvre subventionnée de secours aux prisonniers de guerre (1919), emploi de la main d'œuvre constituée des prisonniers de guerre dans la commune d'Étampes (1919), organisation et aspects financiers du 
fonctionnement du Service général des prisonniers de guerre (1920), liquidation du camp de prisonniers de guerre d'Annecy (1921).

$1919-1921$

Démobilisation des hommes et des services.

265

Opérations de démobilisation concernant différents services, produits ou unités. - Jumelles en prêt au personnel (1919), fonctionnement du Centre de groupement d'animaux démobilisés de Mont-de-Marsan (1919), primes de démobilisation des infirmiers militaires (1919), conditions matérielles du renvoi dans leurs foyers des soldats à démobiliser (1919), liquidation des sommes payées au titre de la «prime d'habillement des démobilisés » (1919), dépôt de matériel automobile de Briare (1921).

$1919-1921$

266-269 Aspects administratifs des opérations de démobilisation.

266 Artillerie, génie, matériels divers, service automobile

1919

267 Service de santé.

268 Habillement.

269 Subsistances, stations-magasins.

\section{Gestion des stocks et du ravitaillement}

270 Service du ravitaillement. - Recherche dans les stations-magasins de produits et denrées périssables susceptibles d'être cédées au ravitaillement civil : rapports, correspondance, en particulier avec le sous-secrétariat d'État au ravitaillement et le sous-secrétariat d'État à la Présidence du Conseil.

271 Situation faite au service des subsistances par les décrets et arrêtés qui ont fixé les attributions respectives du département de la Guerre et du sous-secrétariat d'État au Ravitaillement.

$1919-1920$

272

Stocks. - Cession au ministère de l'agriculture et du ravitaillement de sacs à terre en stock au ministère de la Guerre (1918-1919), liquidation des stocks militaires dans les régions libérées, et en particulier dans le cadre de la chefferie du génie de Commercy (Meuse) (1919-1920).

$1918-1920$

273 Affaires locales. - Fonctionnement du magasin régional du ravitaillement de Saint-Étienne (1919), imputation au budget de la Guerre de céréales achetées pour le ravitaillement civil en Algérie et Tunisie (1919-1921), régie du ravitaillement de Marseille (réquisitions, fournitures en blé, légumes et maïs) (1920), liquidation du « Consortium du jute » (1919-1922).

$1919-1922$ 


\section{ADMINISTRATION CENTRALE}

274 Organisation générale. - Projet de réduction des effectifs de l'Inspection générale des effectifs (1919), comparaison des crédits votés et des dépenses engagées par le Service des imprimés de l'administration centrale pour l'achat des imprimés nécessaires au paiement des indemnités militaires consécutives à la démobilisation (1919), organisation d'une imprimerie centrale au ministère de la Guerre (1920), répartition des crédits du budget des essences (1920), besoins en personnel et en locaux des différents services de l'administration centrale (1920), comptabilités tenues ou vérifiées par l'administration centrale (1922), répartition et horaires de travail du personnel civil entre les divers services (1923).

$1919-1923$

275 Trésor et postes. - Fonctionnement et dépenses du Service central du trésor aux armées, attributions du payeur général, élaboration d'une nouvelle règlementation portant sur les services de la trésorerie et des postes aux armées.

$1921-1923$

276 Service géographique de l'Armée. - Résiliation des marchés en cours au moment de l'armistice (1919), projet de transfert de l'hôtel de Sens vers l'hôtel des Invalides (1920), organisation, installation, fonctionnement administratif et financier (1924).

$1919-1924$

277 Hôtel des Invalides. - Occupation des locaux (1919, 1923, 1924), personnel civil employé dans les services installés à l'hôtel (1924), conditions d'occupation et de chauffage de l'appartement du gouverneur militaire de Paris : rapports, correspondance, plans [à signaler, une liste des services occupant les Invalides en novembre 1924].

$1919-1939$

\section{Personnel-Écoles}

Personnel civil. - Nécessité d'augmenter les masses d'assistance médicale aux établissements militaires employant du personnel civil, pour répondre à la hausse du coût des soins et des médicaments (1919), emploi de la main d'œuvre féminine dans la $3^{\mathrm{e}}$ région militaire (1919), affaires particulières d'importance secondaire (Règlement des commandes de l'aéronautique en 1920-1921, irrégularités commises au parc d'artillerie du Mans, situation militaire de M. Delagneau, directeur du «Journal de Pologne » à Varsovie, construction d'un mur à l'établissement de météorologie du Mont-Valérien, mise à la retraite du gestionnaire du Service des fourrages à Paris) (19211922).

$1919-1922$ 
Travailleurs coloniaux. - Réclamations exprimées par le syndicat des dockers brestois contre les travailleurs coloniaux employés par le département de la Guerre (1919), fonctionnement du Centre de rassemblement des travailleurs coloniaux de Philippeville (1919), créances du Service des travailleurs coloniaux (direction des troupes coloniales) sur la maison de travaux publics Maréchal (1921).

280 Conditions d'emploi et d'effectifs, questions de statuts et d'indemnités du personnel militaire. - Service de la solde du $94^{\mathrm{e}}$ bataillon de tirailleurs sénégalais (1918-1919), effectifs en officiers et sous-officiers du $99^{\mathrm{e}} \mathrm{RI}\left(14^{\mathrm{e}}\right.$ CA, place de Lyon) (1920), situation des cadres inférieurs dans les corps de troupe de l'intérieur (1921), situation sanitaire et administrative des troupes sénégalaises au Maroc (1921-1922), situation juridique et financière du sanatorium du «Mont-des-Oiseaux », appartenant à la Société de secours aux blessés militaires (1939).

1918-1939

281 Mises en cause individuelles. - Conditions de la rétrogradation du sous lieutenant Récopé, du $97^{\mathrm{e}}$ RI (1919), réclamations formulées par le capitaine Nicolle, commandant de la $2^{\mathrm{e}}$ compagnie du $73^{\mathrm{e}}$ bataillon sénégalais, accusé de fautes de gestion (1919), accusations d'enrichissement illicite contre le capitaine Brandon, dans le cadre d'échanges commerciaux avec l'Espagne (1919), faits reprochés au chef d'escadron Doizan, du parc automobile de Casablanca (1920), irrégularités reprochées au lieutenant Lacoste, du $7^{\mathrm{e}}$ tirailleurs (1921), faits reprochés à des personnels de la chefferie du génie de Strasbourg et du service de l'artillerie du camp de Sissonne (1921).

$1919-1921$

282

Administration des écoles militaires à la démobilisation: rapports, correspondance [à signaler, des notes sur l'histoire de certaines écoles pendant la période des hostilités].

1919

283 Irrégularités signalées à l'École normale de gymnastique et d'escrime de Joinville (1920-1921). Situation de la masse de harnachement de l'École d'application de cavalerie de Saumur (1921-1923).

$1920-1923$

\section{ChevauX ET REMONTES, ARTILlerie, MATÉRIEL, INDUSTRIE, SERVICE AUTOMObILE, POUDRES}

\section{Études générales}


différentes unités : rapports généraux et particulier classés par région militaire et par unité (1921).

$1919-1921$

285 Notes et études sur différents aspects de l'utilisation de l'essence et d'autres carburants de substitution.

286 Effectifs et salaires de la main d'œuvre employée dans les établissements d'artillerie.

\section{Affaires locales}

Comptabilité-matières et organisation du magasin central automobile de Paris (1918-1920, 1924).

Organisation du service automobile et emploi des automobiles dans les $14^{\mathrm{e}}, 17^{\mathrm{e}}$ et $20^{\mathrm{e}}$ régions.

$1919-1920$

289 Chevaux et remontes. - Situation du contingent de chevaux cantonné à SaintNom-la-Bretèche (1919), démobilisation des chevaux de la $20^{\text {e }}$ région (1919), enquête dans différentes places sur une morbidité anormale, par gourme, signalée sur de jeunes chevaux arrivant de la remonte (1924).

1919,1924

290 Service des poudres, poudreries. - Conditions de l'explosion de l'usine de pyrotechnie Rollet-Burgalasse à Mérignac (Gironde), le 8 décembre 1916 (1919), situation de la masse médicale de la poudrerie de Sevran-Livry (1920), examen des comptes de l'entreprise Thévenot, chargée de l'exploitation en régie des chutes de Louron (Hautes-Pyrénées) pour le compte du service des poudres (1920), avances consenties par l'État pour permettre le fonctionnement de la Commission des ordinaires de la poudrerie de Lannemezan, annexe de la poudrerie de Toulouse (1920-1921), fonctionnement de la poudrerie de Sorgues (1921).

$1919-1921$

Affaires relatives à certains établissements ou services. - Dépenses du parc d'artillerie de Marseille au sujet des émeris de Naxos (1919), liquidation du matériel des camps de Saint-Raphaël (Var) (1919-1920), opérations d'acquisition de terrains de l'entrepôt de réserve générale de matériel d'artillerie de Chemilly (Yonne) (1919-1921), déficits constatés dans la masse d'assistance de l'atelier de construction de Lyon (1920), plaintes exprimées par des mutilés employés à la manufacture d'armes de Tulle (1920), prolongation de délai pour la production du procès-verbal de recensement général du matériel par le parc d'artillerie de Dijon (1920-1921).

$1919-1921$ 
Recherche, pour les besoins de la $3^{\mathrm{e}}$ direction, de hangars destinés à stocker du matériel d'artillerie et d'aéronautique dans les $12^{\mathrm{e}}$ région (poudreries de Bergerac et d'Angoulême), $15^{\mathrm{e}}$ région (Avord, Istres, Miramas, Sorgues, SaintChamas) et $17^{\mathrm{e}}$ région (Toulouse, camp du Vernet) : rapports généraux et particuliers, correspondance.

$1920-1921$

293 Organisation, gestion et direction des ateliers de construction de Puteaux (1920-1922) et Rennes (1921).

$1920-1922$

294 Commandes et contrats. - Litiges entre l'administration militaire et la Société anonyme des usines à gaz du Nord et de l'Est (1920), commandes de matériel téléphonique exécutées pour le sous-secrétariat d'État des postes, télégraphes et téléphones par des établissements d'artillerie (1921), contrat passé en 1921 entre l'arsenal de Roanne et la compagnie d'électricité «Loire et Centre » en vue de la fourniture réciproque d'énergie électrique (1921-1922).

$1920-1922$

Affaires relatives à certains établissements ou services. — Projet de transfert de l'atelier de construction de Lyon installé à Perrache (1922), existence simultanée de plusieurs ateliers de réparations automobiles dans le $9^{\mathrm{e}} \mathrm{CA}$ (place de Tours) (1923), améliorations à apporter au stockage du matériel des corps et services du $17^{\mathrm{e}} \mathrm{CA}$ (place de Toulouse) (1924), statut de l'entrepôt de réserve générale d'Aubervilliers parmi les établissements d'artillerie (1939).

296 Établissements de l'artillerie (parcs, ateliers, inspections, entrepôts, manufacture). - Collection de rapports prévisionnels de dépenses à inscrire pour l'exercice 1931-1932, état récapitulatif des engagements approuvés.

\section{Aéronautique}

Marchés. - Organisation générale des marchés de l'aéronautique, liquidation de marchés de moteurs, de pièces de rechange de moteurs et de licences de construction de moteurs passés par le Service des fabrications de l'aviation.

1919-1920

298 Organisation générale. - Dépenses de l'aéronautique militaire au titre de l'année 1919 (1919), dépenses engagées pour les opérations préliminaires à la constitution de la mission d'aviation à envoyer aux États-Unis (1919), administration des corps de troupe employés dans les établissements de l'aéronautique (1921), zones de protection du Service de l'aéronautique (1923).

$1919-1923$ sociétaire des établissements Hanriot, constructeurs d'avions (1919), abus dans 
la vente des stocks disponibles aux établissements aéronautiques de Nanterre (1919), travaux d'aménagement du Camp d'aviation de Captieux (1919), modalités d'une convention entre l'Établissement central du matériel de l'aéronautique militaire et la maison Schneider (1919-1920), inconvénients pouvant résulter de l'envoi à des industriels de certaines publications techniques de l'aéronautique (1919-1920), cession d'essence au maire de La Chapelle-la-Reine par le Centre d'instruction d'aviation d'observation (19201921), entrée au service de la société Lorraine-Dietrich de l'ancien chef du $2^{\mathrm{e}}$ bureau (matériel) de la direction de l'aéronautique (1924), déficit d'essence au $2^{\mathrm{e}}$ groupe d'aviation d'Afrique (1925).

$1919-1925$

\section{GÉNIE, DOMAINE MILITAIRE, SERVICES DE TRANSIT}

\section{Règlementation générale}

300

Opérations liées à la fin des hostilités. — Liquidation d'immeubles occupés par l'armée (par réquisition, location, occupation sans titre ou autre), en particulier dans le gouvernement militaire de Paris, liquidation du service du camouflage, logement des officiers et sous-officiers mariés appelés à séjourner dans les villes dévastées.

\section{Affaires locales}

301 Travaux d'aménagement et d'agrandissement du camp de Souge (Gironde).

Place de Paris. - Occupation des bastions de l'enceinte de Paris par différents services, application de la réglementation sur les servitudes et zones non aedificandi, recherche d'emplacements pour le logement de permissionnaires américains.

$1919-1920$

Troupes d'occupation du Maroc. - Travaux exécutés par le service du génie depuis le début de la guerre, fonctionnement général des autres services [à signaler, un album de photographies des bâtiments construits par la chefferie de Rabat en 1919, une liasse de photographies de bâtiments militaires de Taza et Casablanca].

304 Réunion de la chefferie d'étapes de Bar-le-Duc à la chefferie régionale de Verdun (1919), comptabilité du gestionnaire de la gare régulatrice de Connantré (1919), local scolaire occupé par l'administration militaire à Lyon (1919), irrégularités commises par le service du génie à Tunis dans l'organisation des logements d'officiers (1919), installation à la caserne Bernadotte, à Pau, de l'ensemble des services militaires de la place (1920), installation des bureaux de la direction du génie du Mans (1920-1921), 
conditions de cession d'un stock de bois de mines par la chefferie du génie de Landau à un particulier (1920-1921).

305 Recherche par le ministère des Régions libérées de locaux à Amiens (1921), aliénation de la caserne Durutte et des autres emprises militaires de la ville de Douai (1921-1923), relations avec la ville de Paris au sujet des servitudes militaires sur le bois de Vincennes (1922-1923), projet d'abandon de la caserne Saint-Nicolas à Fougères (1922-1923), projet de cession du Parc à fourrages de Nice à l'Office départemental des habitations à bon marché des AlpesMaritimes (1923).

$1921-1923$

306 Projets d'aliénation ou d'acquisition et états des bâtiments militaires dans les places de Verdun, Bar-le-Duc et Montmédy (1924), conditions de stockage du matériel du dépôt du génie de Montpellier (1924), affectation au ministère des finances de la caserne dite «Château de l'Hermine », à Vannes, occupée par le parc régional d'artillerie (1924-1925), projets d'installation et de travaux dans des stations-magasins, cités militaires et autres places du XIX ${ }^{\mathrm{e}}$ corps d'armée en Algérie et Tunisie (1931-1933).

$1924-1933$

\section{Services de transit}

307

Services de transit. - Irrégularités commises au Service du transit maritime militaire de Bône (1919-1921), détermination des prix du charbon utilisé pour les transports maritimes effectués pour le département de la Guerre vers le Levant (1921), organisation des services de transit de la place de Marseille (1924).

$1919-1924$

\section{INTENDANCE ET ADMINISTRATION DES CORPS DE TROUPE}

\section{Enquêtes de portée générale}

Administration des corps de troupe, ordinaires, coopératives

Administration des corps de troupe. - Historique et examen du fonctionnement des conseils d'administration, mise à l'essai d'un mode d'administration régimentaire sans conseil, projet de supprimer les conseils : rapports, études, notes.

$1902-1921$

309 Questions générales. - Fonctionnement du service des ordinaires des corps de troupe, excédents et gestion des stocks de céréales en Algérie et Tunisie.

$1919-1920$ 
310 Organisation administrative, gestion du personnel civil, habillement dans les régiments indigènes d'Afrique du nord.

311 Fonctionnement et gestion des coopératives régimentaires et des sociétés coopératives militaires en métropole et en Afrique du Nord : rapports généraux et particuliers, notes.

$1920-1921$

\section{Habillement et autres services}

312 Habillement et autres services. - Récupérations d'habillement dans les corps de troupes, régime administratif d'unités particulières, bureaux de comptabilité des corps : rapports et notes issues des travaux du contrôleur Piquet (1921). Régime d'exécution des travaux du service de l'habillement par les maîtresouvriers, organisation du service de la ferrure dans les corps de troupe (1922), exécution du service du blanchissage du linge de corps en Algérie (1923).

$313 \quad$ Masses d'habillement des corps de troupe de l'intérieur.

$1922-1923$

314 Affectation des machines à écrire dans les régions militaires (1919). Fonctionnement des masses de chauffage et d'éclairage (1922).

1919,1922

315 Frais de bureaux et de services dans les états-majors, les unités et les établissements.

$1922-1923$

\section{Enquêtes ordinaires dans les unités}

316-329 Administration et fonctionnement de différents corps de troupes et services de métropole et d'Afrique du Nord : rapports, classés par région militaire et par unité.

$1918-1924$

316

1918.

$317-318$

1919.

$4^{\mathrm{e}}$ à $12^{\mathrm{e}}$ région. 
321 Autres enquêtes (Gouvernement militaire de Paris, $1^{\mathrm{re}}$ à $11^{\mathrm{e}}$ région).

323 Corps de troupe de l'aéronautique.

324 Gouvernement militaire de Paris, $4^{\mathrm{e}}$ à $6^{\mathrm{e}}$ région [à signaler, un rapport sur le $13^{\mathrm{e}}$ RA, caserné à Vincennes].

$7^{\mathrm{e}}$ à $18^{\mathrm{e}}$ région.

$326-327$

1923.

326 Gouvernement militaire de Paris, $3^{\mathrm{e}}$ à $18^{\mathrm{e}}$ et $20^{\mathrm{e}}$ régions.

$327 \quad 19^{\mathrm{e}}$ région et division d'occupation de la Tunisie.

328-329

1924.

Gouvernement militaire de Paris, $3^{\mathrm{e}}$ et $10^{\mathrm{e}}$ régions.

$13^{\mathrm{e}}$ à $20^{\mathrm{e}}$ région, division d'occupation de la Tunisie.

\section{Enquêtes extraordinaires}

\section{Unités et régions militaires}

330 Primes et effectifs. - Allocation de primes dans la $5^{\mathrm{e}} \mathrm{RM}$, mesures propres à faciliter le règlement des comptes des corps (1919). Emploi des personnels civils et militaires, emploi des personnels détachés des corps de troupe dans les services, effectifs en officiers des différentes armes dans le Gouvernement militaire de Paris, les $8^{\mathrm{e}}$ et $13^{\mathrm{e}}$ régions (1919-1920), Service du couchage dans les $8^{\mathrm{e}}, 10^{\mathrm{e}}, 11^{\mathrm{e}}$ et $16^{\mathrm{e}}$ régions $(1923)$.

$1919-1923$ 
Affaires locales. - Irrégularités signalées dans la comptabilité-matières du $48^{\mathrm{e}}$ RI, à Guingamp : rapports, correspondance (1919-1921), création d'une caisse de secours au régiment des sapeurs-pompiers de Paris (1919-1921).

$1919-1921$

Affaires locales. - Irrégularités signalées dans la gestion administrative des $32^{\mathrm{e}}$ RI, $54^{\mathrm{e}}$ RI et $16^{\mathrm{e}}$ chasseurs (1921-1922), projet de transfert à Strasbourg du centre de rééducation du $21^{\mathrm{e}}$ corps d'armée, proposition de fusion des centres de réforme de Colmar et Strasbourg (1922), Organisation et fonctionnement du mess des sous-officiers de la caserne Latour-Maubourg (1922).

$1921-1922$

\section{Services; mises en cause individuelles}

Affaires locales. - Marché de fourgons passé avec M. Briel, industriel à Lyon, vols commis à la station-magasin du Tréport, gestion du service des vivres de la place de Montpellier

Transfert de viandes congelées, par voie ferrée et maritime, en particulier en provenance d'Algérie : rapports, correspondance. Ravitaillement maritime de l'armée du Rhin : note de synthèse.

Affaires locales de vivres et de ravitaillement. - Expertise demandée par le tribunal d'instance de Marseille dans le cadre d'une affaire de corruption liée au fonctionnement des services du ravitaillement, avaries constatées dans une expédition de moutons congelés de Marseille à Paris, fonctionnement du Service des cuirs à Vierzon et du centre de tannage de Romans, organisation et gestion du magasin dit des «Petits docks», aux Invalides, relevant de l'intendance du gouvernement militaire de Paris, projet de marché pour la transformation en viande de conserve d'un stock de viande congelée entreposé à La Pallice.

$1919-1921$

336 Affaires locales. - Magasin général de l'habillement de la place de Lyon (1920), mises en causes individuelles sur le territoire de la $6^{\mathrm{e}}$ région (Ateliers de travaux publics) et à Marseille $\left(15^{\mathrm{e}}\right.$ section de commis ouvriers de l'administration) (1920), faux mandats d'indemnité de route accordés à la sousintendance de Perpignan (1920-1921), livraisons de vins avariés par les services de l'intendance à des coopératives militaires (1920-1921).

$1920-1921$

337 Irrégularités et querelles de personnes survenues au magasin général de l'habillement de Vanves.

$1920-1924$

Affaires locales. - Dettes de la société coopérative militaire de Rouen vis-àvis de l'État (1921-1922), situation financière dans différents échelons de la 
direction de l'intendance $\left(4^{\mathrm{e}}, 10^{\mathrm{e}}, 15^{\mathrm{e}}\right.$ et $18^{\mathrm{e}}$ régions militaires, gouvernement militaire de Paris) (1922).

Faits reprochés à des personnels. - Irrégularités constatées au parc du $31^{\mathrm{e}}$ régiment d'aviation de Tours, rémunérations pour travaux supplémentaires attribués au personnel du $3^{\mathrm{e}}$ bureau de recrutement de la Seine, recherche d'un déficit de soixante-huit chevaux au $6^{\mathrm{e}}$ régiment de spahis.

340 Faits reprochés à des personnels. - Abus signalés à la poudrerie d'Angoulême, irrégularités commises à l'École militaire préparatoire d'Autun, déficits en matériel du Service de l'artillerie et faux en écriture publique relevés lors de la dissolution du $7^{\mathrm{e}}$ régiment de dragons.

341 Sous-intendance militaire «A»d'Alger, service des vins : emplacement du chai, gestion du personnel.

\section{SERVICE DE SANTÉ, JUSTICE MILITAIRE}

Affaires locales. - Projet d'implantation de l'hôpital militaire de Rennes (1920), malversations dans les services de l'hôpital de Vaugirard, à Paris (1920), fonctionnement des ateliers généraux du Service de santé au Fort de Vanves (1921-1922), fonctionnement des directions régionales du service de santé des $2^{\mathrm{e}}, 7^{\mathrm{e}}$ et $16^{\mathrm{e}}$ régions (Amiens, Dôle, Montpellier) (1923), traitement médical du personnel civil de la Guerre (1923).

$1920-1923$

$343 \quad$ Organisation des transports automobiles au sein du Service de santé.

$1920-1922$

344 Projet de cession de la fondation Foch et de son hôpital, à Suresnes, au département de la Guerre.

Affaires relatives à la justice militaire. - Conditions dans lesquelles des détachements de condamnés militaires des établissements pénitentiaires d'Afrique du Nord (Téboursouk, Douéra, Aïn Beida, Bossuet, Bougie) ont été mis à la disposition de particuliers ou de sociétés (1919), masse de couchage de la prison militaire de Paris (1919), difficultés de procédures signalées dans les établissements pénitentiaires militaires de Paris (vols de scellés, retard dans la libération de prévenus, etc.) (1920). 
AlsaCe-Lorraine - Troupes de la SARRe - Armée DU RHIN

\section{Alsace-Lorraine, Sarre}

Territoires d'Alsace-Lorraine. - Comptabilité de la division aérienne de Neustadt (1919), situation matérielle et morale des officiers des garnisons de Colmar et Neuf-Brisach (1920), approvisionnement en matériel de réfectoire des corps de troupe stationnés (1920), terrain d'aviation de Haguenau (1921), service automobile de Metz (1921), service du génie de Colmar et Mulhouse (1921), service de santé des places de Strasbourg, Colmar et Mulhouse (1921), modalités d'incorporation des recrues alsaciennes et lorraines (1921), charges fiscales pesant sur les officiers (1921), installation des casernes de gendarmerie, en particulier à Bischwiller (1922), indemnités accordées aux brigades de gendarmerie de Strasbourg (1922).

$1919-1922$

347 Examen de la situation financière de l'Administration supérieure de la Sarre.

1919-1920

348 Abus de toutes sortes signalés par le service de l'intendance dans l'administration des troupes de garnison de la Sarre.

349 Administration des troupes de garnison de la Sarre. - Projet de budget pour 1922 des services automobile, de santé et du génie (1921), dépenses effectuées en marks par les troupes (1922), frais de traitement des militaires de l'Armée du Rhin à l'infirmerie-hôpital de garnison de Sarrelouis (1922), indemnités de logement (1922) et de chauffage (1922), logement des officiers et hommes de troupe dans le territoire (1923).

$1921-1923$

\section{Armée du Rhin}

\section{Organisation générale. Finances}

350 Armée du Rhin. - Élaboration du budget (1924), régime financier, exemptions d'impôts pour les personnels d'occupation, fonctionnement des coopératives, aspects administratifs variés : notes et rapports réunis par le contrôleur général Boone, répertoire des pièces et des rapports réunis dans le cadre des missions du «groupe Boone» (1920-1922), « résumé général annuel » du groupe de mission de l'armée française du Rhin et d'AlsaceLorraine (1920).

$1920-1924$

351 Mission du contrôleur Gache auprès de l'armée du Rhin. - Préparation et objectifs de la mission, activité et suivi des affaires en cours: notes, correspondance, documentation imprimée. 
Dépenses effectuées à la charge du budget de la Guerre pour le fonctionnement des services de l'Administration des territoires rhénans et de la Restitution industrielle. - Détermination du montant, imputations budgétaires : notes.

353 Conséquences financières des accords de paix pour l'armée du Rhin. Réquisitions effectuées à l'Armée du Rhin en 1918 et 1919 dans la région d'Aix-la-Chapelle, application de la loi du 3 avril 1918 qui interdit l'exportation des capitaux, paiement de la solde en marks.

$1920-1922$

354 Aspects financiers de l'occupation. - Taux de change à adopter pour la conversion en francs de la valeur en marks des fournitures en nature livrées par l'administration allemande (1922), propositions de mise au compte de l'Allemagne des frais de déplacements de l'Armée du Rhin et des dépenses des brigades de gendarmerie de Kehl (1922), réparations des dommages causés aux personnes et aux biens par l'Armée française du Rhin (1922), administration des crédits du compte spécial d'entretien troupes d'occupation à l'étranger (1922), avances en marks faites aux gestionnaires et évaluation des pertes de crédits dues à la baisse du mark (1923), régime administratif de l'armée du Rhin (1925).

$1922-1925$

355 Frais des armées d'occupation. - Pourparlers entre les Alliés et l'Allemagne en vue de déterminer les conditions de prise en charge des frais des armées d'occupation, projet de fixation d'une somme forfaitaire, prise en compte des réclamations allemandes, évolution de l'arrangement financier: notes personnelles du contrôleur général Boone, études, procès-verbaux, rapports, états, coupures de presse.

$1920-1923$

356 Évaluation des sommes dépensées et des prestations fournies en nature par le Reich pour le stationnement des troupes françaises depuis l'armistice jusqu'en 1923 : dossier de travail, réunissant notes, notes de synthèse, rapports imprimés et extraits de procès-verbaux de différentes commissions interalliées.

Prestations en nature fournies par le Reich en exécution des articles 8 à 12 de l'Arrangement rhénan du 28 juin 1919. - Situation en octobre 1924, décisions du Comité des prestations en nature dues aux armées d'occupation, litiges de toute sorte : rapports, notes, correspondance, en particulier entre le service spécial, le contrôleur Litschfousse et le ministère des Affaires étrangères.

1924-1928

\section{Personnel civil et militaire}

Soldes et indemnités du personnel militaire. — Primes d'alimentation (1920), indemnités aux troupes de l'Intérieur envoyées provisoirement dans les pays rhénans (1920), indemnités de logement aux officiers et sous-officiers mariés (1921), traitement des agents de la $50^{\mathrm{e}}$ section de CFC (1921), indemnités 
accordées aux troupes de la tête de pont de Kehl (1921), situation générale des soldes de l'AFR (1922), impôt sur les traitements et salaires (1922-1923).

Affaires courantes relatives au personnel civil et militaire. - Situation matérielle et morale des militaires de carrière de l'Armée française du Rhin (1920), centres de rapatriement de Rastadt et de Kehl (1920), dénonciations contre deux officiers du $3^{\mathrm{e}}$ régiment d'aviation de bombardement (1921), mise en cause d'un sous-officier comptable de la ferme-école «Armada (1922), rattachement administratif des troupes de la tête de pont de Kehl, officiers détachés ou mis à la disposition de la Haute commission interalliée des territoires rhénans (1922), régime administratif des personnels civils et prévisions de dépenses sur ce chapitre dans le projet de budget de 1925 (19241925), application de la législation sur le droit du travail par le bureau juridique et judiciaire (1925).

$1920-1925$

\section{Artillerie, matériel, service automobile, aéronautique, génie}

Artillerie, matériel, service automobile, aéronautique, génie. — Distorsion entre les stocks d'essence conservés à l'armée du Rhin et les besoins déclarés (1920), emploi des voitures automobiles (1922), reconstitution de la réserve de guerre (1922), travaux lancés par la chefferie du génie de Mayence, prestations en nature offertes par la chefferie du Génie de Mayence et la Commission des logements (1924), réparation des moteurs d'avion par l'industrie civile (1925), primes-crédits des masses de casernement (1925).

$1920-1925$

\section{Administration des corps de troupe, intendance, habillement}

\section{Études de portée générale}

361 Intendance, subsistances, coopératives. - Organisation du service de l'intendance (1920), fonctionnement des coopératives (1921), fourniture par le service des subsistances des denrées alimentaires et fourragères, et en particulier des farines et de la viande congelée (1925).

$1920-1925$

Habillement, trésor et postes. - Situation de l'habillement des troupes (1920), fonctionnement du service de l'habillement (1922), situation du service du trésor et des postes (1920), alimentation des caisses des payeurs de l'armée en numéraire allemand (1920-1922), emploi des mandats de virement pour les paiements en marks (1922).

$1920-1922$

Gestion et comptabilité des prestations en nature dans les services du génie, des logements, des subsistances, du couchage et de l'ameublement. 
Enquêtes ordinaires dans les unités

364-365 Années 1921-1922

364 Parc de réparations d'infanterie de Sarrelouis, parcs d'aviation $\mathrm{n}^{\text {os }} 12$ et $33,12^{\mathrm{e}}$ régiment d'aviation.

365 Services de l'alimentation, de l'habillement et du couchage dans les corps de troupe.

366 1923-1924. Service automobile, $42^{\mathrm{e}}$ et $44^{\mathrm{e}}$ bataillons de sapeurs télégraphistes, $12^{\mathrm{e}}$ régiment du génie.

367-372 Année 1925.

$367 \quad$ Infanterie $\left(5^{\mathrm{e}}\right.$ et $6^{\mathrm{e}}$ spahis, $\left.28^{\mathrm{e}} \mathrm{RTT}, 17^{\mathrm{e}} \mathrm{BCP}\right)$.

368 Artillerie $\left(129^{\mathrm{e}}\right.$ RAL, Service techniques de l'artillerie à Sarrelouis, parcs d'artillerie des $30^{\mathrm{e}}$ et $32^{\mathrm{e}} \mathrm{CA}$, parc de réparation d'artillerie de Mayence, matériel du service de l'artillerie dans les corps de troupe).

369 Service automobile (parc automobile, service des essences du parc automobile, compagnies automobiles du train des équipages).

$370 \quad$ Service aéronautique.

371 Service du génie (parc du génie, parc télégraphique, $42^{\mathrm{e}}$ bataillon de sapeurs télégraphiques).

372 Services de l'intendance (sections de COA, sous-intendances, services de la solde, coopératives d'alimentation), fermes écoles.

Affaires locales, mises en cause individuelles

373 Affaires d'intérêt local. - Irrégularités commises par un payeur de la place d'Ems-les-Bains, (1921), demande de crédits pour la création d'un café maure à Siegburg (1921), litige soulevé par les autorités allemandes au sujet des meubles des appartements de réception du Quartier général du $32^{\mathrm{e}}$ corps d'armée (1922), indiscrétions commises au cours d'une instruction sur les coopératives (1924), économies à réaliser par le Service des fourrages (1925), frais de déplacement du service de la sûreté (1925), dommages causés par des Allemands au personnel ou au matériel (1925),

$1921-1925$

Prévôté, service de santé, transports

Autonomie administrative de la prévôté de l'armée du Rhin (1922). Service de santé. - Frais d'hospitalisation et soins dentaires des militaires et de leurs 
familles dans les formations sanitaires (1920-1921), ration journalière de vin allouée aux sous-officiers infirmiers (1922), réclamations formulées par M. Fassina, fournisseur français de Wiesbaden (1925).

375 Organisation et fonctionnement de l'hôpital militaire de Coblence.

376 Transports maritimes. - Irrégularités et négligences dans les services administratifs des bases de Rotterdam et du Rhin.

377 Transports maritimes. - Organisation et fonctionnement de la base de transit d'Anvers (1922), inspection administrative de la flottille du Rhin (1923).

1922-1923

Affaires particulières relatives aux transports. - Taux des frais de service à attribuer aux présidents des Commissions de chemins de fer et de navigation de campagne, dépenses de chauffage et d'éclairage des locaux occupés par la direction générale des communications et ravitaillements aux armées (1920), déplacements d'isolés comprenant la traversée de la Sarre (1925), statistique des transports d'isolés (1925), organisation et fonctionnement de la sousintendance des transports de l'armée du Rhin (1926).

$1920-1926$

\section{LEVANT}

\section{Groupe de missions de 1921-1922}

Rapport d'ensemble du groupe de missions 1921-1922, correspondance avec le général Gouraud, commandant en chef de l'armée du Levant.

Affaires financières. - Organisation et fonctionnement du bureau financier et des bureaux de la comptabilité, demandes de crédits, taux des traitements et salaires du personnel civil, frais de déplacement, établissement des prévisions budgétaires et contrôle des dépenses, comptabilité des dépenses du haut commissariat de la Syrie et du Liban, organisation et coût de l'Armée syrienne.

381 Effectifs, organisation et fonctionnement des centres de rassemblement et dépôts de transition.

Solde et indemnités. - Projet de refonte du système des allocations aux militaires, situation des soldes et indemnités, abus dans l'attribution des indemnités représentatives de vivres, dites «prêt-franc ». 
383 Intendance. - Fonctionnement général des services de l'intendance, gestion des services de subsistance, administration des coopératives militaires, prix de revient de la viande frigorifiée. Services de la Guerre entretenus à Port-Saïd (Égypte).

384 Intendance. - Alimentation, fourrage, chauffage, éclairage, habillement, campement et couchage des corps de troupe.

Artillerie et cavalerie, aéronautique, service de santé. - Service de remonte, service de l'artillerie, train hippomobile, service aéronautique.

Génie et domaine militaire. - Fonctionnement du bureau topographique et du service géographique, errements suivis pour l'installation des troupes et services, dépenses nécessaires pour le génie et la télégraphie militaire, suppression de la base militaire de Tripoli.

387 Transports, service automobile. - Organisation des transports par terre, direction du service automobile, chars de combat, groupes d'automitrailleuses, service des carburants et ingrédients automobiles, parc et formations automobiles de Beyrouth, organisation des transports et du transit maritimes, affrètement du cargo Irma Woermann.

Transports par chemins de fer. - Organisation générale, contrôle et liquidation du réseau de Syrie-Cilicie, cession de charbon à l'exploitation en régie du réseau de chemins de fer de Syrie-Cilicie.

\section{Groupe de missions de 1922-1923}

$$
\text { Rapport d'ensemble sur la mission de contrôle de 1922-1923. }
$$

Affaires financières. - Surveillance à exercer pour éviter les vols des comptables, irrégularités dans l'ordonnancement et l'emploi des crédits.

Effectifs, personnel, écoles. - Organisation de l'école militaire de Damas, salaires du personnel civil, dépassements d'effectifs d'officiers et de gendarmes.

Artillerie, matériel. - Parc d'artillerie, entretien du matériel de la base militaire de Beyrouth. 
393 Génie et télégraphie militaire. - Service de la télégraphie militaire, organisation et fonctionnement du service du génie, parc du génie.

394 Intendance. - Services du logement et de l'ameublement de la direction de l'intendance, première sous-intendance militaire d'Alep et annexe du service des subsistances de Djerabliss.

Administration des corps de troupes. $-4^{\mathrm{e}}$ bataillon $\mathrm{du} 17^{\mathrm{e}}$ régiment de tirailleurs sénégalais, $1^{\text {re }}$ compagnie $d u 1^{\text {er }}$ bataillon du $19^{\mathrm{e}}$ régiment de tirailleurs algériens, $2^{\mathrm{e}}$ régiment mixte syrien, $2^{\mathrm{e}}$ bataillon du $21^{\mathrm{e}}$ régiment de tirailleurs algériens, $4^{\mathrm{e}}$ compagnie du $3^{\mathrm{e}}$ régiment mixte syrien et $3^{\mathrm{e}}$ compagnie $\mathrm{du} 1^{\mathrm{er}}$ bataillon du $1^{\mathrm{er}}$ régiment indochinois.

396 Transports, service automobile. - Organisation des transports par chemin de fer, $3^{\mathrm{e}}$ compagnie automobile et service automobile du Quartier général, centre de ravitaillement en essences.

397 Service de santé. - Fonctionnement de la direction du service de santé, réserve de matériel, hôpital de campagne de Damas.

Aéronautique. - Fonctionnement du service de l'aéronautique et du centre d'aviation de Rayack, installations et terrains d'atterrissage du service de l'aéronautique, $54^{\mathrm{e}}$ et $58^{\mathrm{e}}$ escadrilles et parc aéronautique.

\section{Groupe de missions de 1926}

Affaires financières, personnel. - Participation des états syriens aux dépenses d'entretien des troupes, fonctionnement du bureau financier, fonctionnement du service de la solde, dépôt des isolés métropolitains et coloniaux, situation matérielle et bien-être des contingents français et des indigènes coloniaux, Indochinois en surnombre au Dépôt des isolés coloniaux.

401 Artillerie. - Administration et comptabilité du parc d'artillerie, du parcannexe de Damas et du service des munitions, entretien des armes portatives.

Cavalerie. - Organisation et personnel du service des remontes et des haras, dépenses de nourriture des animaux. 
Service automobile, blindés. - Fonctionnement de la direction du service automobile, du détachement automobile du Quartier général et des ateliers de réparation du matériel automobile en Syrie, organisation des formations de chars de combat et du peloton autonome d'autos mitrailleuses légères du désert à Palmyre.

404 Matériel, service des essences. - Fonctionnement du centre de ravitaillement en essences, cessions de matériel consenties en 1922 aux Turcs et aux gendarmeries syriennes.

405 Génie, transmissions. - Budget du service du génie, fonctionnement du service des transmissions.

406 Intendance, ravitaillement, couchage. - Organisation du service des subsistances, ravitaillement du poste de Palmyre et des colonnes en opération dans le djebel druze, coopératives militaires, couchage et ameublement.

407 Service de santé. - Direction du service de santé, hôpital militaire d'Alep, hôpital de Damas et hôpital Saint-Jean de Beyrouth, matériel du service de santé, soins donnés aux blessés après le combat de Soueida (25 avril 1926).

408 Unités et autres services. - Administration générale du $39^{\mathrm{e}}$ régiment d'aviation, fonctionnement du parc aéronautique $n^{0} 39$, service de la sûreté, imputation aux budgets des États syriens des dépenses d'alimentation des inculpés civils du service de la justice militaire.

1926

\section{Mission conjointe des années 1927-1928, missions des années 1929 et suivantes}

Mission conjointe du Levant, composée d'inspecteurs des finances et de contrôleurs de l'armée

409 Rapport général sur l'état actuel du Levant sous mandat français et sur les effectifs entretenus par la France.

Affaires financières. - Situation financière des troupes d'occupation et participation des États syriens sous mandat à leurs dépenses, budget des troupes françaises du Levant, fonctionnement du bureau financier de Beyrouth.

411 Créances de la France sur les États syriens. 
Personnel et effectifs. - Régime administratif et budgétaire des troupes auxiliaires et supplétives, établissement et règlement de leur budget, incorporation de ce budget dans le budget français de la Guerre.

413 Administration et budget des troupes spéciales au Levant.

414 Domaine militaire. - Domaine public et privé des États sous mandat et domaine privé de la France, affaire des expropriations réalisées à Rayack en 1924 et 1925, cession de la voie ferrée Ezraa-Soueida exploitée par le service du Génie.

1928

415 Logements militaires. - Logements des officiers au Levant, contentieux lié à la construction de pavillons d'officiers à Adana, conditions de mise à disposition par les États sous mandat des casernements et accessoires nécessaires aux troupes du Levant, échange d'immeubles entre l'État français (camp Foch) et la ville de Beyrouth.

$1928-1932$

416 Service du génie et service automobile, ravitaillement des troupes du Levant en carburants pour véhicules automobiles et pour avions.

$1927-1928$

417 Situation domaniale et acquisition de l'hôpital Saint-Jean de Beyrouth.

$418 \quad$ Service de santé et service aéronautique.

419 Service des transmissions. - Conditions d'exploitation du réseau téléphonique installé.

420 Missions de 1939-1940. - Établissements de l'artillerie au Levant, statut des formations autochtones incorporées dans le groupement des forces mobiles, éléments de correspondance adressée au chef de la mission spéciale de contrôle au Levant.

$1939-1940$

\section{MISSIONS À L'ÉTRANGER - ORIENT}

\section{Allemagne, Europe centrale, Russie}

Contrôle de missions ou de services français à l'étranger, en particulier par le biais du Service interministériel des dépenses à l'étranger (SIDE). - Organisation administrative et moral des éléments militaires français stationnés 
en Russie du Nord, et en particulier à Arkhangelsk (1919), régularisation des dépenses acquittées par la mission militaire française en Sibérie (1922-1923), Irrégularités dans l'administration de la délégation française à la Commission militaire interalliée de contrôle en Hongrie (1923), Liquidation de la part française du matériel d'armement bulgare et contrôle des opérations administratives réalisées à Sofia par la Mission française en Bulgarie (1923, 1933).

1919-1923, 1933

422 Missions et services généraux français présents à Londres.

\section{Orient}

Liquidation des stocks de l'armée d'Orient et des stocks laissés sur place par les ennemis.

Collection de procès-verbaux de la Commission militaire interalliée de contrôle des chemins de fer ottomans (décembre 1919-février 1923, lacunes).

425 Macédoine, Turquie et Syrie-Cilicie. - Exploitation militaire et régime financier des chemins de fer.

426-428 Dépenses du Corps d'occupation français de Constantinople (missions du groupe « Orient-Levant »).

426 Services comptable, automobile, aéronautique, médical, gendarmerie, train des équipages, remontes, alimentation de la troupe, officiers détachés.

Entretien des réfugiés russes, soldes et indemnités, frais de déplacement, transports, personnel civil, génie, réparations civiles, alimentation de la troupe et effectif de la section de C.O.A., fourrages, chauffage et éclairage, habillement et campement, couchage et ameublement.

Trésorerie et postes aux armées. Conclusions des missions du groupe. 


\section{ANNEXES : INDEX DES AUTEURS DES RAPPORTS DE CONTRÔLE}

\begin{tabular}{|c|c|}
\hline Allaire & 103,157 \\
\hline Alombert & $61,63,64,82,98,104,110,123,172,178,189$ \\
\hline Arvengas & $158,159,164$ \\
\hline Audibert & $98,122,180,182,1183,189,209,235,316-329,421,422$ \\
\hline Barret & 129,161 \\
\hline Beauregard & 23,91 \\
\hline Beuve-Méry & $\begin{array}{l}101,113,172,178,189,199,219,222,232,233,240,243,245,248, \\
303,316-329\end{array}$ \\
\hline Birouste & 129,130 \\
\hline Boisbrunet & $108,119,129,130$ \\
\hline Bois & $334,359,366,367-372,410,412,413,416,418$ \\
\hline Boitel & $52-54,93,122$ \\
\hline Bonhomme & $\begin{array}{l}84,98,123,152,169,199,210,230,244,259,266-269,276,278,279, \\
284,286,287,290,291,293,316-329\end{array}$ \\
\hline Boone & $\begin{array}{l}64,75,99,102,103,173,219,275,281,282,311,316-319,332,346, \\
350,354-356,358-362,364-365,373,374,376,378\end{array}$ \\
\hline Bosch & $79,90,113,122,182,183,189,195,237,250,298$ \\
\hline Bossut & $73,95,148,155,168,184,210,237$ \\
\hline Boulanger & 423 \\
\hline Boysson & $82,103,117,123,150,159,160,177,206-208,234$ \\
\hline Bralley & $223,226,227,236,240,280,306,353,354,358,366,377$ \\
\hline Bramas & 113,122 \\
\hline Brichard & $\begin{array}{l}73,74,103,108,124,133,148,159,160,164,165,167,169,170,191 \text {, } \\
191 \text { bis, } 191 \text { ter, 194, } 197\end{array}$ \\
\hline Bugnaud & 106 \\
\hline Caillé & $134,157,167,191$ \\
\hline
\end{tabular}




\begin{tabular}{|c|c|}
\hline Calonnier & 125,195 \\
\hline Cazères & $\begin{array}{l}232,248,262,273,295,300,306,314,316-329,335,353,358,361 \text {, } \\
362\end{array}$ \\
\hline Chandelier & 295,420 \\
\hline Chapelle & $\begin{array}{l}90,98,123,166,175,176,189,219,226,262,240,241,246,248,274 \text {, } \\
277,299,346\end{array}$ \\
\hline Chappuis & $131,233,261,272,276,277,278,299$ \\
\hline Chareyre & $62,122,123,183,242,243,277,278,280,285,292,311,316-329$ \\
\hline Chaumont & $113,122,124,133,167,172,177,178,180,182,193$ \\
\hline Chenou & $62,122,183,189,265,266-269,290,291,294,300,304,305,316-329$ \\
\hline Chocqueuse & $229,250,279,284,286,315,316-329,383,385$ \\
\hline Claerebout & $115,116,118,122,189,245,249,379,380,381,382,384,387,388$ \\
\hline Coulombeix & $103,105,129,143,146$ \\
\hline Cretin & $158,161,168,183$ \\
\hline Delande & $33,298,302,312,316-329,332,338$ \\
\hline Delmare & 130 \\
\hline Demeunynck & $98,122,168,191$ bis, 200 \\
\hline Denis & $220,226,229,231,232,233,242,245,298,334,335$ \\
\hline Desmares & 120,124 \\
\hline Dresch & 195 \\
\hline Drouot & $\begin{array}{l}122,189,218,219,259,266-269,273,281,286,291,295,298,299, \\
311,316-329,332,335,338,342\end{array}$ \\
\hline Ducru & $\begin{array}{l}122,123,169,182,183,189,206-208,264,266-269,274,290,300 \text {, } \\
302,311,316-329,342,343\end{array}$ \\
\hline Du Marché & 124,157 \\
\hline Durand & $124,137,173,178,180,189$ \\
\hline Duval & $113,122,123,178,189$ \\
\hline
\end{tabular}




\begin{tabular}{|c|c|}
\hline Endrès & $134,167,169,178$ \\
\hline Enjalbert & $57,106,111,119,124,166$ \\
\hline Favardin & $226,228,281,292,294,304,305,311,315,316-329,340,348$ \\
\hline Feydeau & $138,180,197$ \\
\hline Foucrière & $113,177,178$ \\
\hline Gaboriau & $75,95,122,169,177,178,180$ \\
\hline Gache & $\begin{array}{l}123,189,250,260,273,274,285,292,297,298,299,312,313,315 \\
316-329,332,333,338,339,340,342,351,359,360,361,363,367- \\
372,373,374,378\end{array}$ \\
\hline Gaillard & $122,123,189,291,347$ \\
\hline Gallo & $122,137,155,177,178,185,187,200$ \\
\hline Gamelin & 142,154 \\
\hline Garnier & $138,172,195,199$ \\
\hline Gay & $\begin{array}{l}82,93,113,122,123,172,178,183,189,219,236,241,242,266-269, \\
272,335\end{array}$ \\
\hline Genty & $316-329$ \\
\hline Gillet & 229,358 \\
\hline Goby & $33,310,316-329,345,357,424,425$ \\
\hline Goubet & $\begin{array}{l}225,248,250,265,273,288,292,298,304,305,307,309,311,313 \text {, } \\
314,316-329,332,336,338,339,341,345\end{array}$ \\
\hline Granet & 99 \\
\hline Gras & $283,284,286,291,299,304,316-329,339,360,367-372$ \\
\hline Guinand & 239,246 \\
\hline Hagniel & $\begin{array}{l}103,113,122,169,173,180,183,196,229,232,242,247,265,266- \\
269,270,289\end{array}$ \\
\hline Hagron & $59,62,122,137,142,143,158,189,190,191,191$ bis, 204, 209 \\
\hline Hamant & $124,128,155,191 \mathrm{bis}$ \\
\hline
\end{tabular}


Henry

Hervier

Jacobée

Jaussaud

Jugnet

Keller

Kopf

Lainé

Lamothe

La Perrelle

La Pomelie

Lavit

Lazerme

Leblanc

Lenormand

Letourmy

Litschfousse

Ligneau

Lottin

Lévêque

Loison

Longuet

Louis

Macherat
$261,271,275,311,316-329,330,332,333,335,336,346,349,360$, $362,364-365,373,374,420$

$246,250,280,284,316-329,336,421$

$73,100,122,129,133,134,139,141,148,150,168,172,180,205$, $210,211,231,233,236,242$

$113,123,177,178$

417

$143,159,191$

$189,240,244$

$113,182,189,240,244,245,265,266-269,316-329$

$246,270,304,309,315,336$

$33,410,411,414,415,417,419$

403, 404, 407, 408

$150,152,182,184,210,224,238,239,240$

$113,122,152,180,185,199$

$98,113,122,177,178,180,189,198,205,226,236$

106

$250,294,312$

$225,250,264,270,283,311,316-329,331,337,340,356,357,380$, $383,389,390,391,394,395,397$

130

$113,137,182,183$

$33,289,310,316-329,340$

310, 316-329

106

$261,282,316-329$

315 
Maréchal

Martinie

Mathieu

Maucourant

Mercier

Meunier

Nollet

Olivier

Papon

Pasquier

Peria

Peyrolle

Piquet

Plos

Prioux

Rebouet

Ricard

Romanet

Rouvière

Roy

Sauvage

Schweitzer
$122,188,189,217,219,226,227,233,236,264,273,274,281,295$, $307,309,311,316-329,336,345$

130

78,105

130,157

$73,172,178,189,210,218,232,244,298$

$219,220,240,241,244,274$

130

33

278, 287, 302, 303, 316-329, 337, 380, 381, 382, 386, 387, 389, 392, $393,395,396,398$

$113,178,180,182$

$316-329,342,345,364-365,409,410,411$

$98,110,135,168,172,174$

$221,229,232,261,264,265,266-269,278,281,288,289,290,306$, $207,311,312,313,314,316-329,330,311,312,313,314,316-329$, $330,333,380,381,382,383,384,385,386$

$305,316-329,359,367-372,373,374,375,376$

$80,121,134,148,169,173,181,210$

229,277

$78,103,142,155,157$

$78,130,148,155,159,191$

$74,82,98,113,122,123,182,189,199,219,236,240-242,244,266-$ $269,316-330,333$

$98,178,182,183$

$122,123,172,182,183,189,219,236,242,244,279,280,316-329$

$74,150,151$ 


$\begin{array}{ll}\text { Signoret } & 280 \\ \text { Simon } & 262,263 \\ \text { Soubeyrand } & 33 \\ \text { Tastavin } & 155,159,191,197 \\ \text { Ventre } & 60,73,98,160,168,171 \\ \text { Vidal } & 33,246,306,399,400,401,402,404,405,406 \\ \text { Vigo-Roussillon } & 129 \\ \text { Vintéjoux } & 158,159,160,191,191 \text { bis } \\ \text { Vivensang } & 169 \\ \text { Vuillaume } & 89 \\ \text { Weil } & 73,112,118,123,131,178,189,226,240,241,244\end{array}$

